دراسات في آثار الوطن العربيه 1

\title{
ملامح من أدوار المعبود "ست" بمتون الأهرام
}

أ. منار مصطفى محمد إسماعيلن

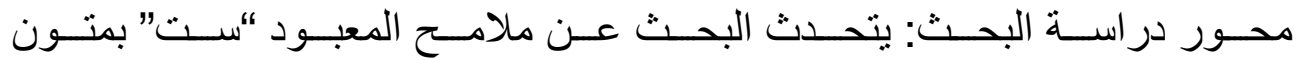

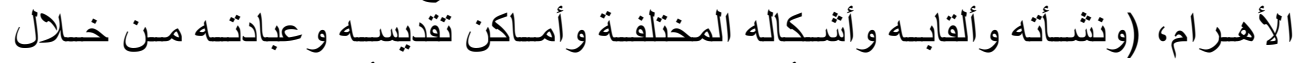

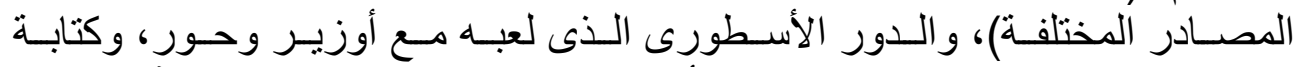

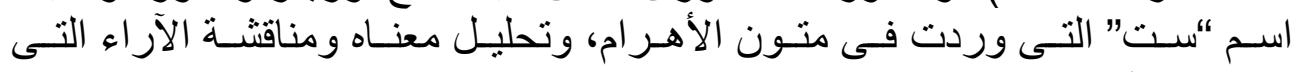

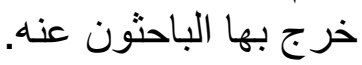

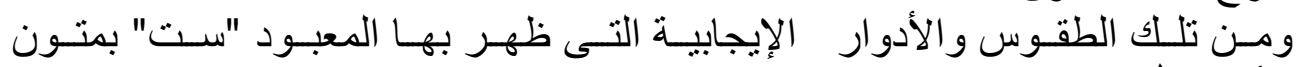

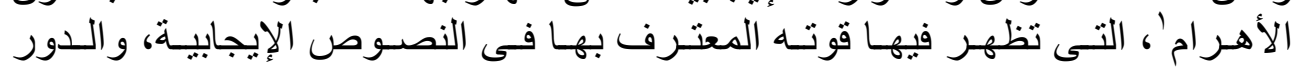

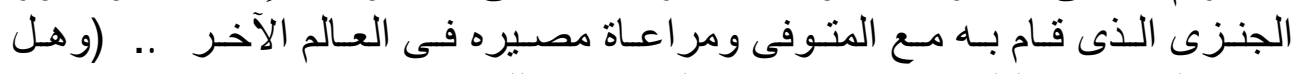

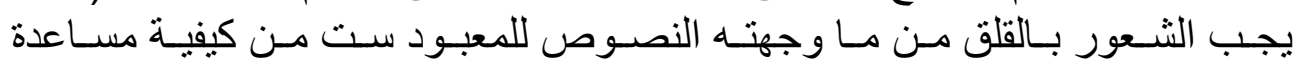

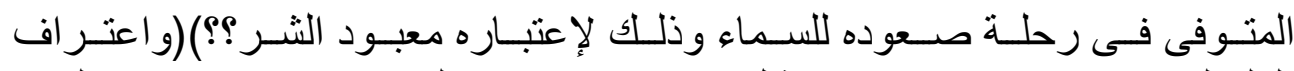

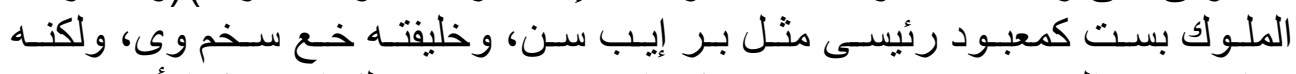

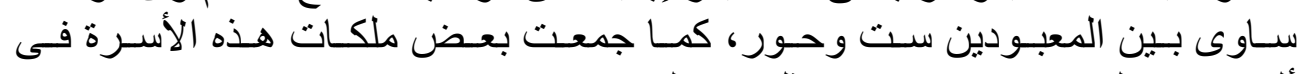

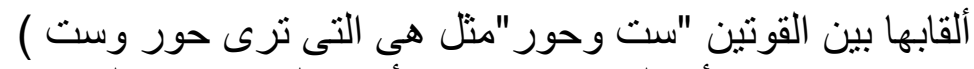

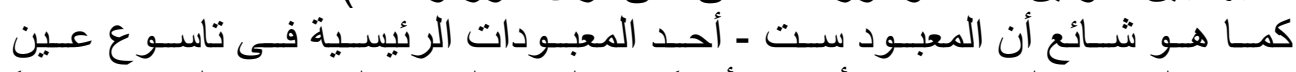

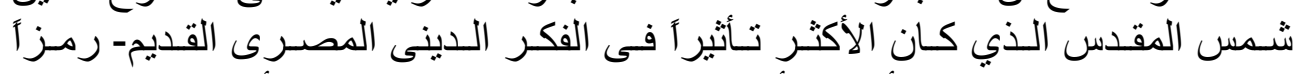

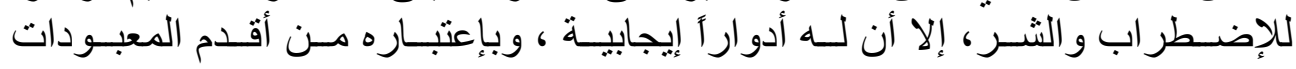

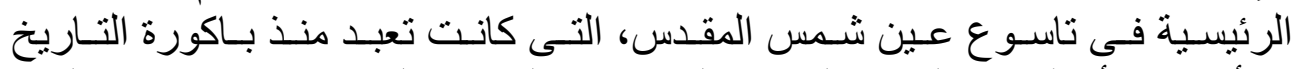

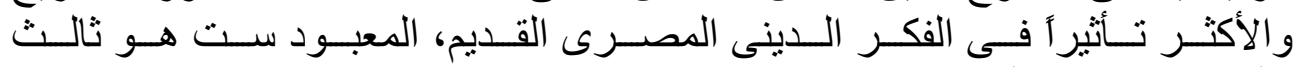

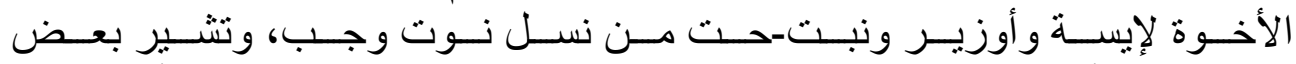

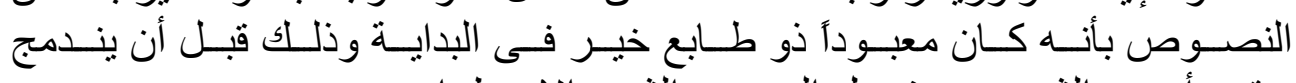

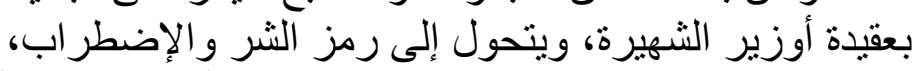

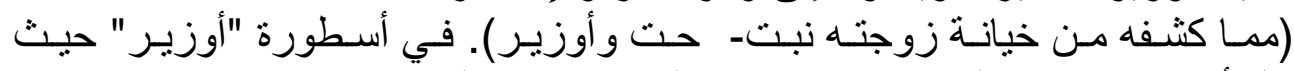

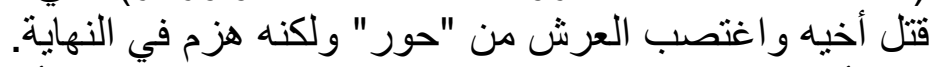

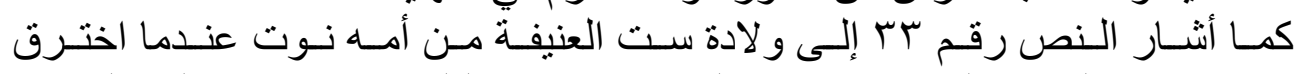

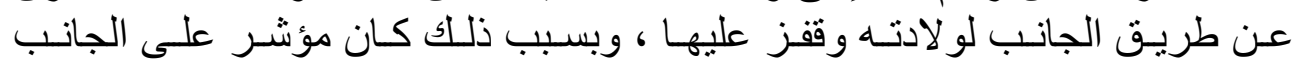

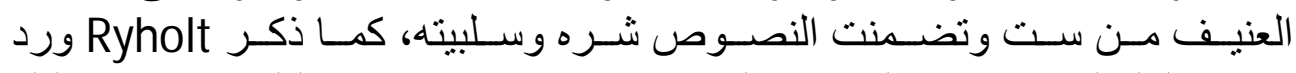

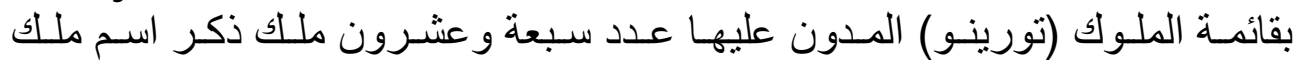

•باحثة بالماجستير فى الاراسات المصرية القيمة، قسم الآثار المصرية القيمة، كلية الآداب،

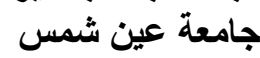

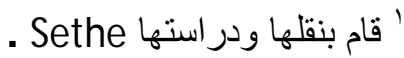




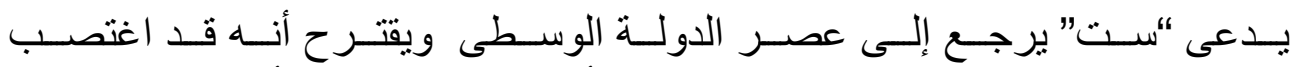

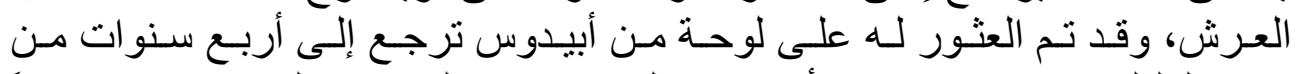

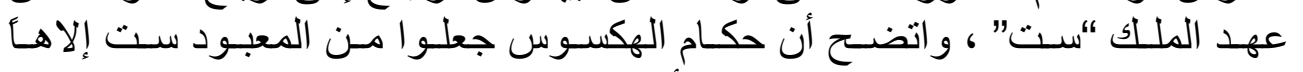

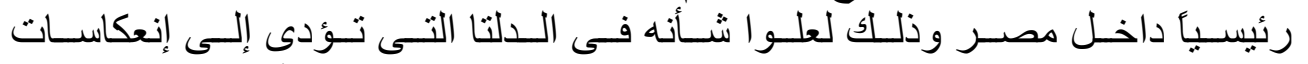

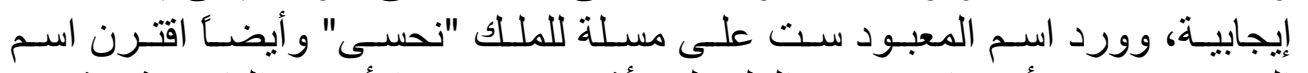

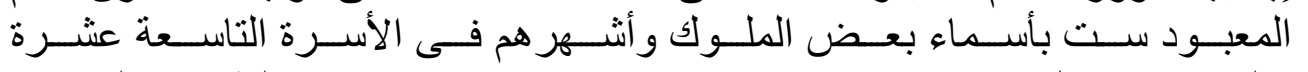

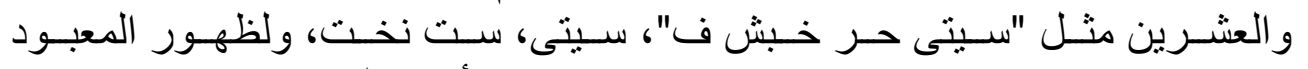

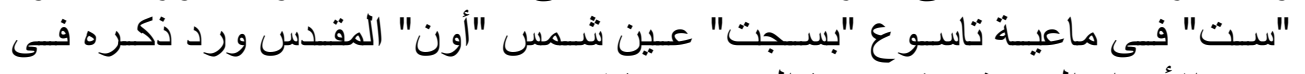

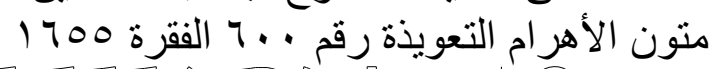

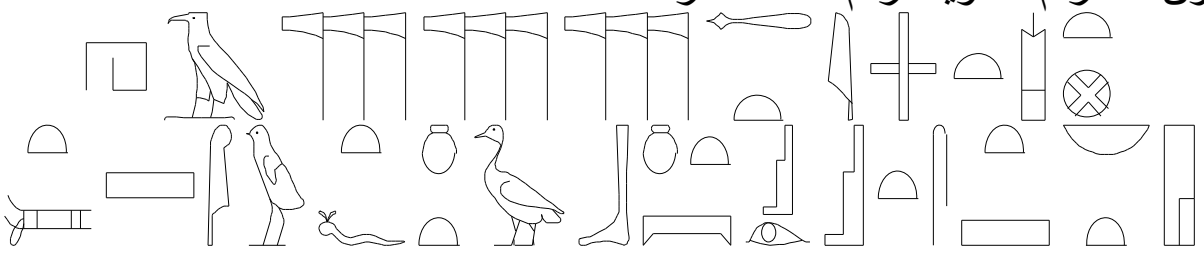

hA psDt aAt imyt I wnw Itm Sw Truwt Gb Nwt Wsir Ast StS Nbt-H

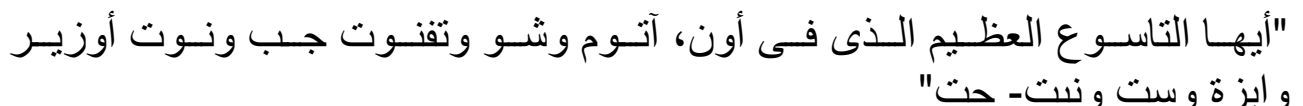

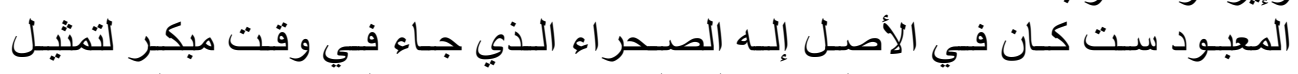

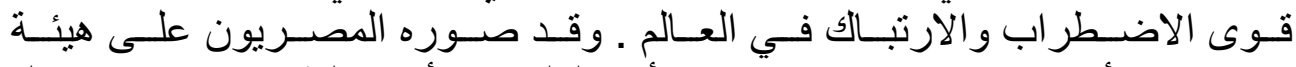

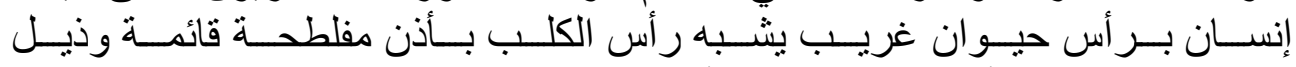

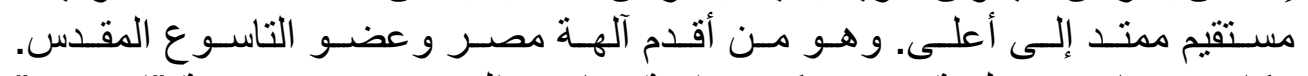

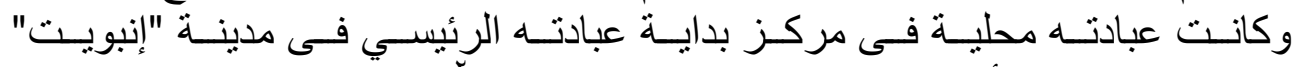

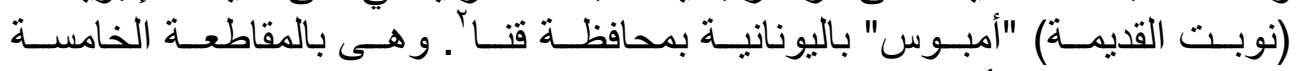

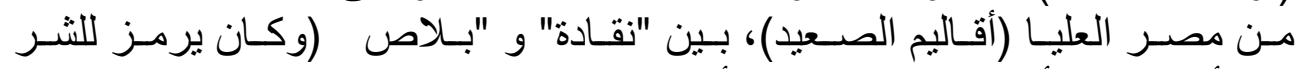

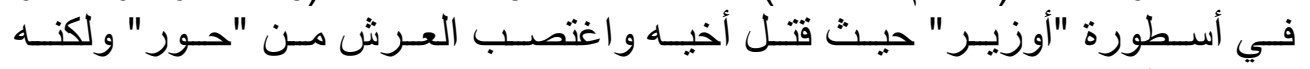
هزم في النهاية).

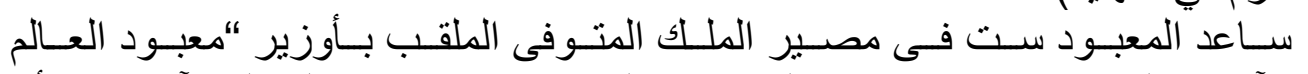

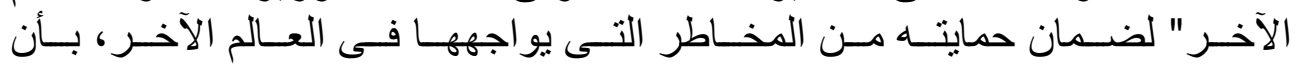

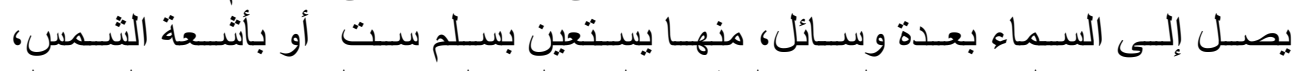

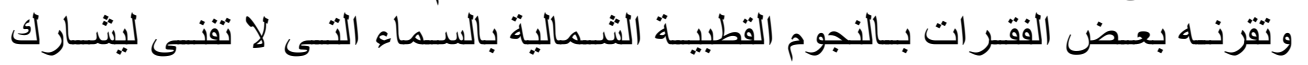

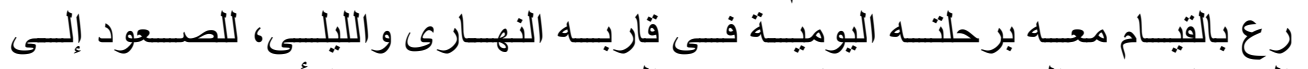

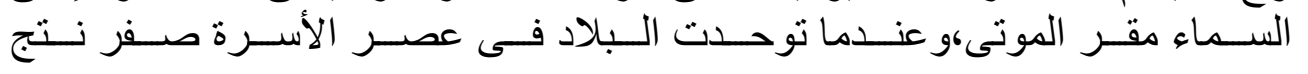

r باروسلاف تثرنى، الديانة المصرية القديمة، ترجمة: أحمد قدرى، مراجعة: محمود ماهر طه، $-\varepsilon$ К八- 


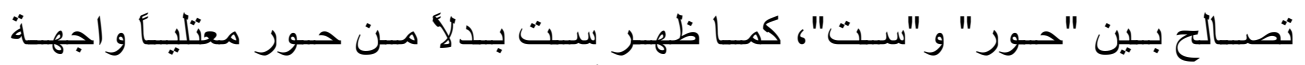

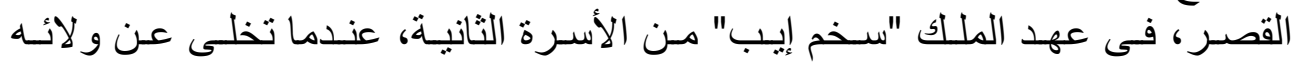

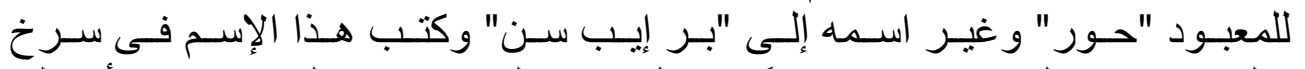

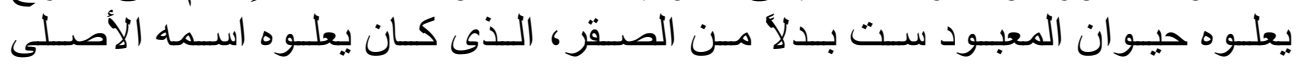

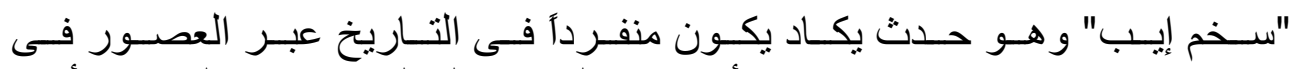

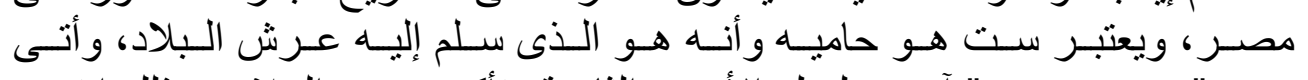

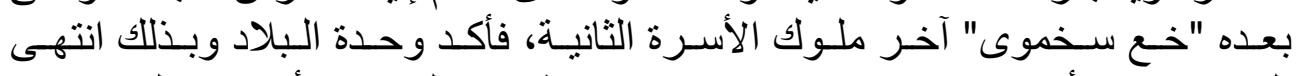

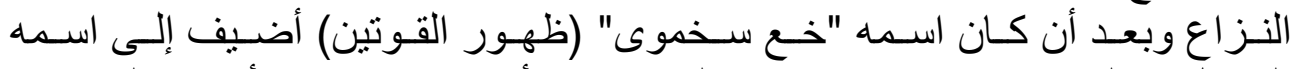

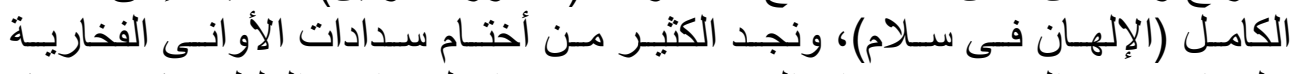

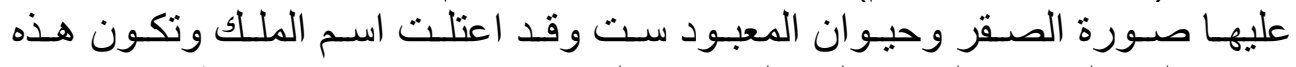

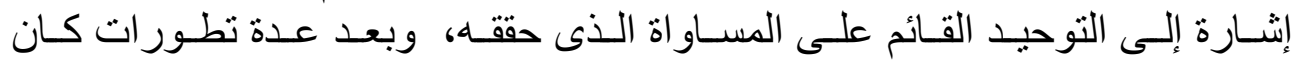

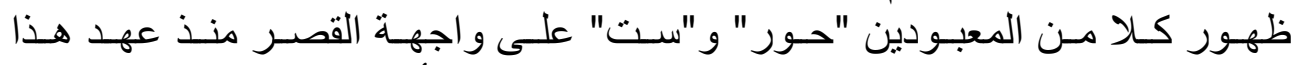

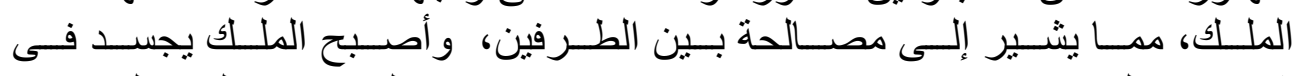

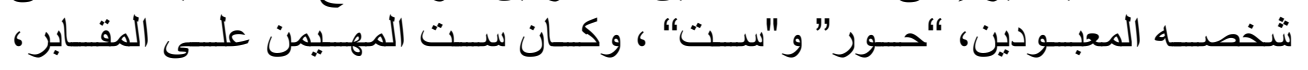

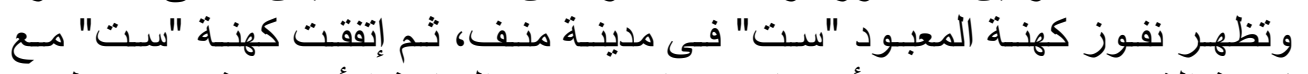

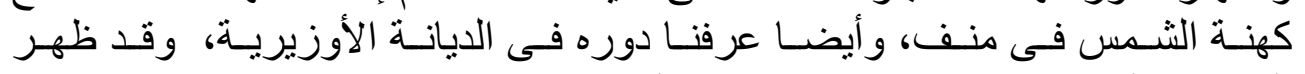

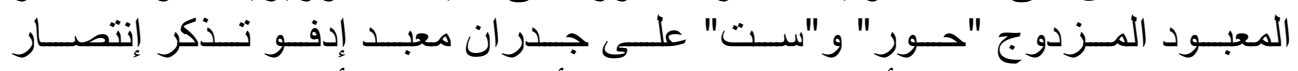

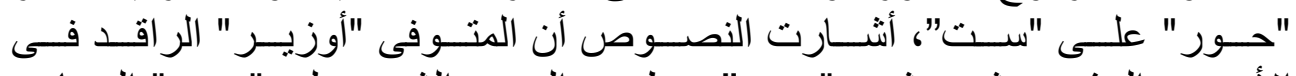

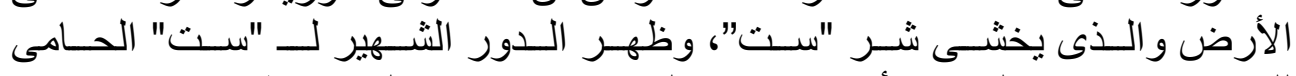

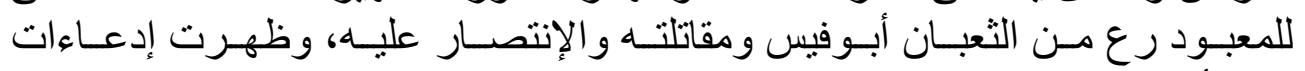

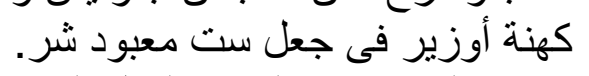

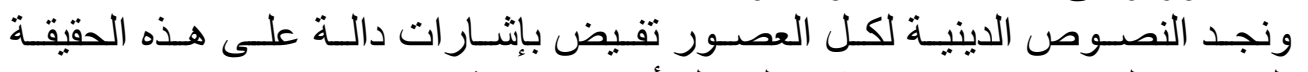
التى بهذا الصدد كونه معبود شر ولكن لهن الهن أدوار إيجابية.

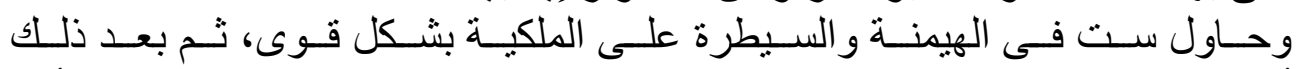

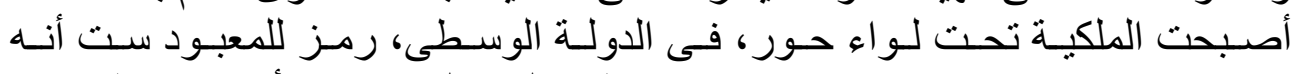

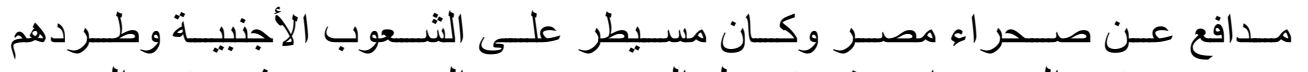

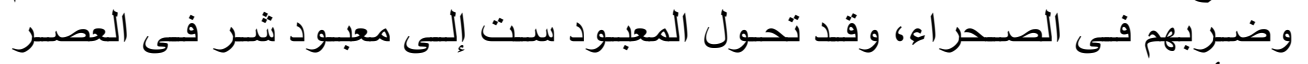

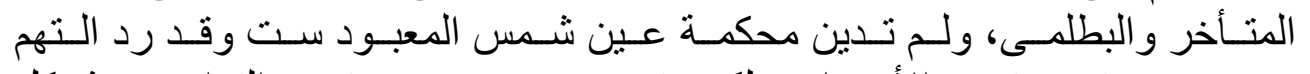

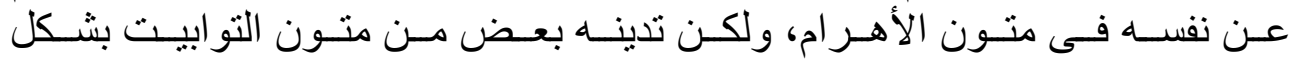

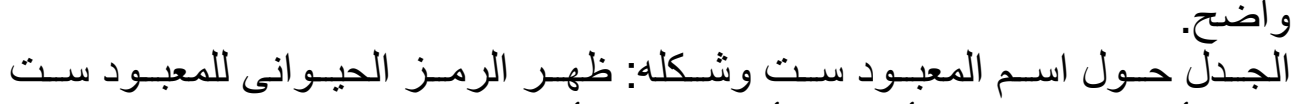

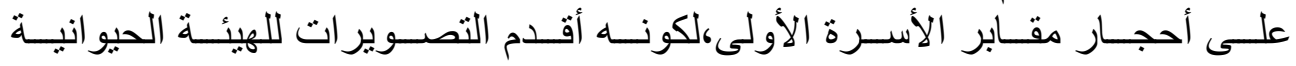

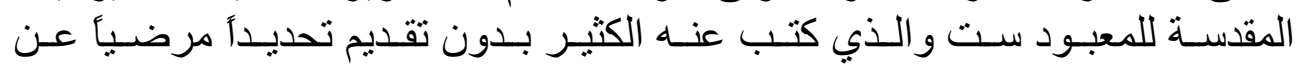




\section{دراسات في آثار الوطن العربيه}

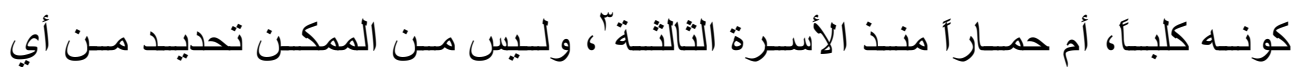

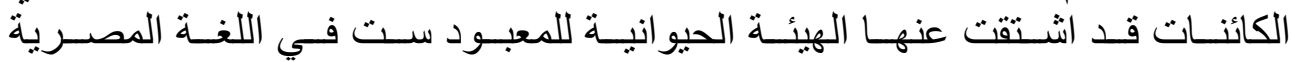
القديمة، لكنه حيو انأ خر افياً

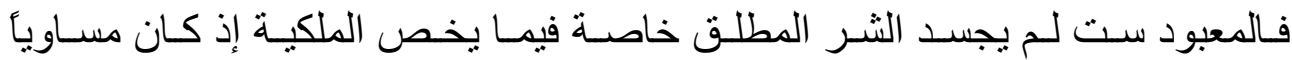

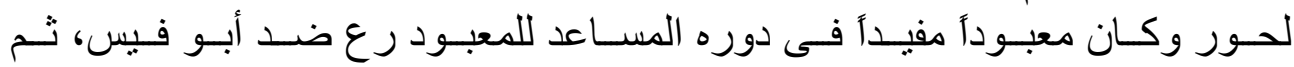

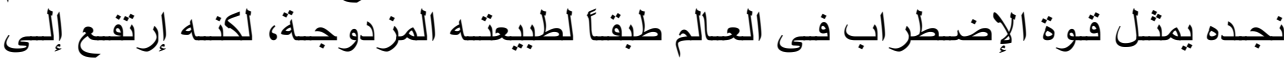

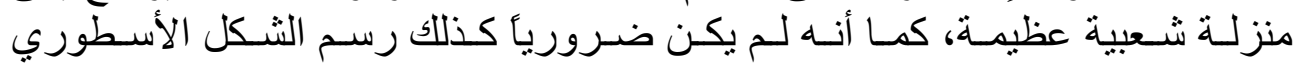

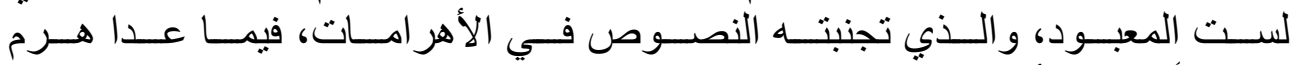

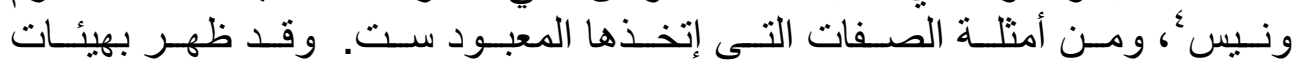

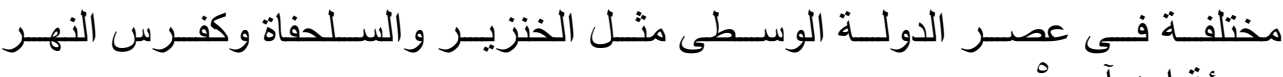

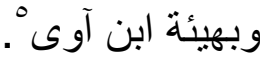

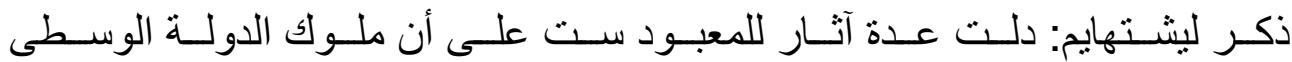

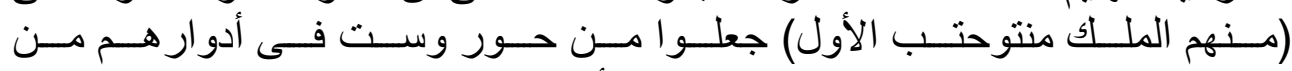

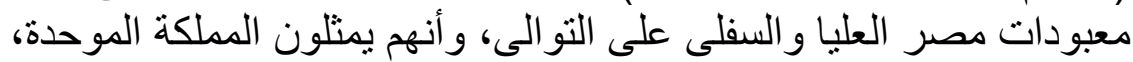

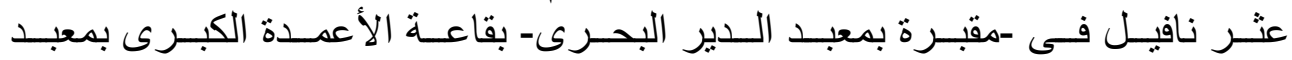

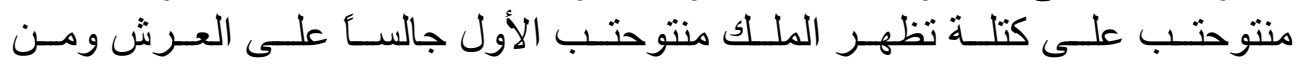
خلفه ممثل ست وحتحور ،

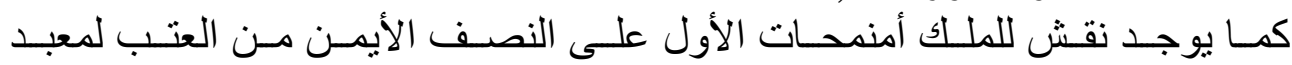

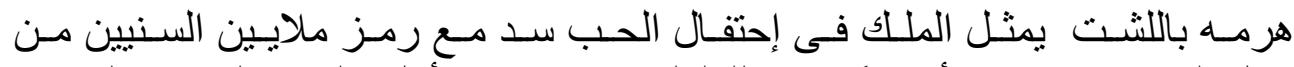

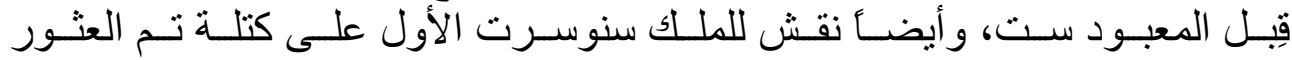

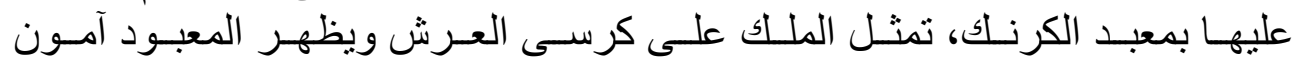

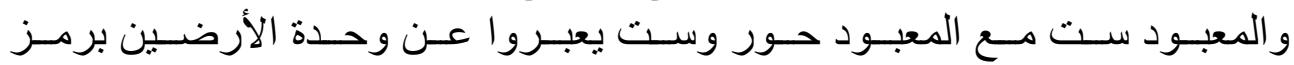

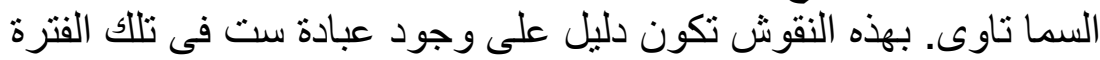

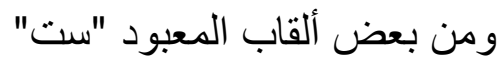

3 Te Velde, Sethe The God of Confusion, A Study of his Role in Egyptian Mythology \& Religion, (1967), 1-7; Richard H. Wilkinson, The Complete God and Goddesses of Ancient Egypt, (AUC Press, 2007), 197-199; Herman te Velde, "Seth", in: Donald B. Redford (ed.), The Oxford Encyclopedia of Ancient Egypt, 3 vols., $1^{\text {st }}$ ed. (New York-Oxford; Cairo: (AUC Press 2001) vol. 3, 269-271.

${ }^{4}$ Te Velde, op.cit., 1-7.

${ }^{5}$ Te Velde, op.cit., 22-25. 
دراسات في آثار الوطن العربيه 1

\begin{tabular}{|c|c|c|}
\hline atx mry n Ra & 我 & ست محبوب رع \\
\hline atXaApHty & ISI & ست عظيم القوة \\
\hline $\begin{array}{l}\text { atX nTr aA nb } \\
\text { pt }\end{array}$ & $\eta_{1} y=$ & 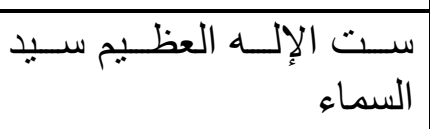 \\
\hline atX sANwt & $3^{n}$ & ست إبن نوت \\
\hline
\end{tabular}

ومن بعض العلامات التى كتب بها مثل":

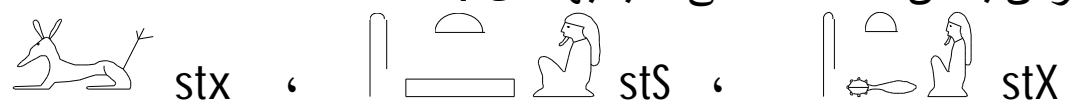

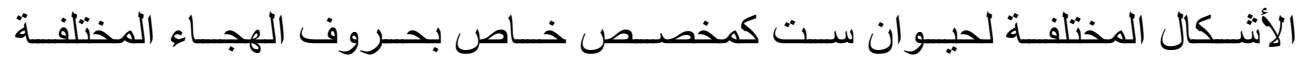

\begin{tabular}{|c|c|}
\hline$\neq \beta \approx$ & C(w)tx \\
\hline$\bigcap_{0}^{\infty}$ & $a X$ \\
\hline$\prod_{\infty}^{0}$ & atX \\
\hline 0 & atS \\
\hline$\frown$ & AS \\
\hline$\triangle$ & $\mathrm{at}$ \\
\hline$\therefore$ d & $\operatorname{at}(y)$ \\
\hline$J$ or & G(w)t(y) \\
\hline $\int_{\ominus} \curvearrowright$ & $O x$ \\
\hline
\end{tabular}

ومن أمثلة الصفات التى إتخذها المعبود ست:

${ }^{6} \mathrm{~Wb}$. IV, 345; Chr. Leitz, L̈̈GG VI (2002), 690-698, 
دراسات في آثار الوطن العربيه 1

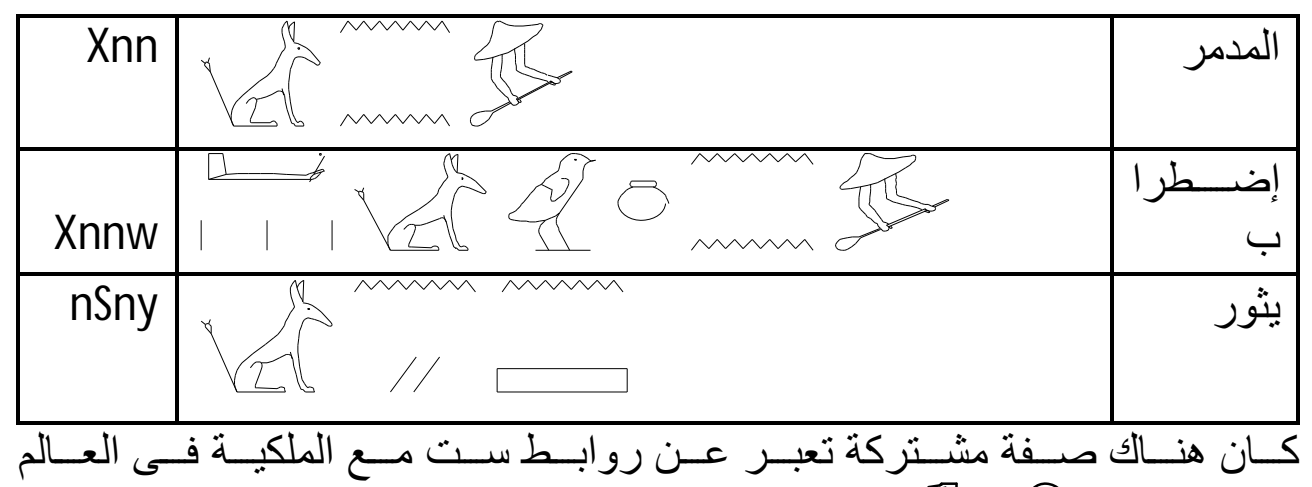

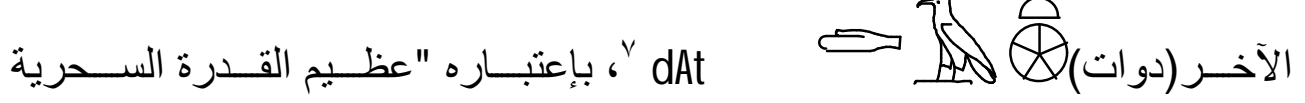

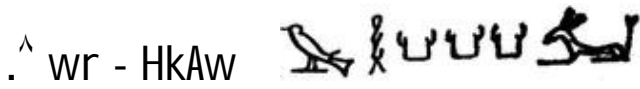

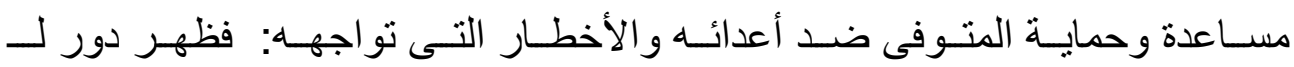

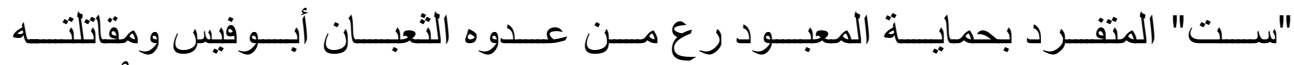

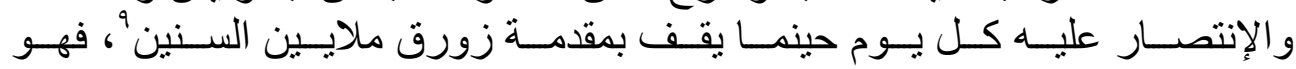

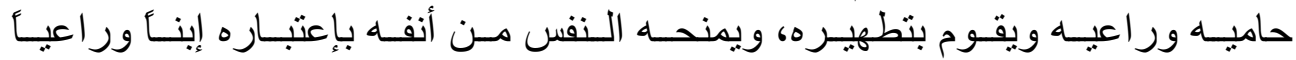

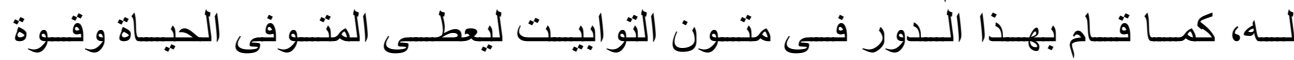

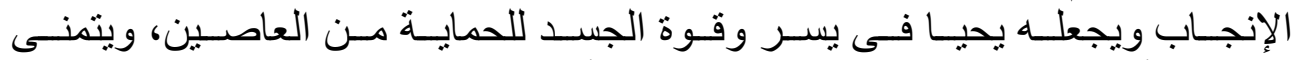

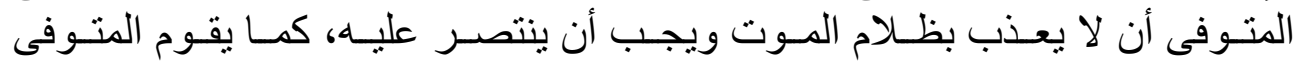
بقع رؤوس المتمردين الذين فى حقل الحتب ليتجنب شرور هم.

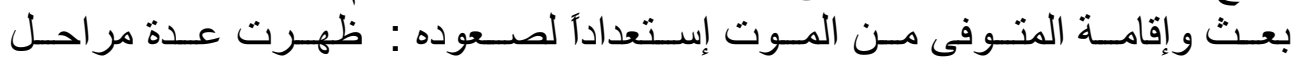

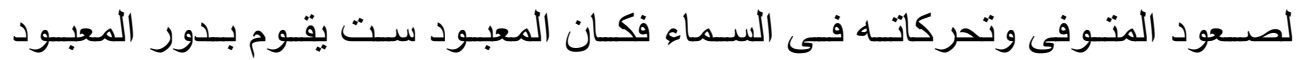

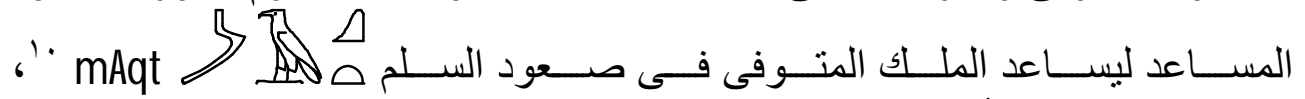

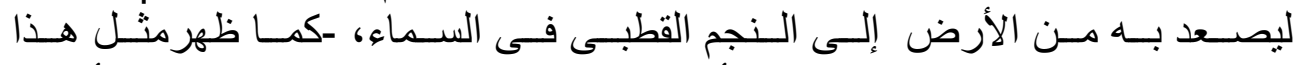

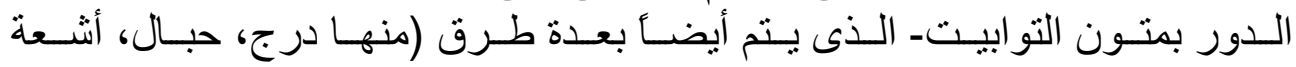

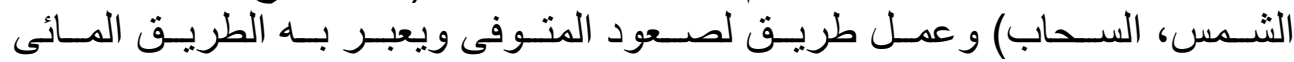

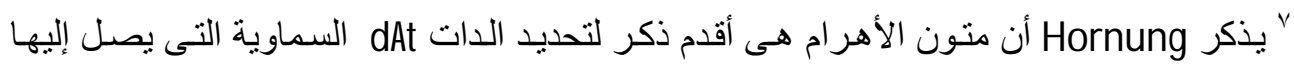

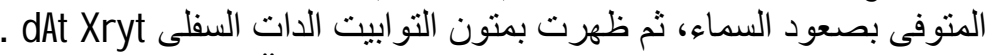
- Wb, V, 415; Erik Hornung, "Dat", LÄ, I, col. 994-995.

^ إيز ابيل فر انكون، أساطبر وآلهة (نفتنات رع إلـه الثمس)، ترجمـة حليم طوسون، مراجـة محمود ${ }^{9}$ Te Velde, 'Seth', $L \ddot{A} \mathrm{~V}$, col. 909.

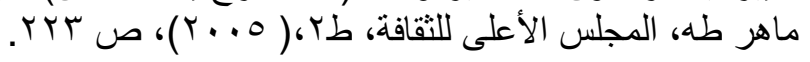
${ }^{10} \mathrm{~Wb}$. II, 33. 
دراسات في آثار الوطن العربيه

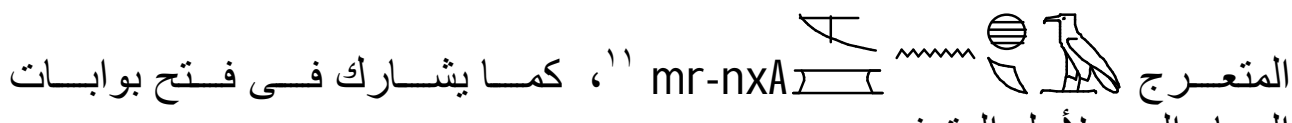

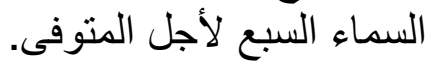

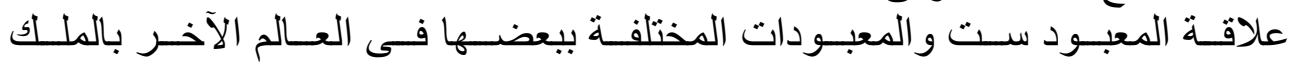

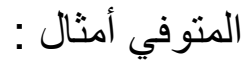

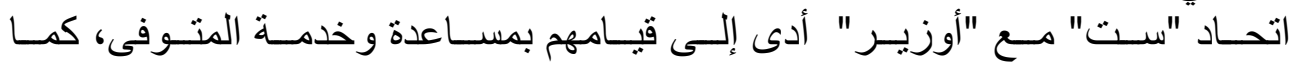

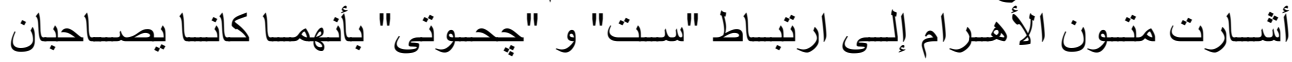

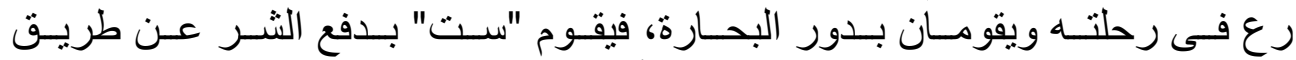

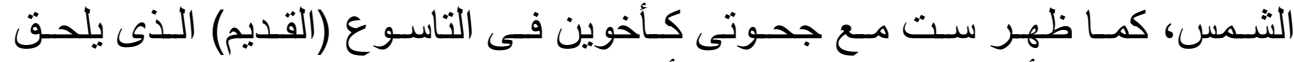

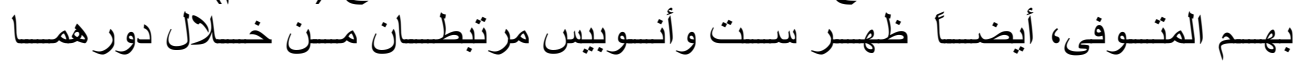

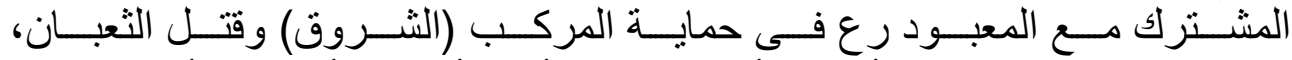

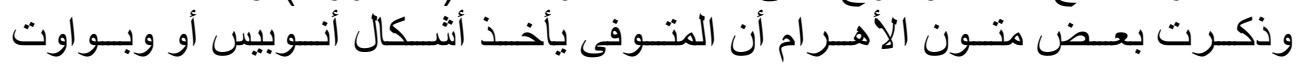
و إبن آوى، بكن

\a $_{0-5}^{6}$

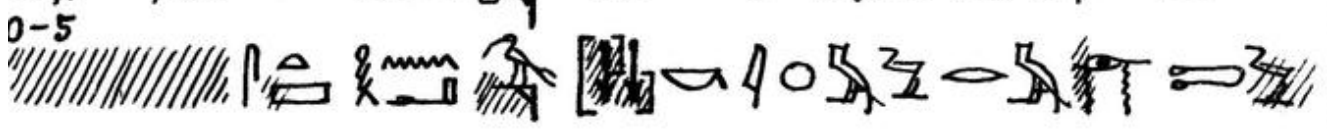
mk irtj n atS tha CHuty snwy $=k$ ixmw rmj Tw أنظر ماذا فعل ست وجحوتى، أخو الك اللذان لا يعرفان كيف ينوحان عليك.

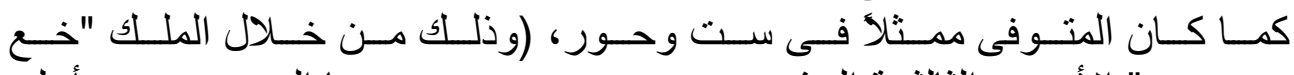

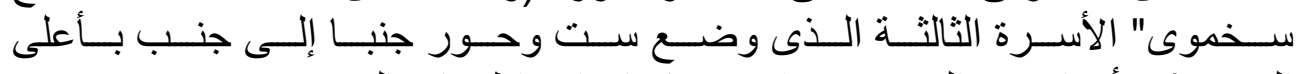

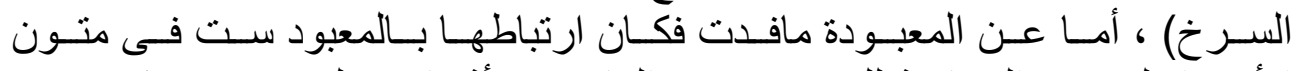

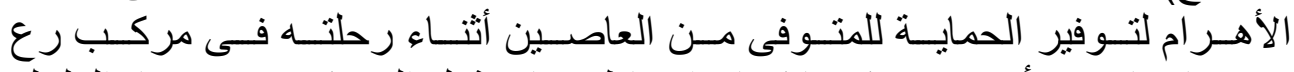

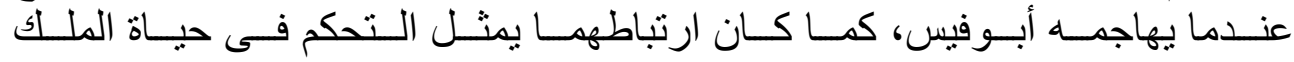

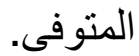
ست و رع: تثشير النصوص إلى أن ست هو حبيب رع و و إينه.

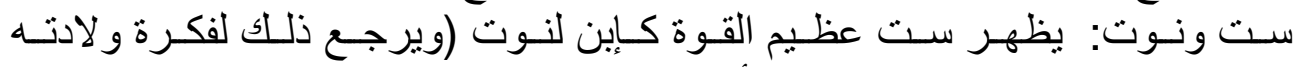

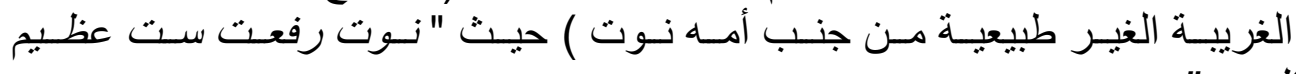

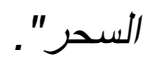

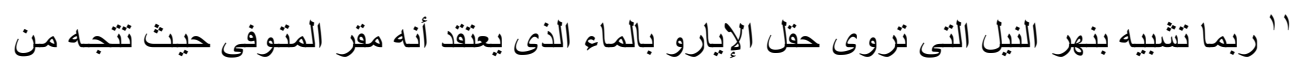

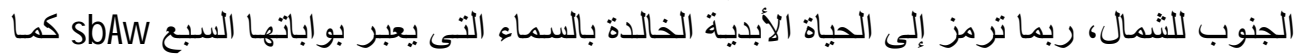
ذكر Budge - Wb. III, 222; Sethe, Pyr., 719; Faulkner, Pyr., 309; Budge, Book of the Dead (Theban Recension) $2^{\text {nd }}$ ed.,(1909), 473-478. 
دراسات في آثار الوطن العزبيه 1

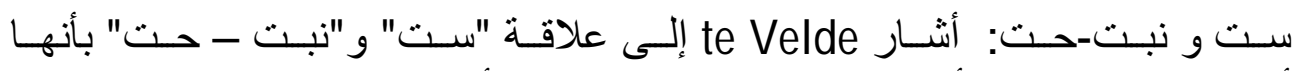

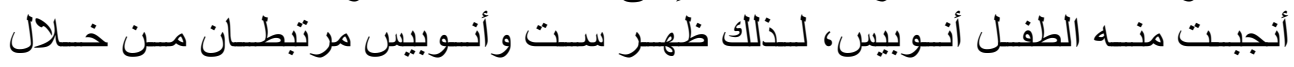

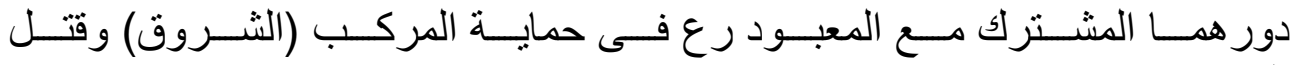

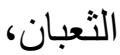

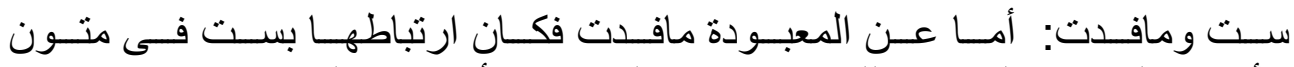

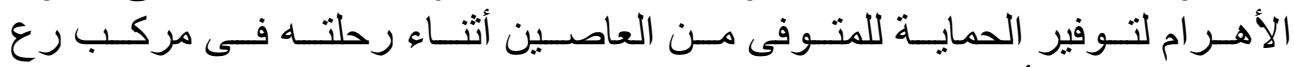

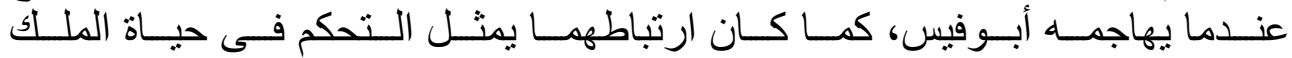

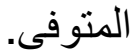

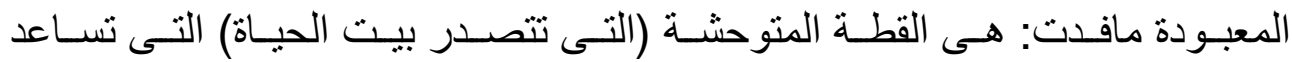

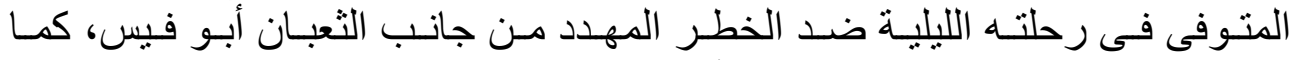

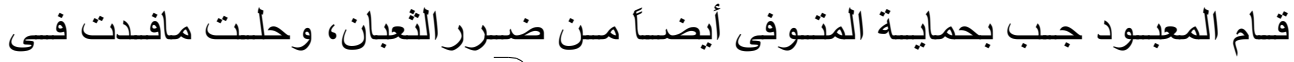

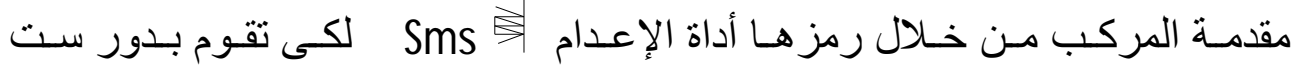
في مقدمة مركب الثمس.

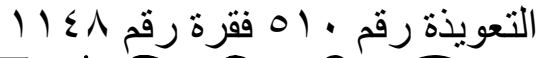
fA @rw (Mry-Ra) sis sw \%

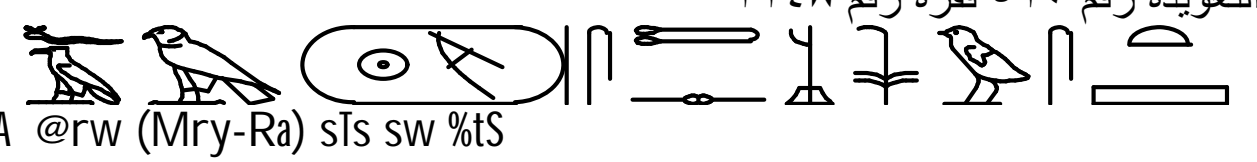

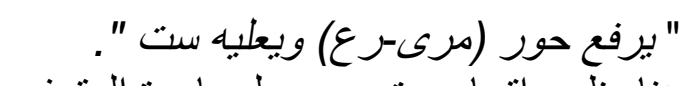

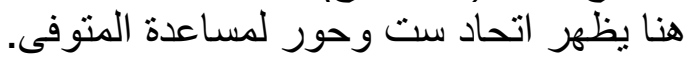

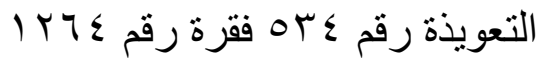

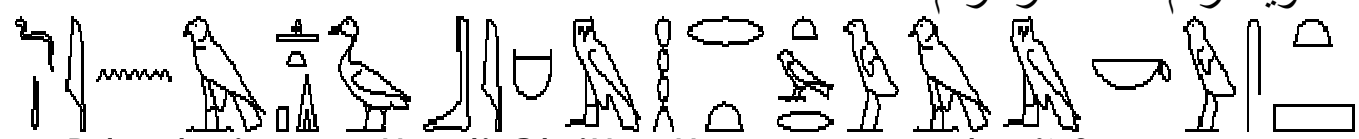
Dod mdw in @rw Htp di Gb iHm H.t twr @rw mkw \%

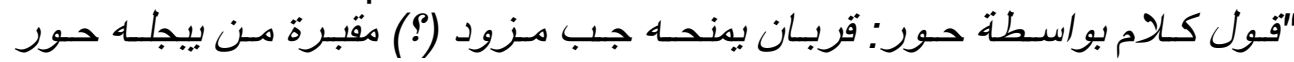

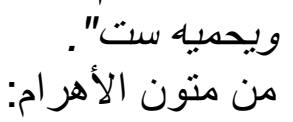

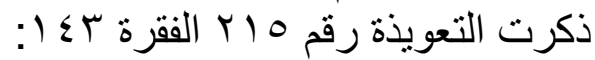

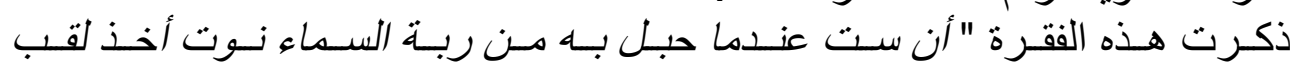

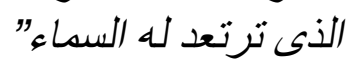

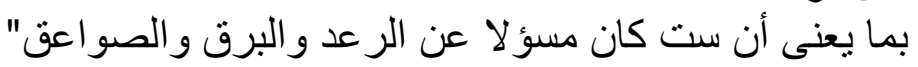

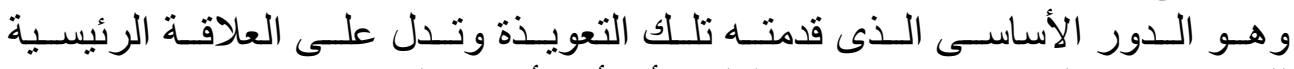
للمعبود ست بالمعبودة نوت وهو إلـانـأ لها و أنه أحد أرباب السماء.

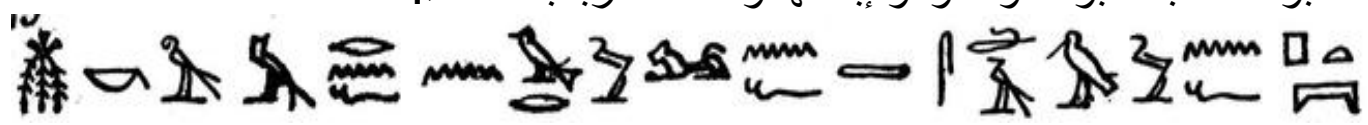
$m s(w)=k ; r m r n=(. k) n(y)$ wrw $n=f$ tAsdAwn=f pt 


\section{دراسات في آثار الوطن العربيه 1}

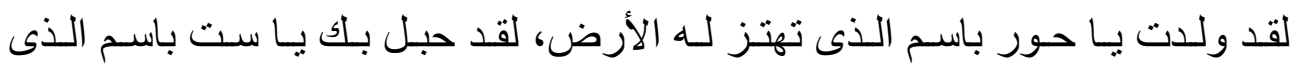
ترتعد لله السماء

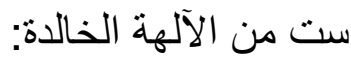

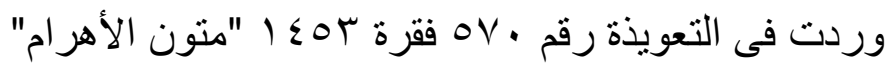

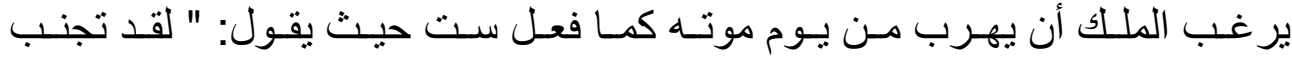

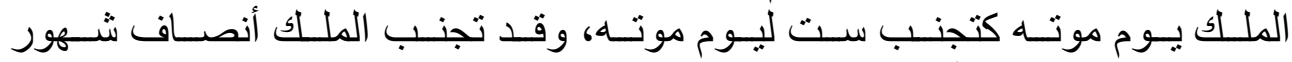

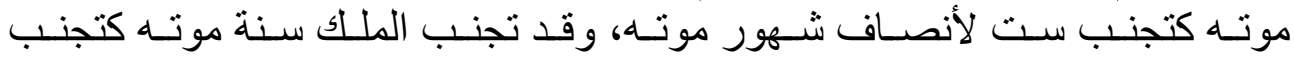

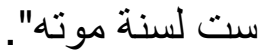

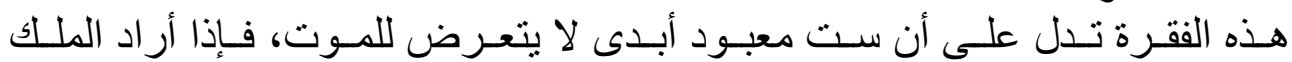

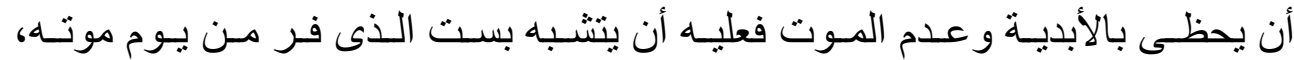

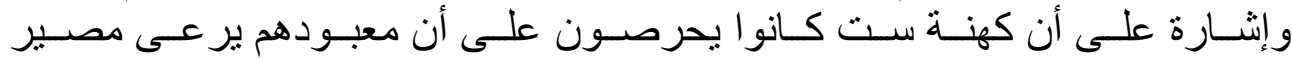

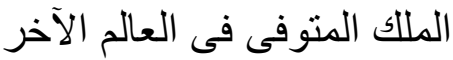

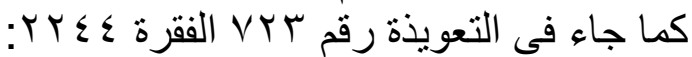

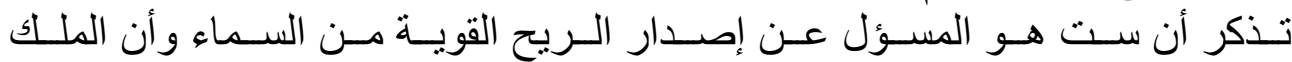

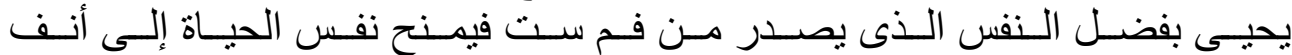

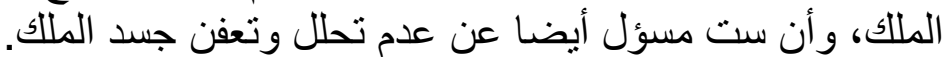

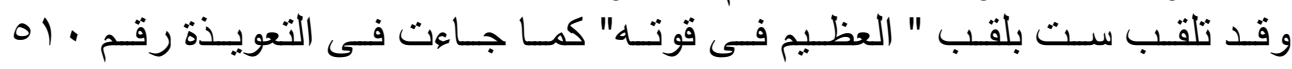

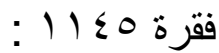

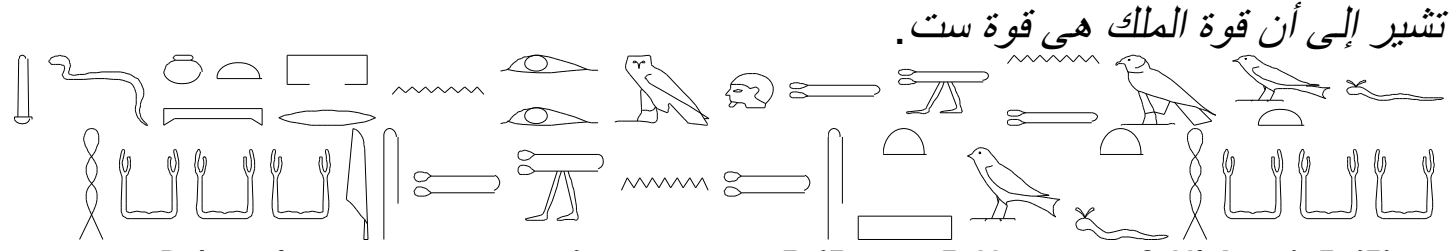

Dd mdw nut, pr $n$ irty $m$ tp .TiTy $n$.TH wrt .f HKAw isTiT n .Ts Swrt .f HAAw

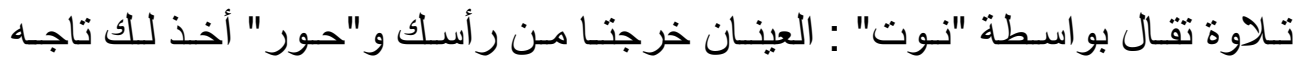

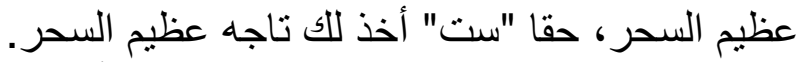
الطقوس التى تؤدى للملك الكت المتوفى فى العالم الأخر منها:

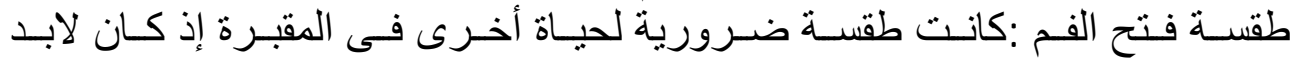

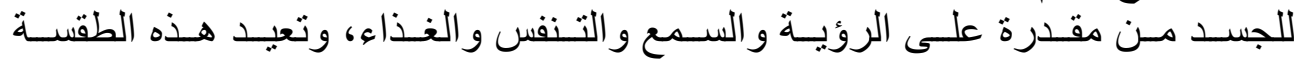

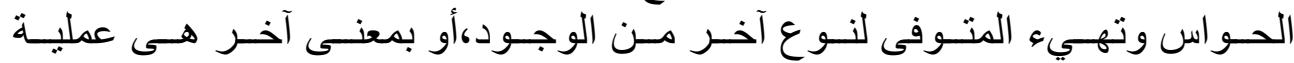

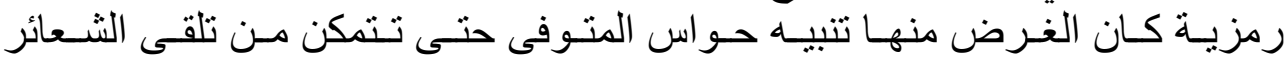

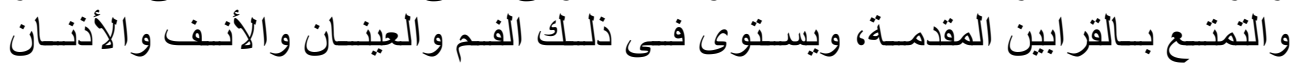

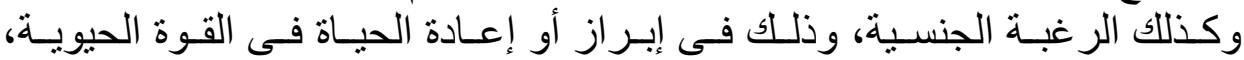

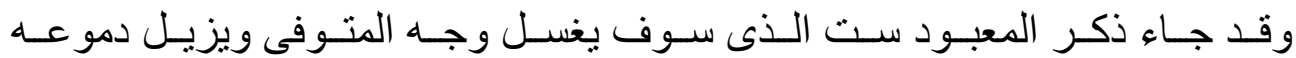




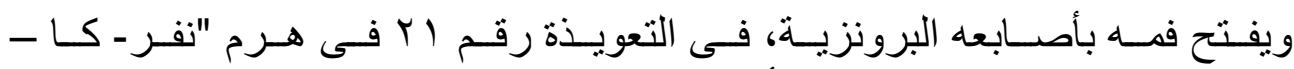

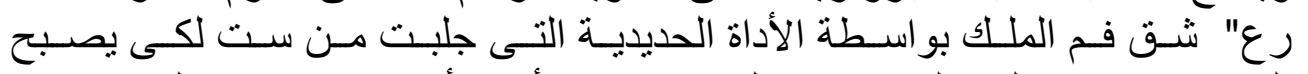

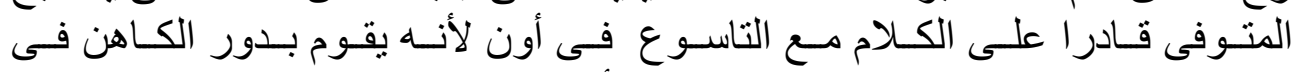

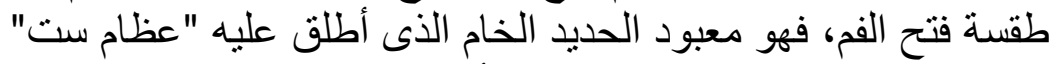

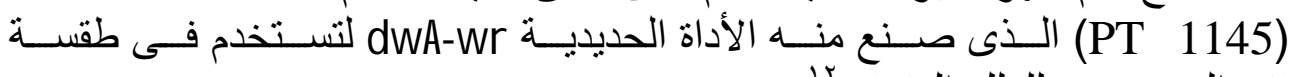

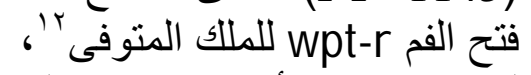

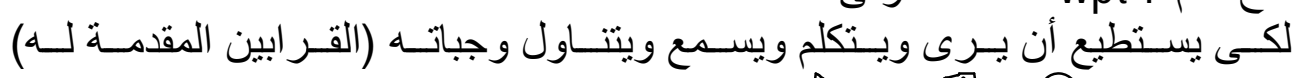

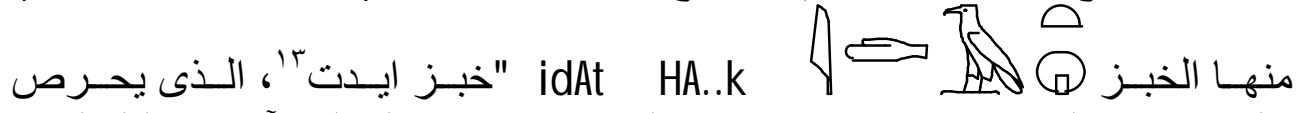

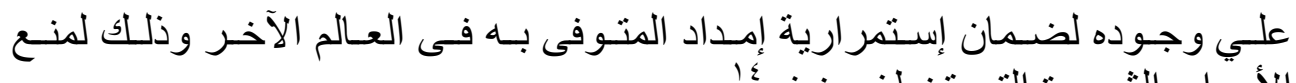

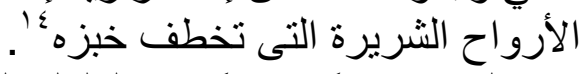

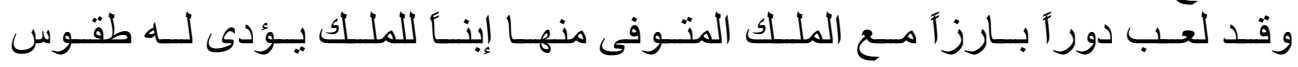

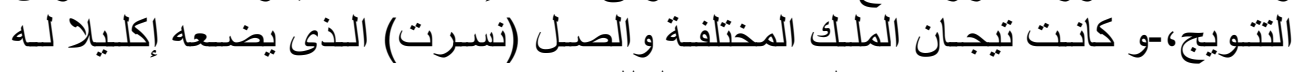

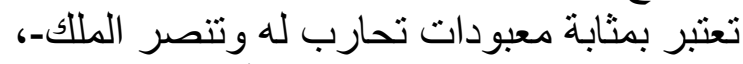

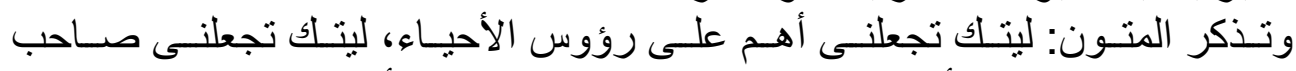

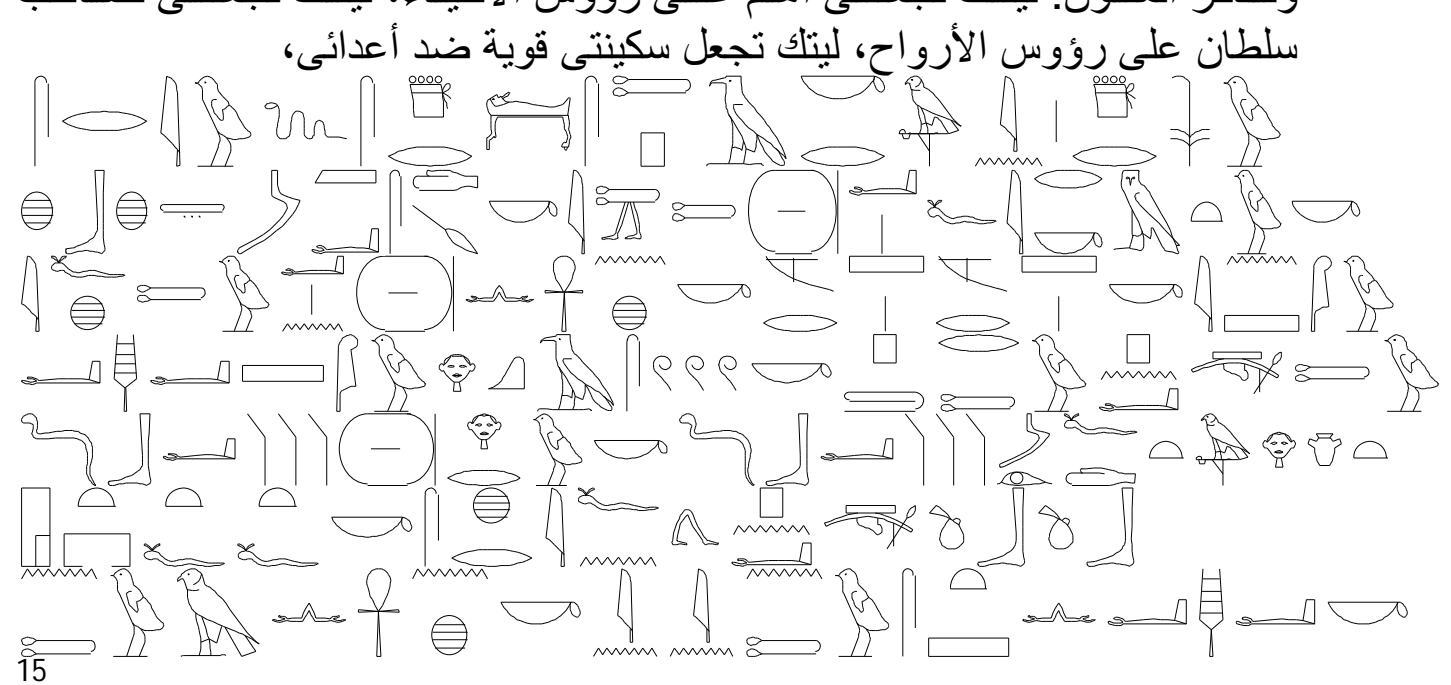

${ }^{12}$ Ann Macy Roth, "Opening of the Mouth", in: Donald B. Redford (ed.), The Oxford Encyclopedia of Ancient Egypt, 3 vols., vol 3, $1^{\text {st }}$ ed. (New York-Oxford; Cairo: AUC Press 2001) p.605-609

${ }^{13}$ Wb. I, p.152.

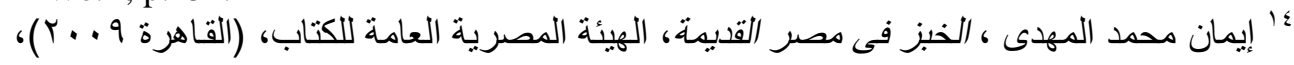

15 Sethe, Pyr. Text, 675 C - 678 C

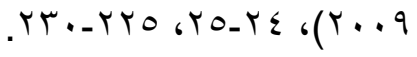


دراسات في آثار الوطن العربيه 1 (

sriw sDr sTp Arr in Dr sw xbx mAasd .k Itt (T) aA.f ir .k mut.k ifx Tw Aa n (T) nn anx.k mry i mr.k n Sw ath Sw H oAsw .k pX Tw pna Tw Dbav (T ) Hrw .k Dbaw mefdt Ht ib Hut anx tf [t]. $k$ sxr ifn pna gbgb $n$ Tw $\mathrm{H} \mathrm{n}$ anx.k inin n.TwstSn tha.k

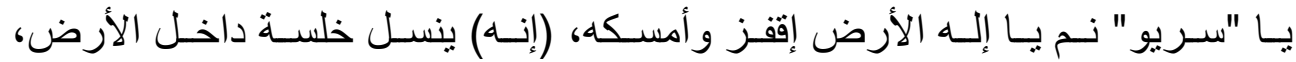

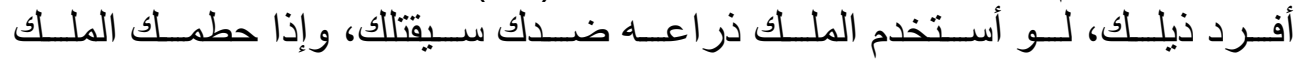

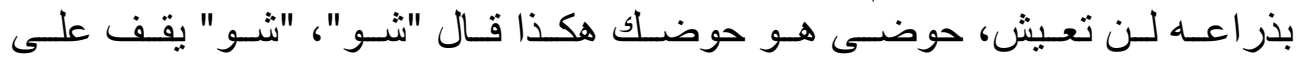

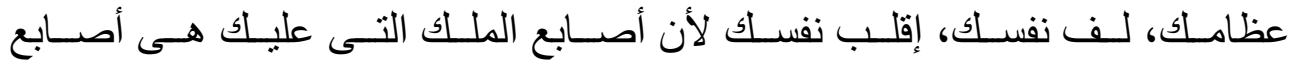

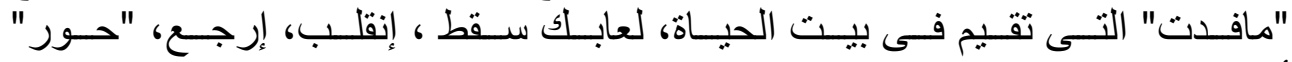

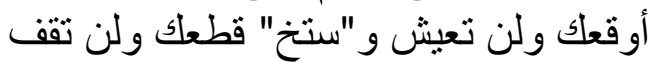

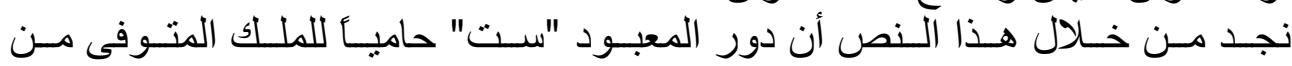

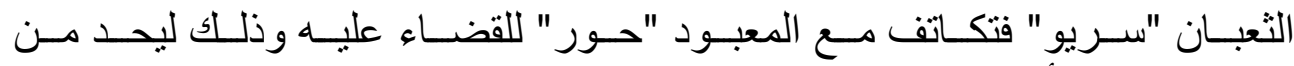

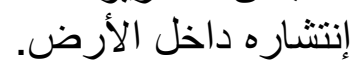

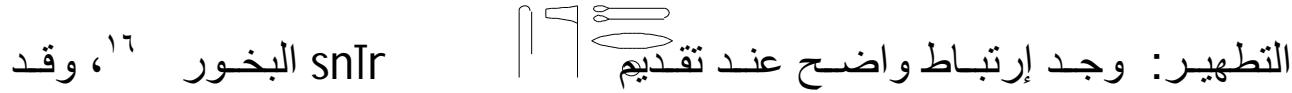

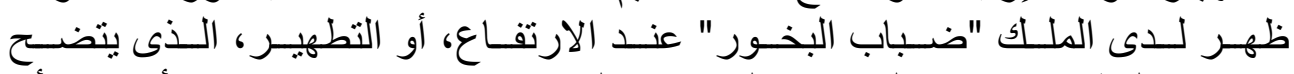

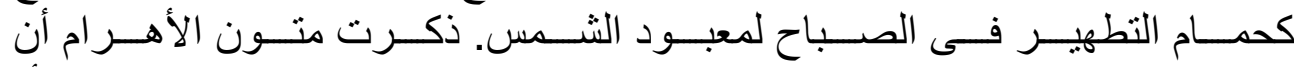

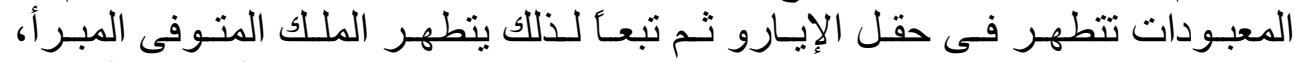

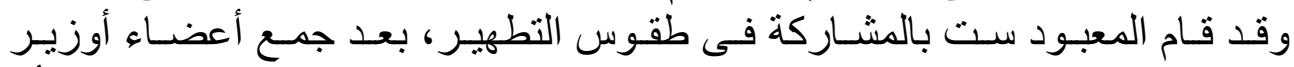

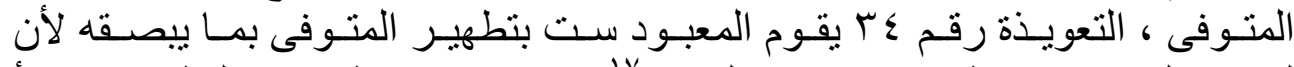

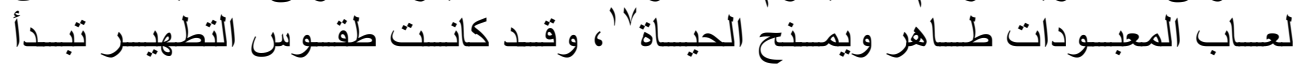

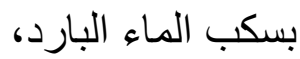

'17 ربما عملية التطهير كانت تتم بعد الوصول إلى حقل الإيـارو عبر السماو ات العليا التى يعبر هـا

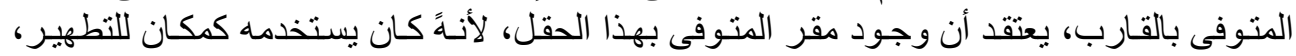

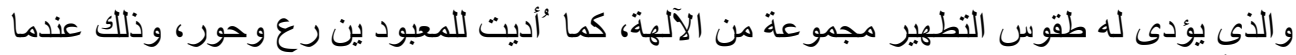

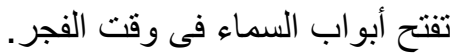

- S. Morenz, Gott und Mensch in alten Ägypten, (Heidelberg, 1964), 145.

${ }^{17}$ Claude Carrier, Textes des Pyramides ded L'Egypte ancienne, Preface de James Allen, Tome I, Textes des Pyramides d'Ounas et de Teti, col.16,s.34,pr.26c,d,27a,28a,p.16-17;

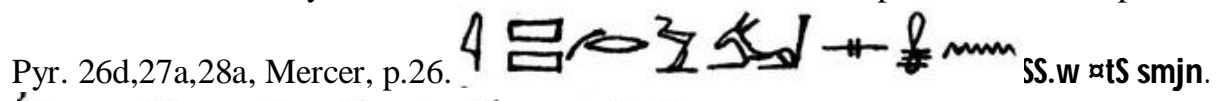

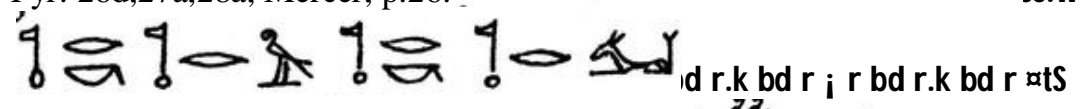
I의 ไ⿸丆冫广 roHhy, 


\section{دراسات في آثار الوطن العربيه 1}

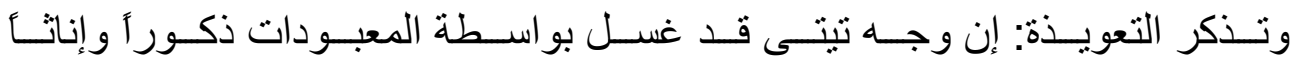

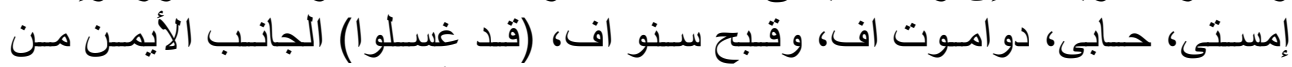

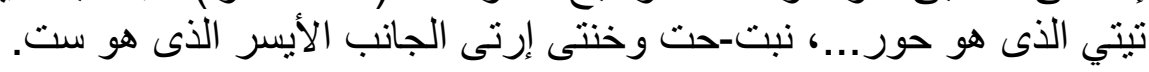

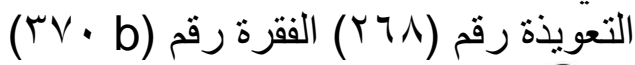

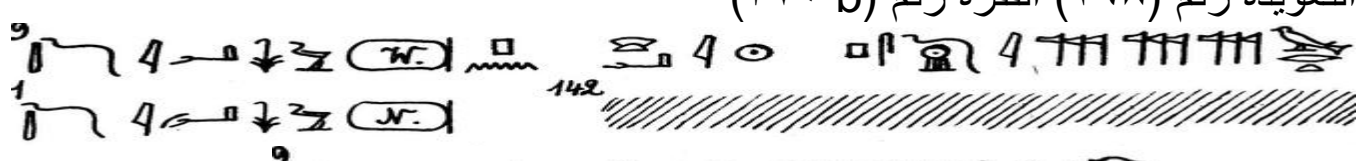

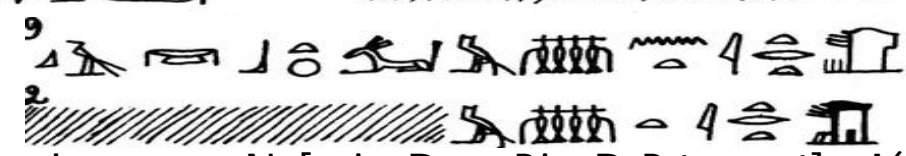

Dd mdw jav sw $N$ [xaj RapsDj PsDt wr.t] $q A(w)$ Nbi .t atS $m$ xmt itr.t

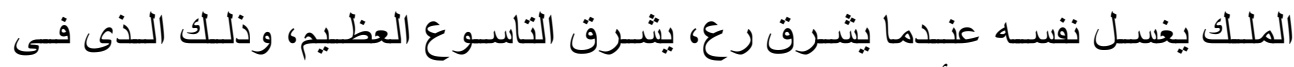
نوبت ست عالى عند رأس المجلس.

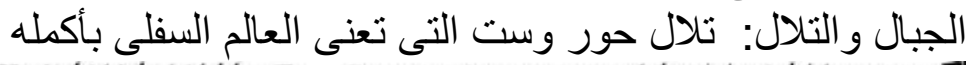

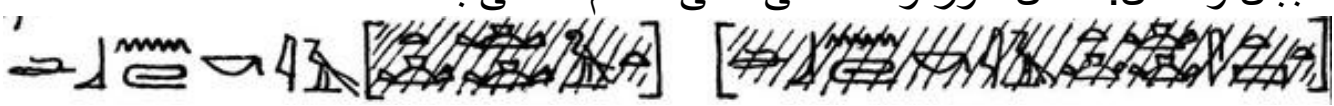
Don.k iAut i r don.kiAut ats

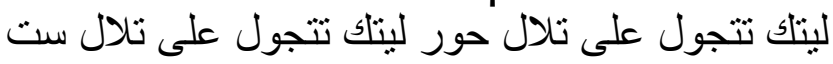

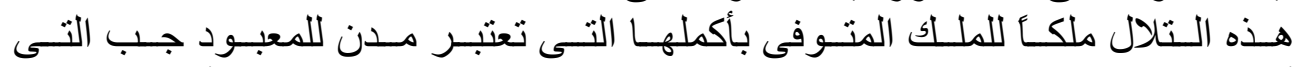

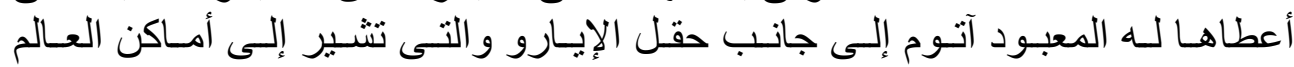

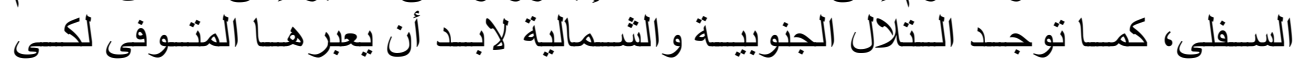

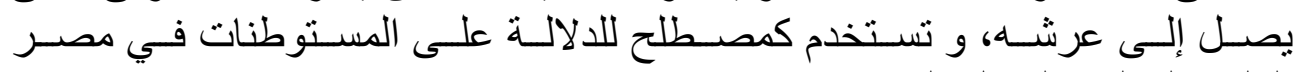

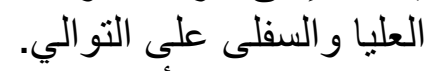

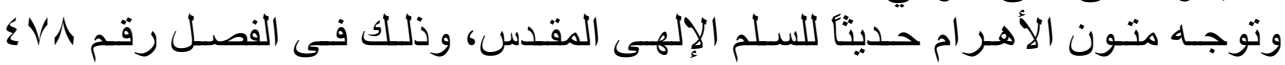

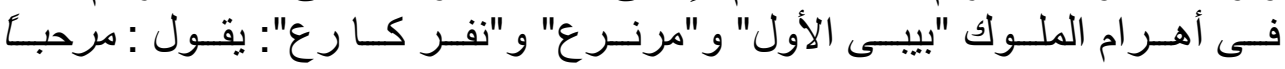

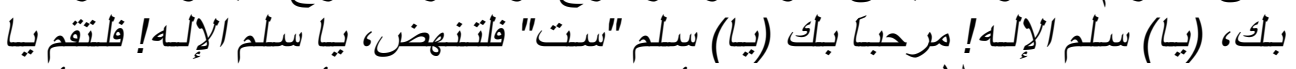

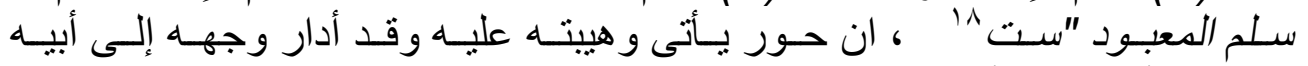

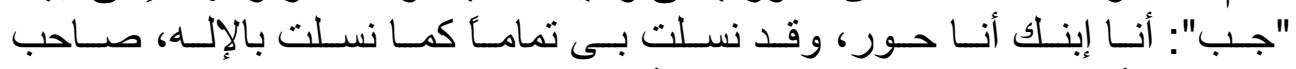

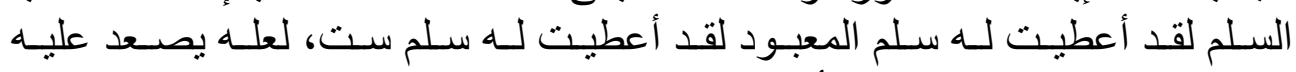

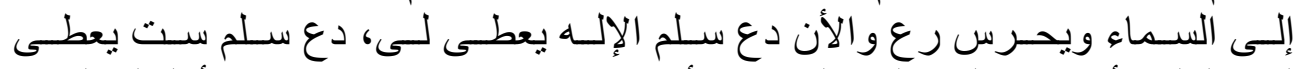

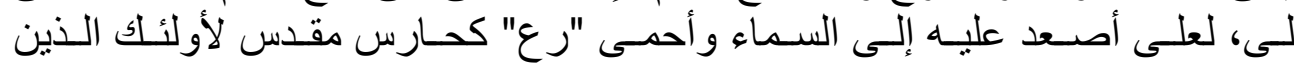

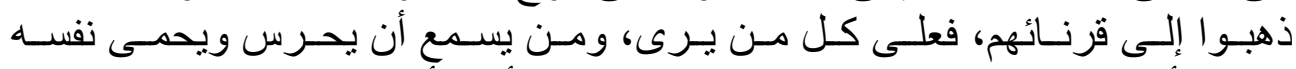

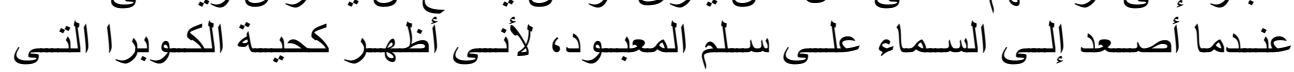

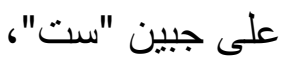

18 Sethe, Pyr., 472-473, 971; Faulkner, Pyr., 93-94, 165-166. 
دراسات في آثار الوطن العربيه 1

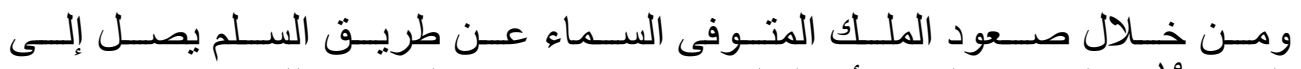

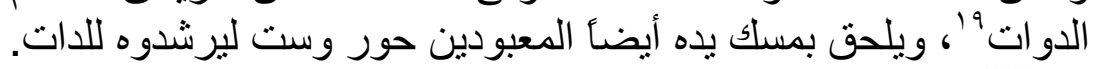

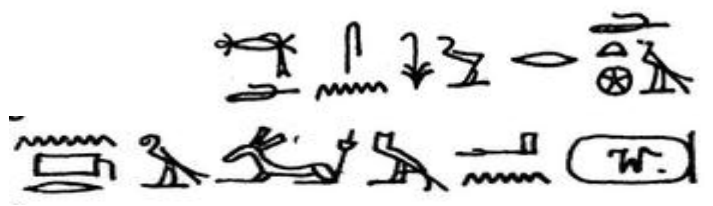

$n D$ i r atXman $w$. Sol.snswr dAt

sxut-iAxw iAnt i $r$ iAt ars

$$
\begin{aligned}
& \text { يمسك حور وست بيد الملك ويجذبانه إلى الدات }
\end{aligned}
$$

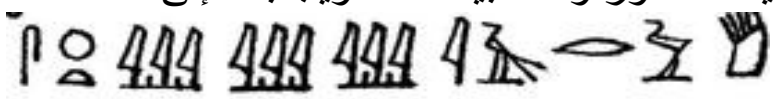

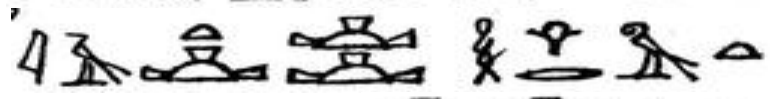

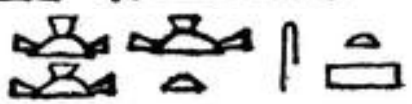

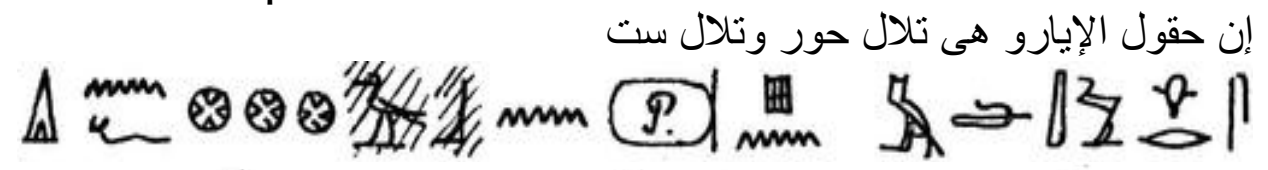

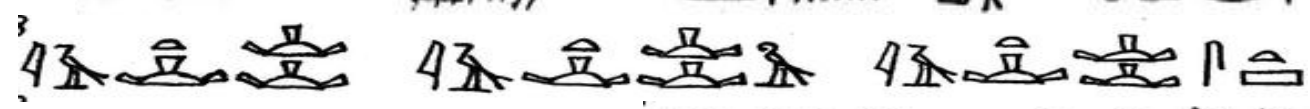

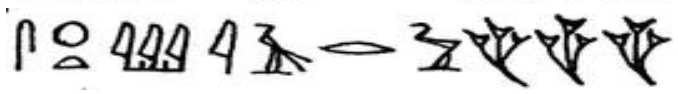
di.n.f njunt Gb n $\mathbb{P}$ pn molw H s iAut iAnt iAnt i $r$ iAut atS sxt-iArw

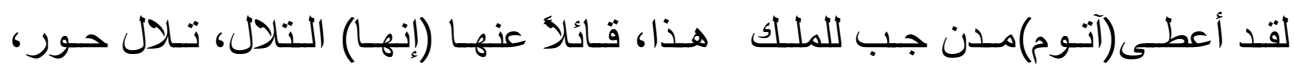

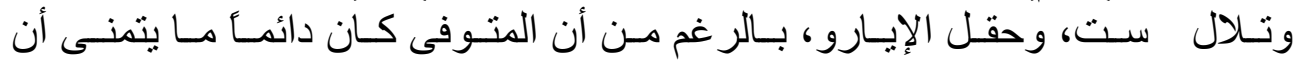

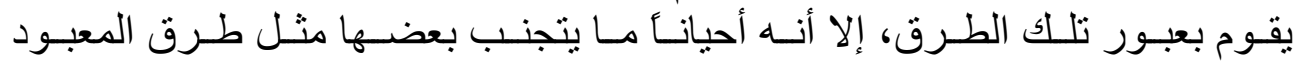

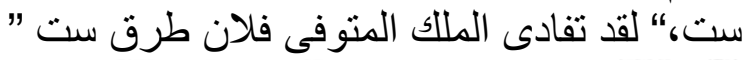

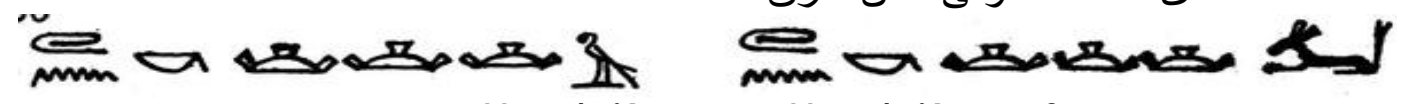

pXr n.kjAnt i r pXr n.kjAnt atS

تتجول تلال حور، تتجول تلال ست.

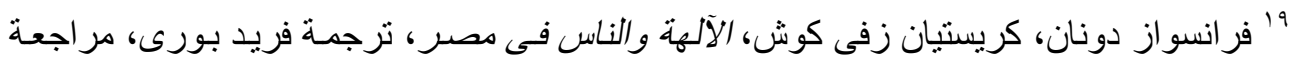

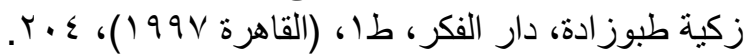




\section{دراسات في آثار الوطن العربيه 1}

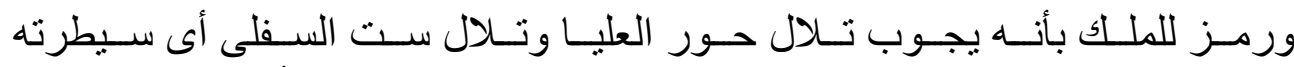

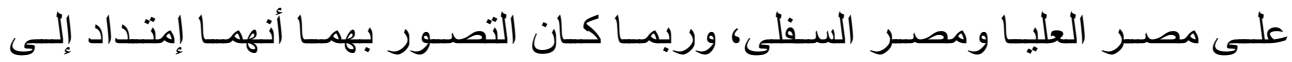

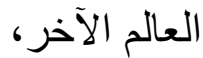

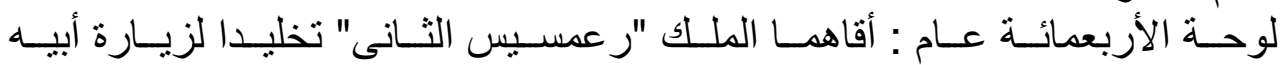

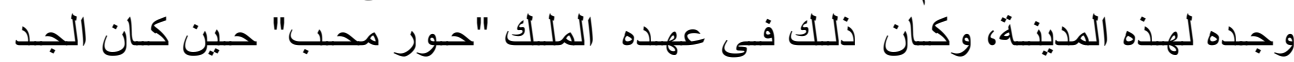

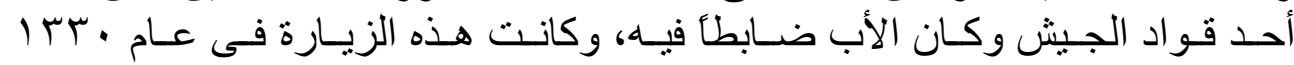

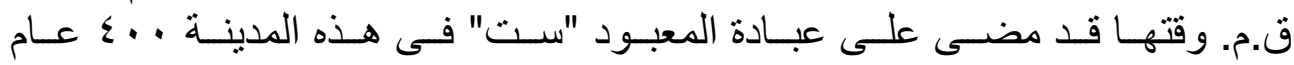

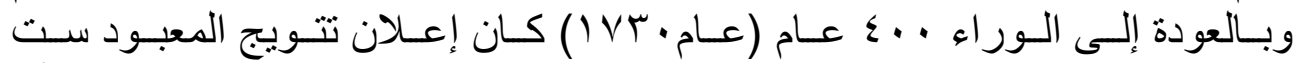

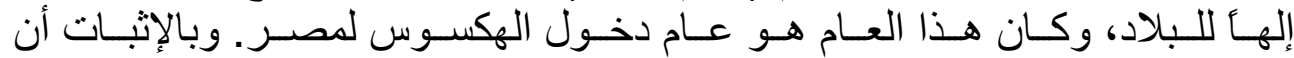

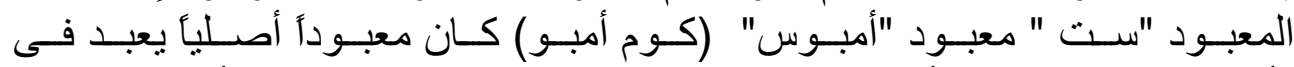

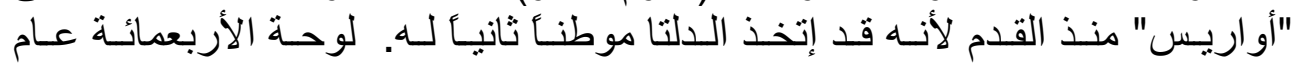

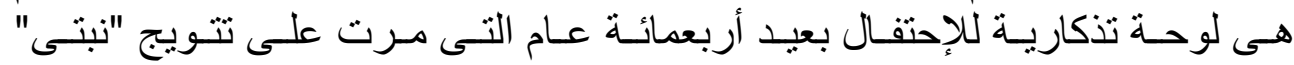

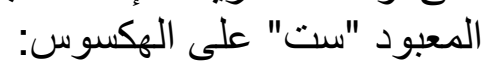

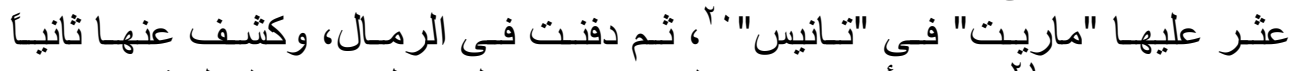

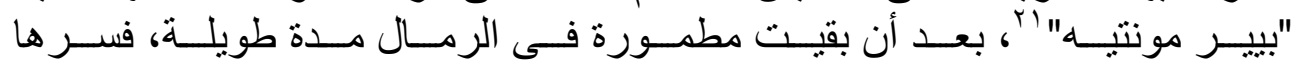

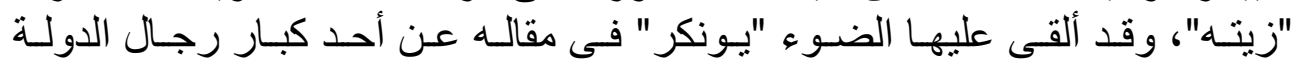

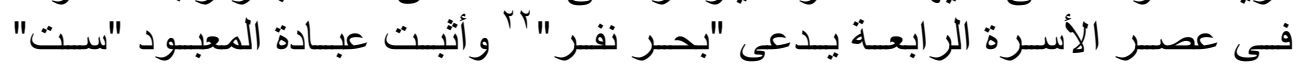

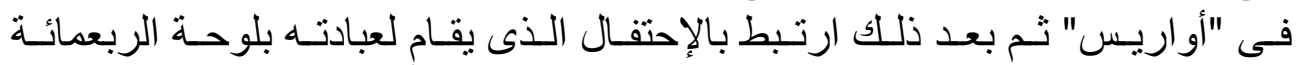

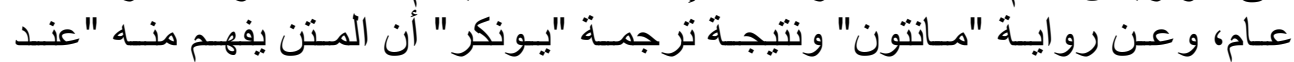

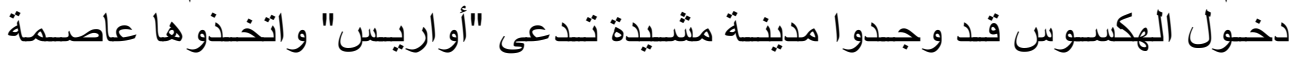

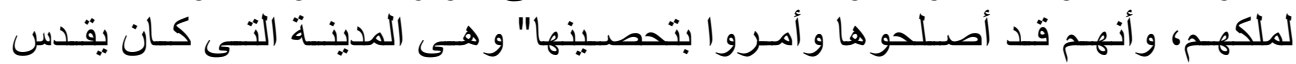

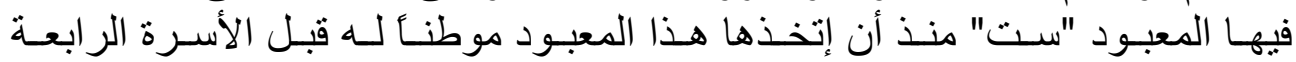

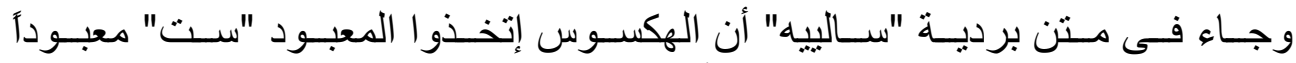

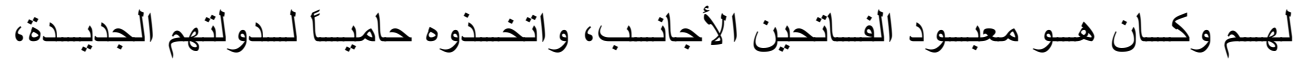

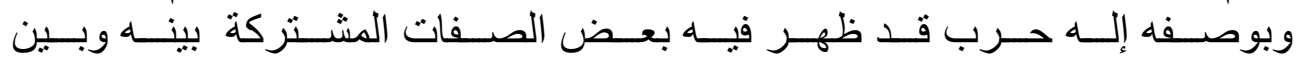

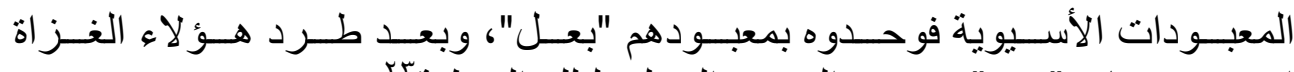

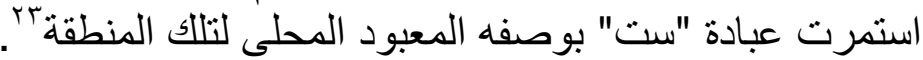

${ }^{20}$ Revue d'Archeologie, N. S. XI. 1865, pp. 169-90

${ }^{21}$ Montet, "La Stele de L'An 400”, Kemi IV, 1933, pp. 191-215.

${ }^{22}$ Junker, "Phnfer", A. Z. vol, 75, pp. 63-84. 


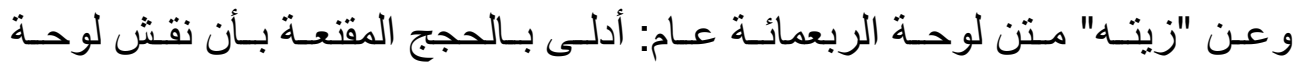

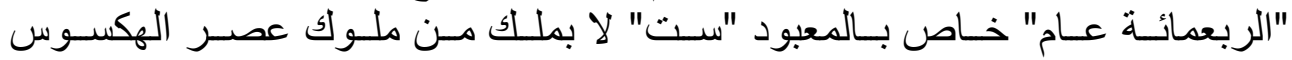

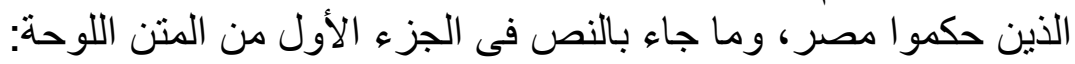

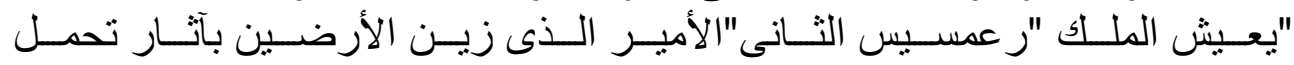

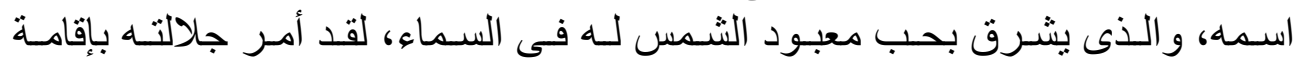

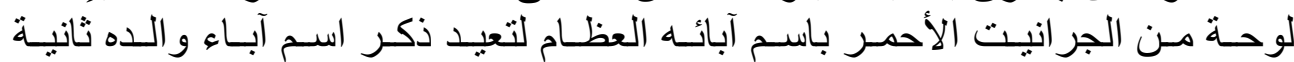

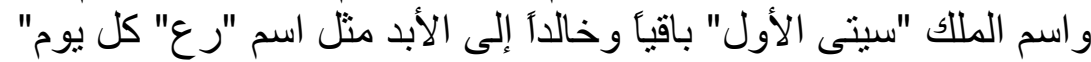

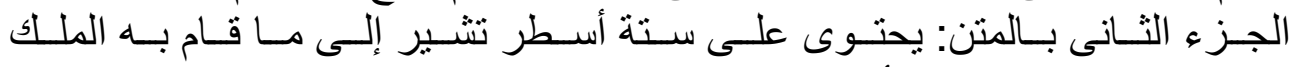

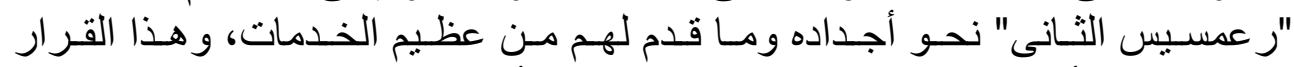

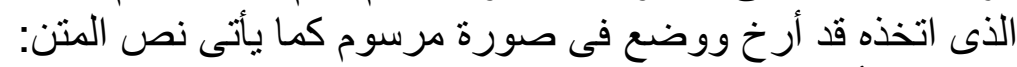

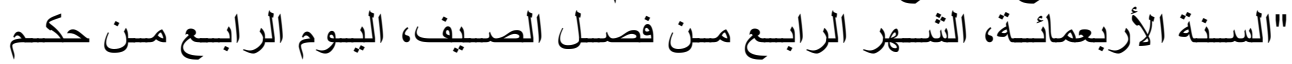

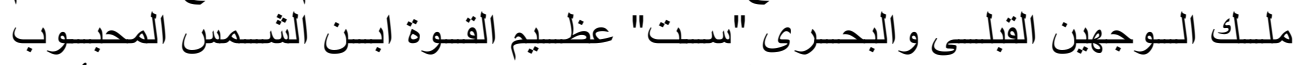

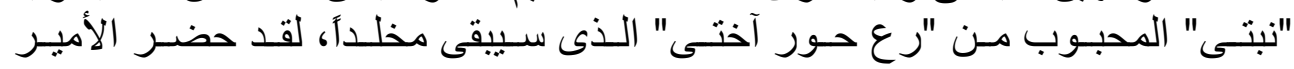

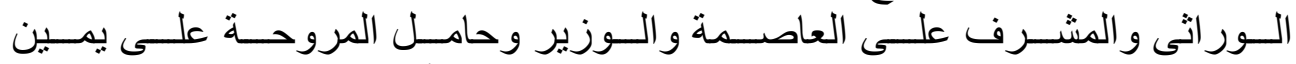

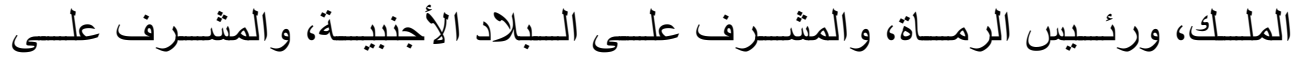

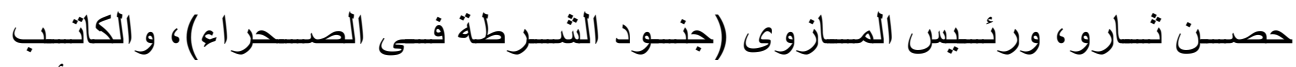

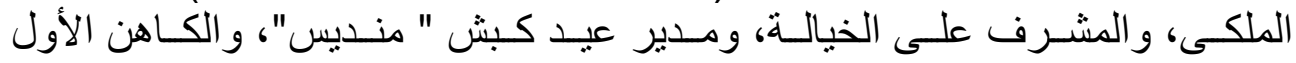

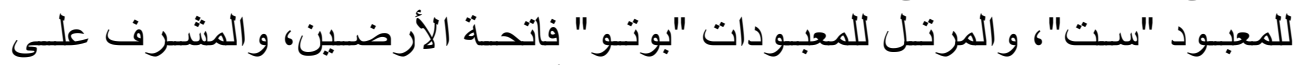

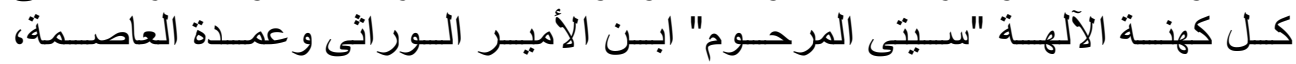

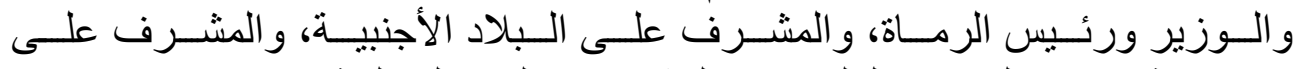

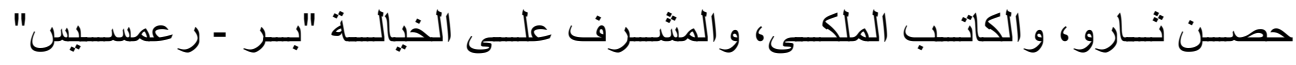

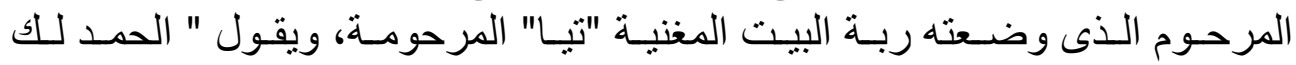

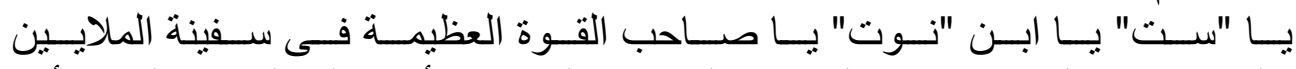

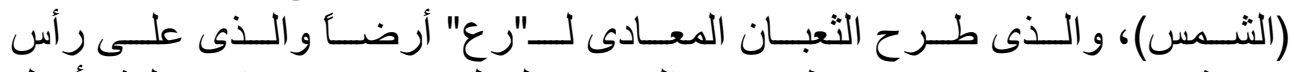

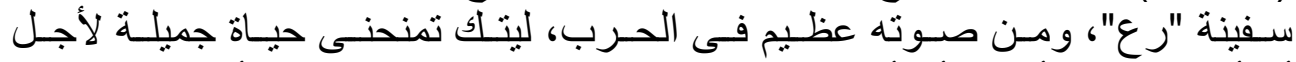

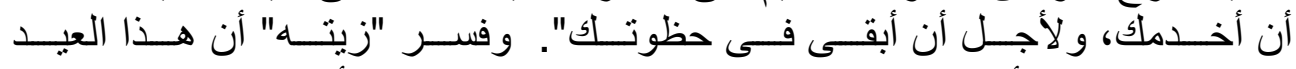

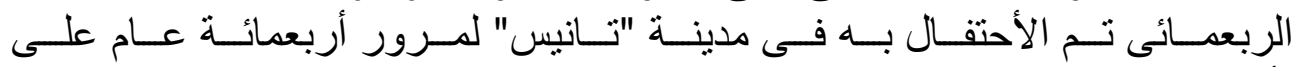

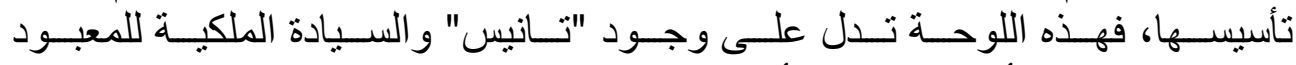

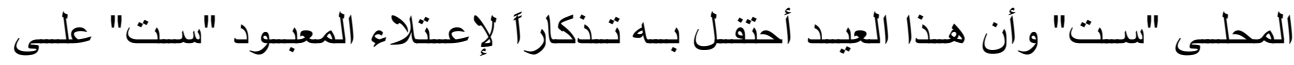

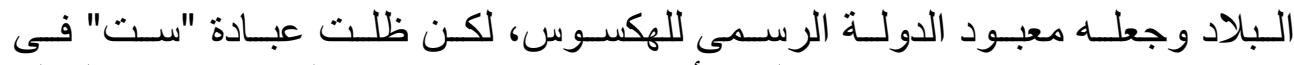

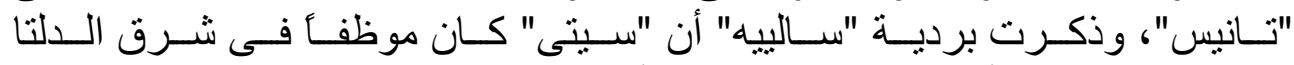

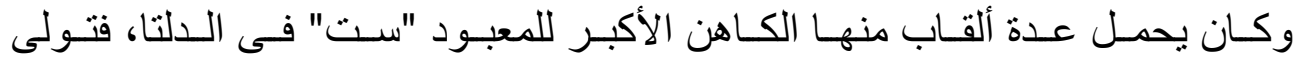

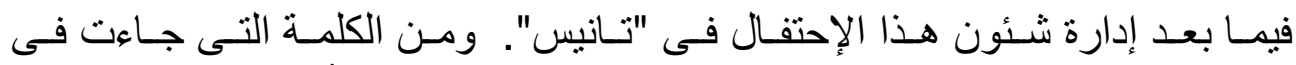

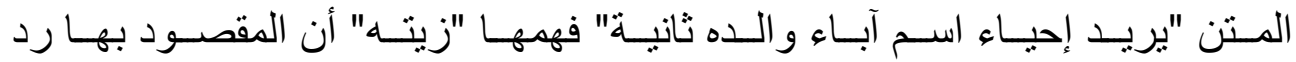




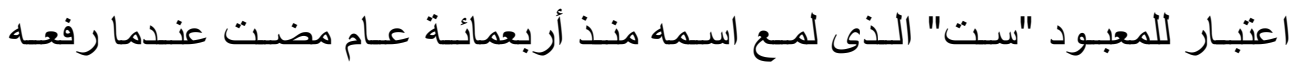

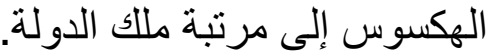

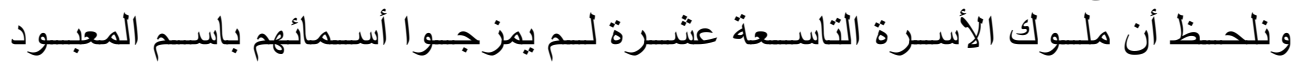

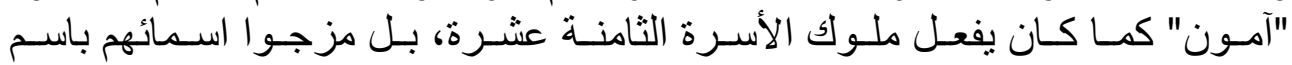

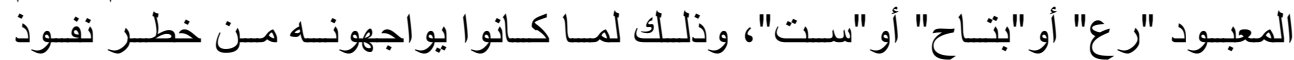

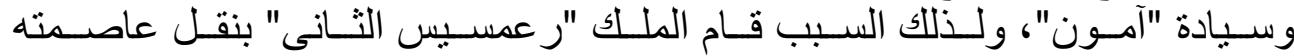

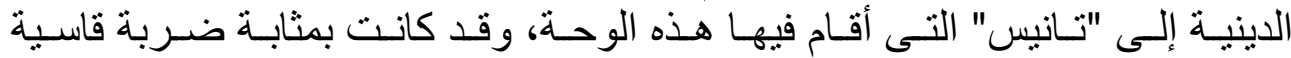
لمدينة "طيبة".

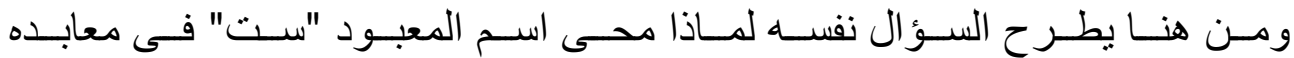

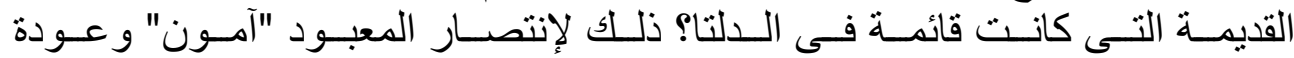
عاصمة الملك إلى "طيبة" في نهاية عصر الأسرة التاسعة عشرة.

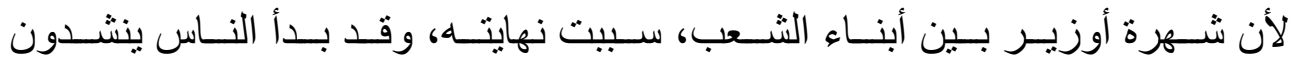

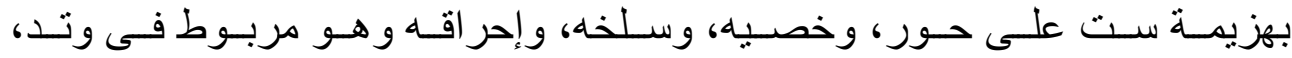

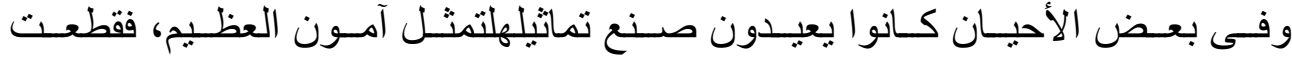

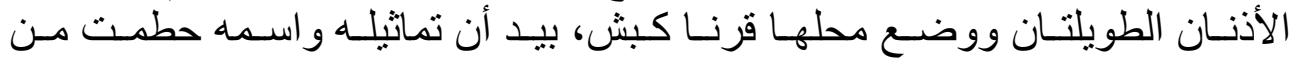

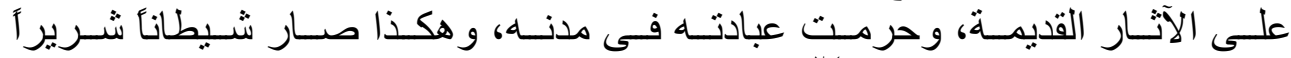

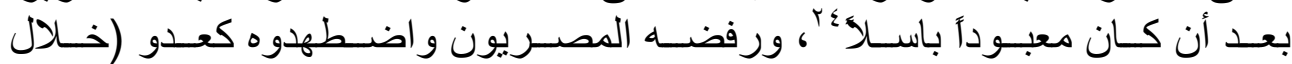

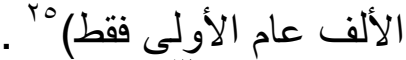
متون الأهر امجام الأبى

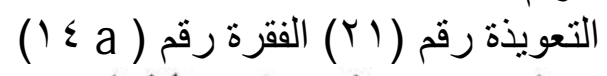

\section{[}

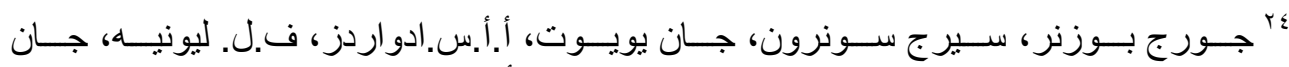

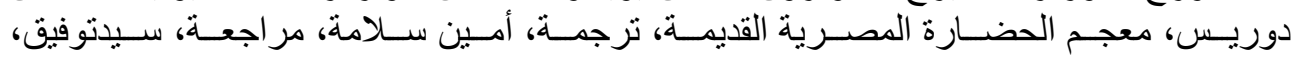

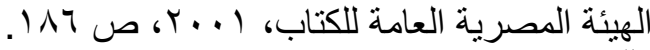

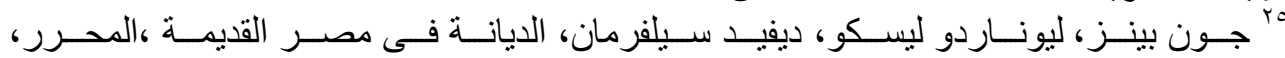

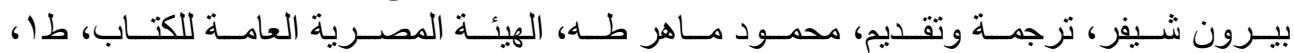
. 170 . 17

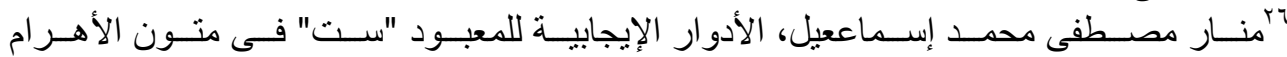

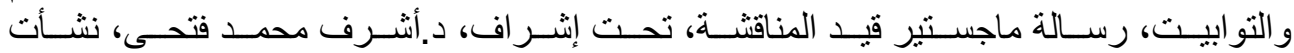

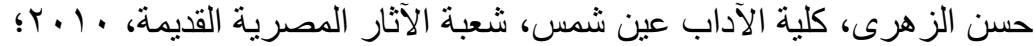
K. Sethe, Die Altagyptische Pyramidentexte, 2Bde, 1908-9; R. O. Faulkner, The Ancient Egyptian Pyramid Texts, Oxford, 1969.; Faulkner, PT. ; Kees, Gatterglaube;Piankoff, Unas,; Speleers, Textes des Pyramides,; Mercer, Pyramides Texts I,; Altenmuller, in LÄ V,col.14-23. 
دراسات في آثار الوطن العربيه 1

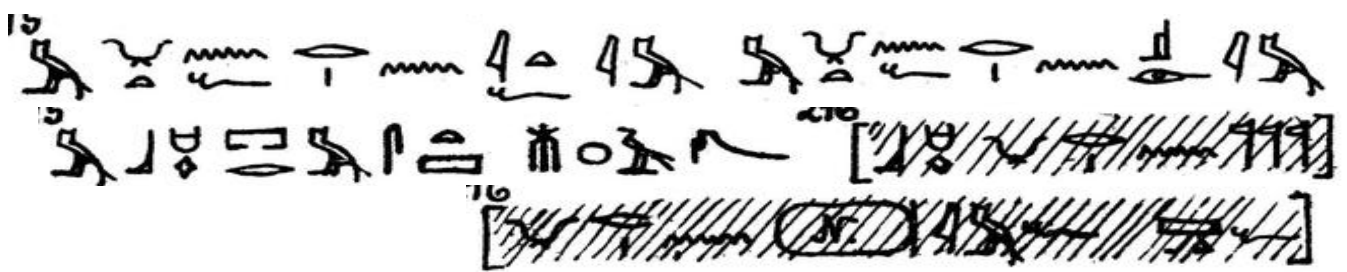

wn .n@r $\mathrm{r}$ N pn, wp @ $\mathrm{r} n \mathrm{~N}$ pn, mwpt. N.f $\mathrm{r}$ n It.f im, $m$ wpt .n ff $r \mathrm{n}$ Wsir im $m$ biApr matS msxtiw, biAwpi- $r$. n nTrw, wpr. n N im.f.

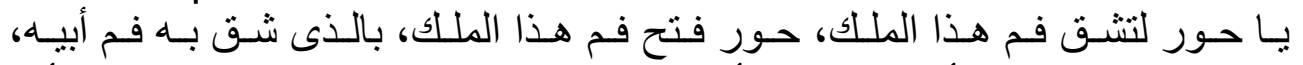

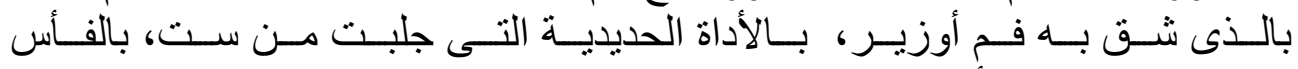
الحديدية التى فتحت أفو اه المعبودات.

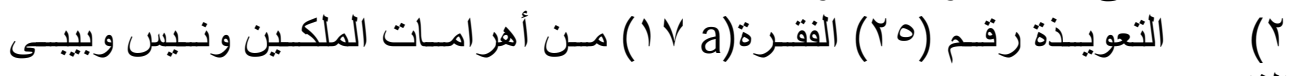
الثانى:

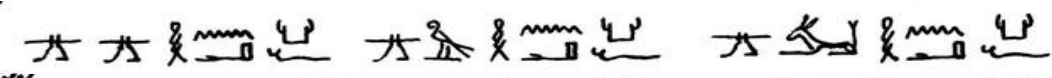

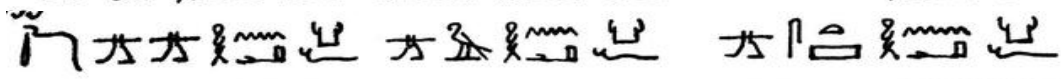

W: sb sb HakAf sb i $r$ HakAf sb \%SHakAf

$\mathrm{N}$ : Dd mdw sb sb tha kAf sb i $r$ HakAf sb \%SHakAf

ذهب من ذهب مع كائه، ذهب حور مع كائه، ذهب ست دمع دم كائه.

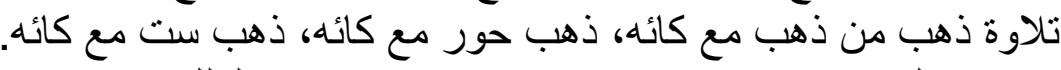
(r

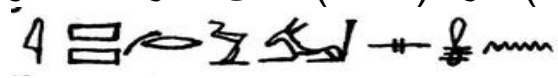

iSSw \% 6 smin $^{27}$

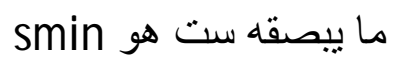
كان اللعاب رمز أ أسطورياً للحياة، وكان الفم المكان الأسطورى للو لادة،

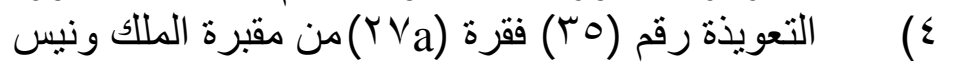

$b^{28}$ r.k bd r \%

$$
\text { "ต }
$$

ان تطهيرك هو تطهير ست

${ }^{27}$ Ahmad Kamal Pascha, Lexique de la Langue Égyptienne Ancienne, vol.14, p.125 بمعنى عطر أو نطرون Blackman, in: Z̈̈S, 47, 125. يقترح Blackman أنه دهانر اجع: Gr. P.564 بنوع من ملح النطرون 
دراسات في آثار الوطن العربيه 1

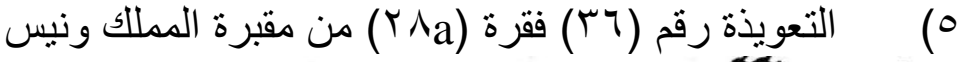

$$
\begin{aligned}
& \text { ' }
\end{aligned}
$$

bd r.kbd r i r bd r.kbd r \%

تطهيرك (الملك) يماتل تطهير حوروتطهيرك يماتل تطهير ست (يت

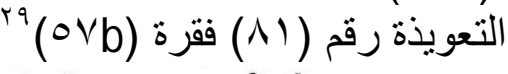

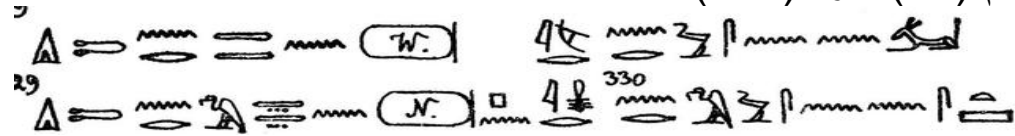

di.Tnr tAwy n W jmr nrw.sn(y) n atS

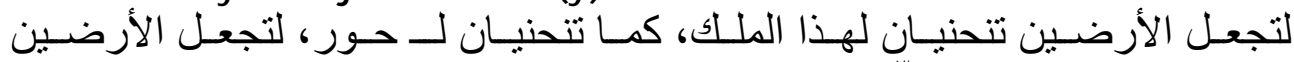

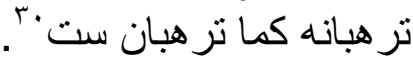

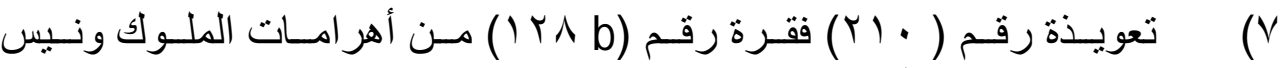
وتيتى ومر نرع و بيبى الثنانى

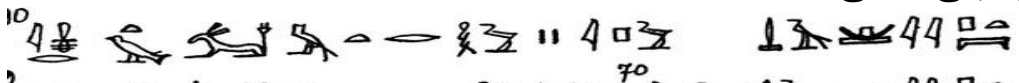

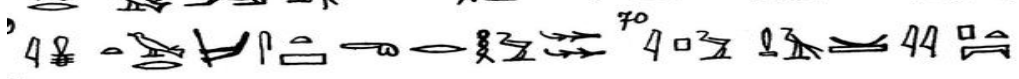

mi twr \%5mt RHwy ipw DAy p.t

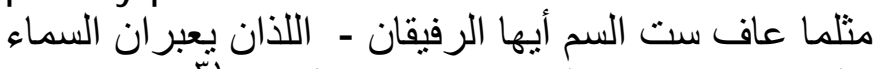

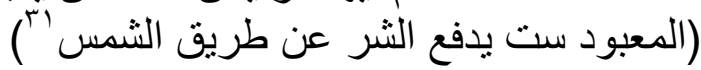

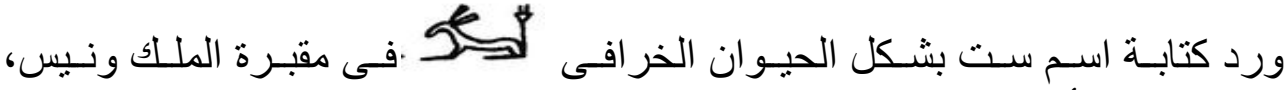

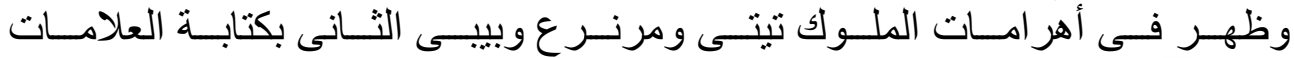
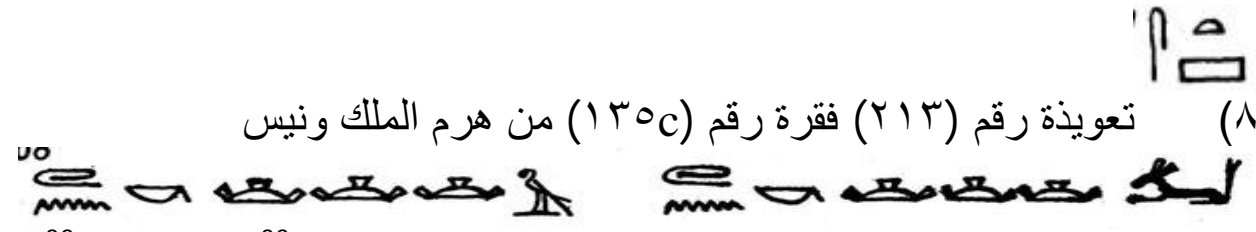
pXr ${ }^{32}$ n.k iAwt ${ }^{33}$ i r pXr n.k iAwt \%5

$$
\text { 9تجوب تلال (أقاليم) حور وستجوب تلال (أقاليم) ست. }
$$

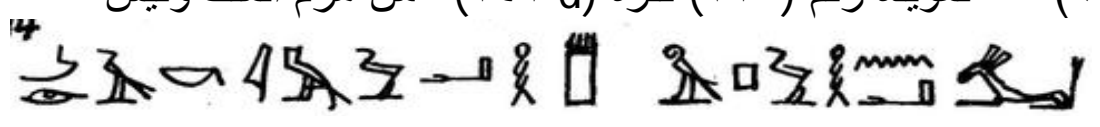

${ }^{29}$ Claude Carrier, Textes des Pyramides ded L'Egypte ancienne, Preface de James Allen,

Tome I, Textes des Pyramides d'Ounas et de Teti, p.27.

${ }^{30}$ R. O. Faulkner, P. T. 19

${ }^{31}$ Jequier, Egyptian Relgion III, p.20-23.

${ }^{32}$ Gr. p. 566

${ }^{33}$ Wb. I. p. 26 
دراسات في آثار الوطن العربيه 1 إس

$m A(w) . k$ im(y).w aH i $r$ pw Hha \%

انظر الآن إلى من الذين فى القصر هما حور وست.

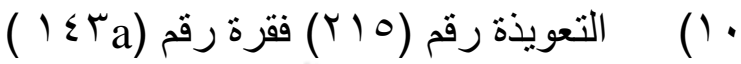

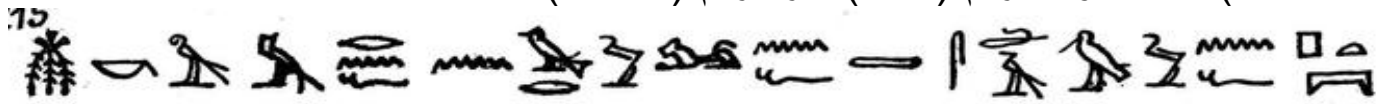
ms(w).k i $r$ mrn.(.k) n(y) wrwn.f tAsdAwn.f pt

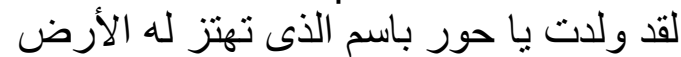

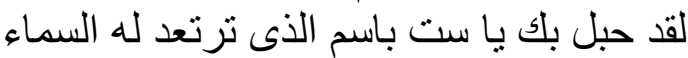

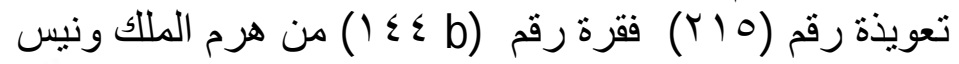

(1)

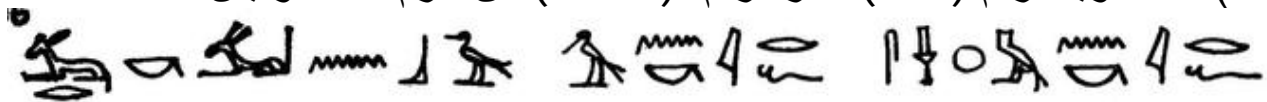
$\operatorname{iwr}(w)^{34} . k \%$ \% $5 n$ Gb, bAn(y) .k ir .f, sxm ${ }^{35} n(y) . k$ ir .f

لقد حبل بك يا ست لـ جب و إن للك القدرة أكثر منه ولام الك القوة أكثر منه.

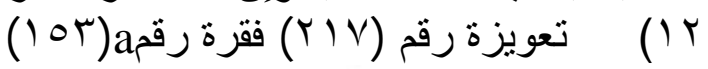

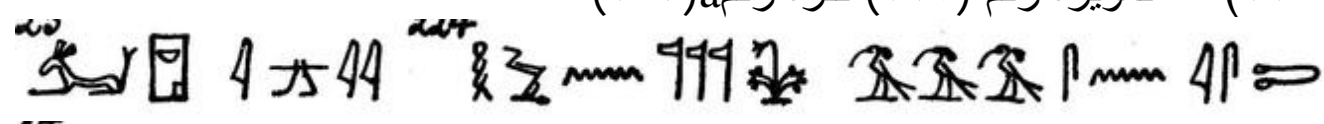

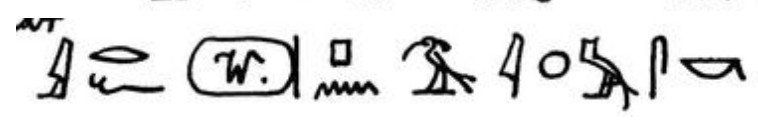

\% 6 S Nb.t- Hw.t iy Hw n nTr.w Smaw Ax.w .sn ist, j if W pn Axjxm-sk

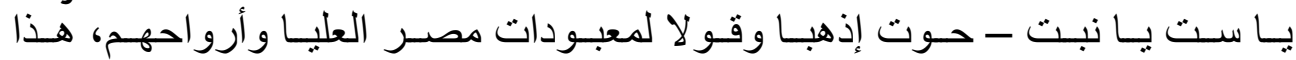

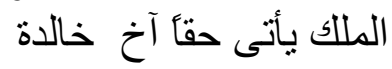

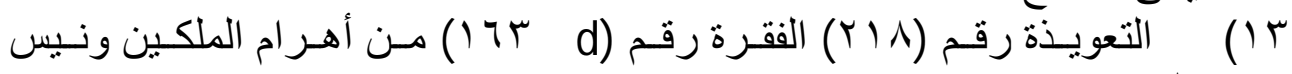

员 a 离 mk irtj $n$ ats tha CHuty snwy.k ixmw rmj Tw أنظر ماذا فعل ست وجحوتى، أخو الك اللذان لا يعر فان كيف ينوحان عليك.

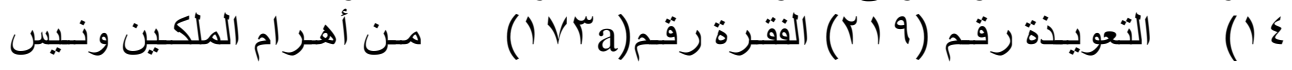
وبيبى الثانى

莫 aIS sn.k pw pw-nn ${ }^{36}$ Wsir rdj solb.f anx.f ss $^{37}$.f Tw

\footnotetext{
${ }^{34}$ Wb. I. p. 56

${ }^{35}$ Gr. p. 591

${ }^{36} \mathrm{~Wb} .506,1$
} 
دراسات في آثار الوطن العربيه 1

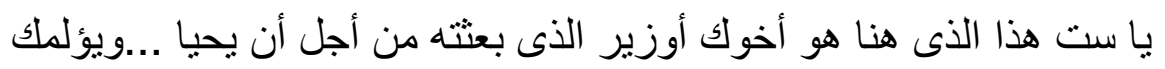

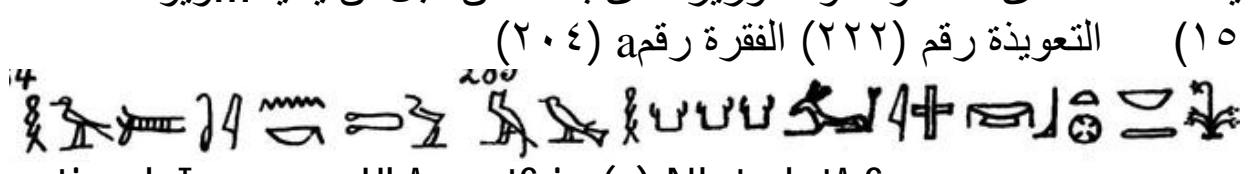
Htm.ti n.kTw, mwr HkAw atSim(y) Nb.t nb tASmav

خذ لنفسك عظيم السحر، ست الساكن فى نوبت سيد مصر العليا.

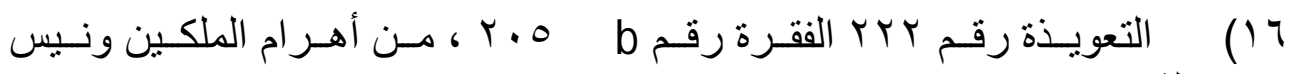
وبيبى الثنانى

min min

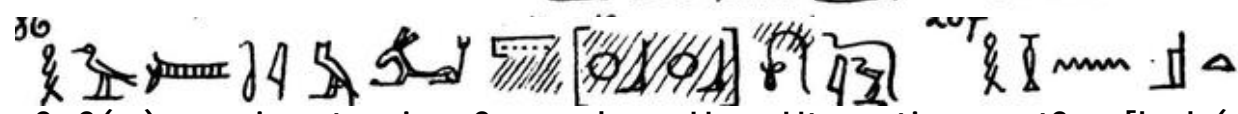
$n \hat{S} \mathrm{~S}(\mathrm{w})$.n jwr.t j-spS .n .k grH $\mathrm{Htm} . t \mathrm{~m}$ atS $x[\mathrm{bxb}(\mathrm{w})]$ wADWW Hs(w) $\mathrm{n}$ Ast

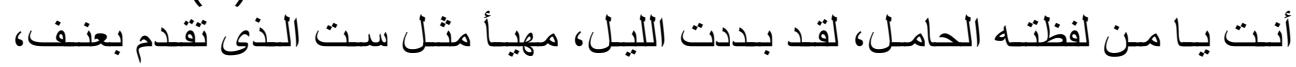

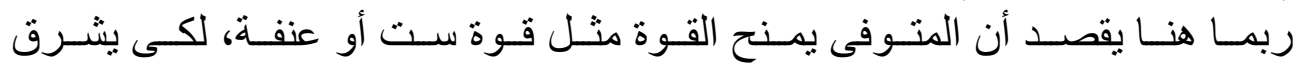

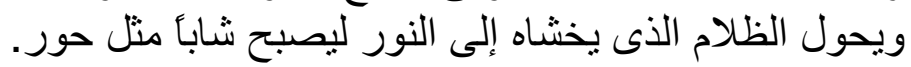

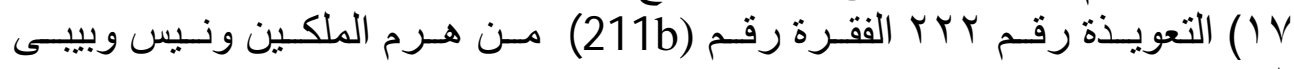

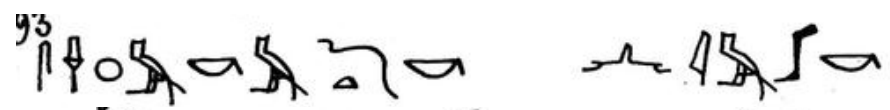

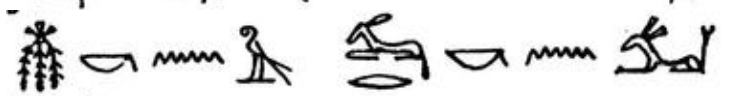

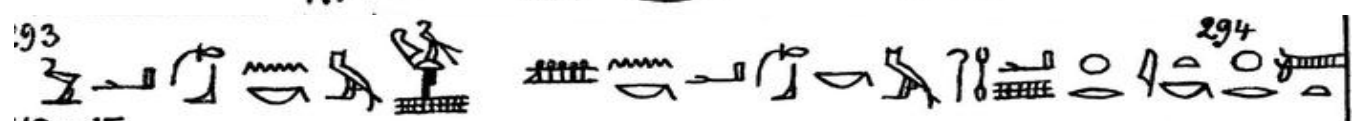

${ }^{37}$ Wb. 474. 


\section{دراسات في آثار الوطن العربيه 1 (لاسي}

sxm(w) .k m Dt .kn jm(y) -rd .k, ms.kn i r iwr ${ }^{38} . k n$ atS, wab .n .k m spAt jmmt(y).t Ssp .n .k ab .k spAt i qAa nDw xr jt.k xr | m

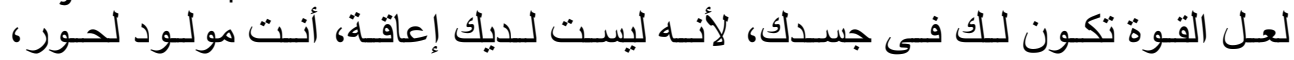

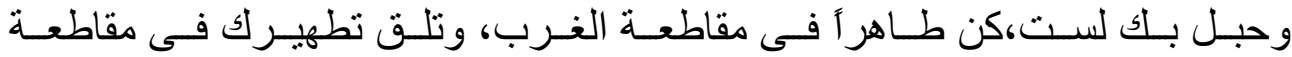

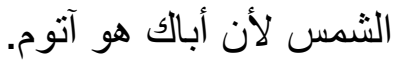

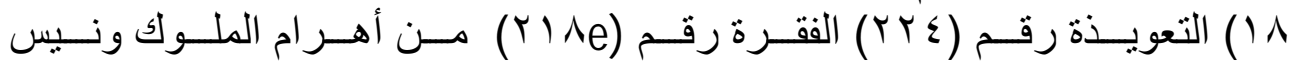
وتنتى ومرنرع وبييى الثنانى

197 m

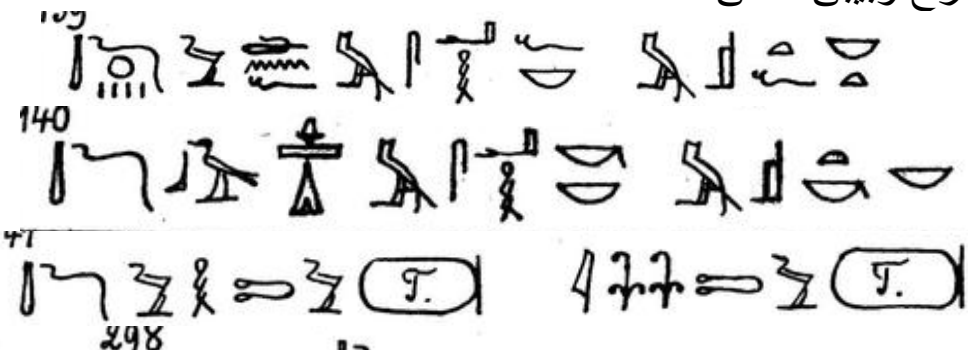

เy8

s $\underset{1}{\mathrm{~m}}$

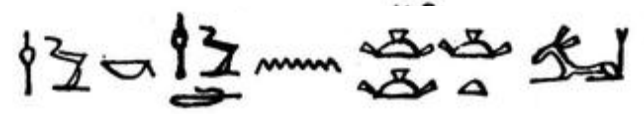

rys

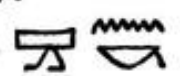

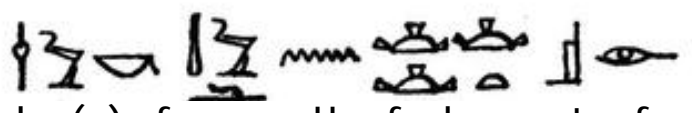

Dd molw sp 4 wdn (n) .f $\mathrm{m}$ saH .f nb ms.t .f nb.t, Dd mdw $d(w) \mathrm{Gb} H \mathrm{tp} m$ saH .k nb ms.t .k nb, Dd mdw Hw Tw jnn Tw I Sm n .k wD(w) ${ }^{39} . k$ mdw $n$ jAwt i $r$ Sm n .k wD(w) .k mdw $n$ jAwt atS, Sm $n$.k wD(w). k mdw $n$ jAwt Wsjr

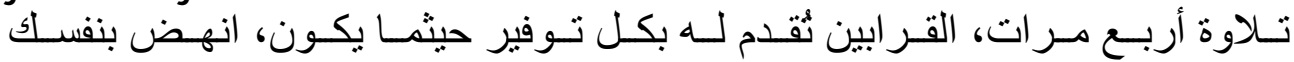

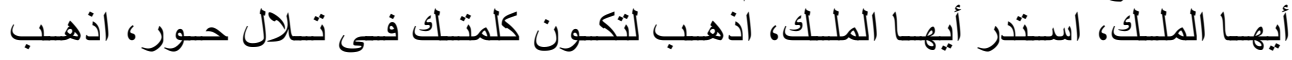

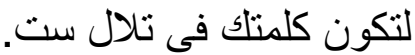

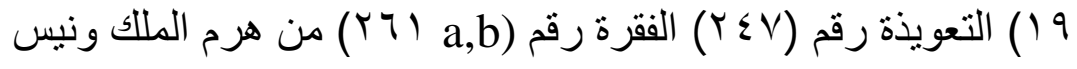

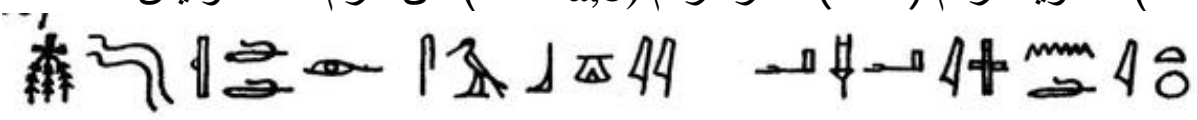

${ }^{38} \mathrm{Ahmad}$ Kamal Pascha, Lexique de la Langue Égyptienne Ancienne, vol.14, p. 14.

${ }^{39}$ Ahmad Kamal Pascha, Lexique de la Langue Égyptienne Ancienne, vol.14, p.66 $-\varepsilon \circ V_{-}$ 
دراسات في آثار الوطن العربيه 1

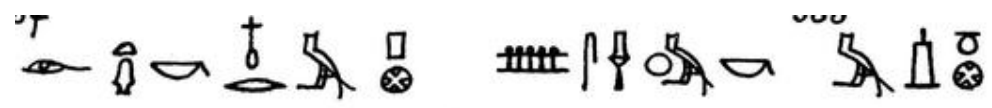

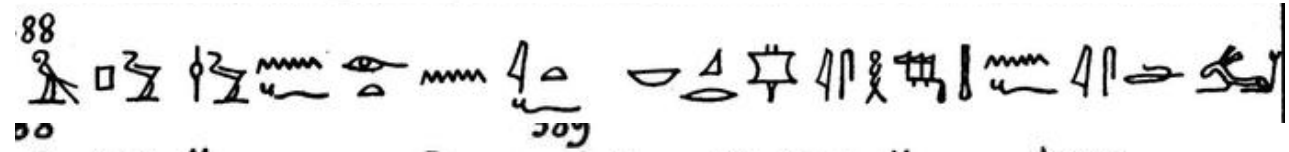

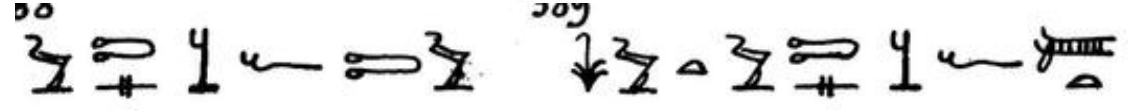

msDD add sbAg.y ata jm(y) Ndj.t, jr t .k nfr $m$ P Ssp sxm .k $m$ J wnw, i $r$ pw wD $n$.f ir.t $n$ itf $n b q^{40}$

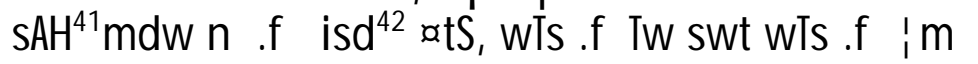

انهض يا من كنت فى نديت، خبزك الجيد معد فى بى خذ قوتلك فى آون،

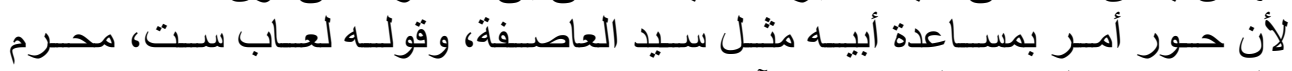

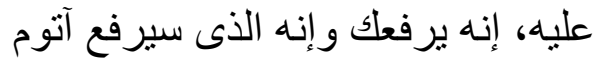

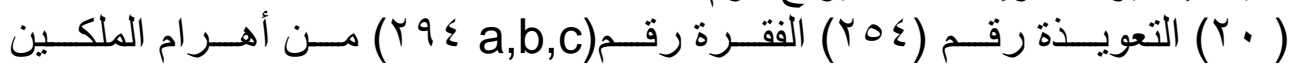

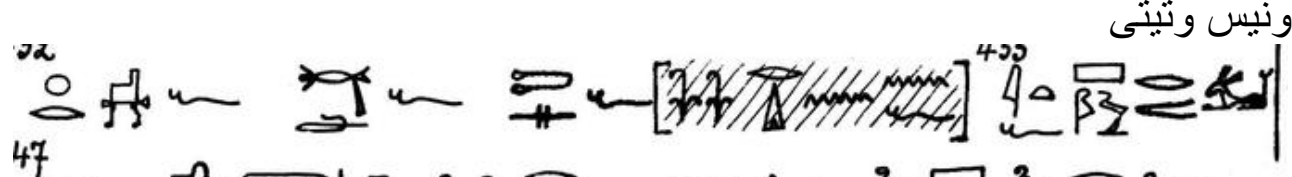

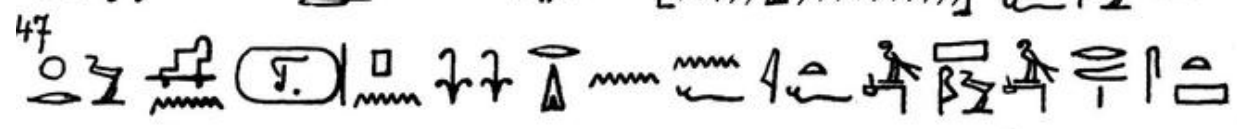

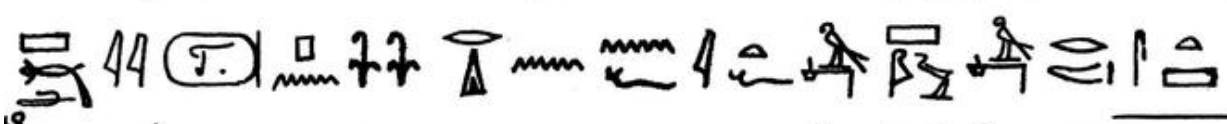

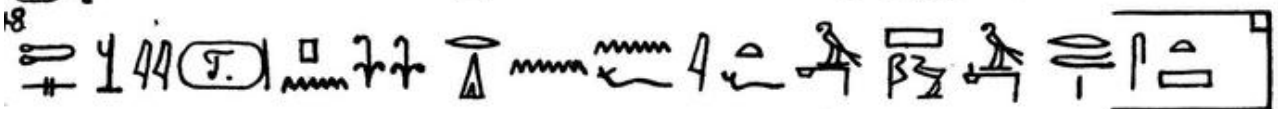
xr st.f Sd .f Tsw.f nn rdw $n$ n.f it ¥w $r$ gs atS

xrw s.t $n$ i pn nn rdw $n$ n. $f$ it $¥ w r$ gs ats

Soly i pn nn rdw n n.f it ¥wr gs atS

Tsy i pn nn rdw n n .f it ¥w r gs atS

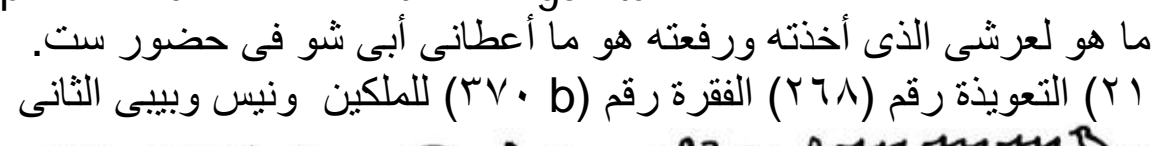

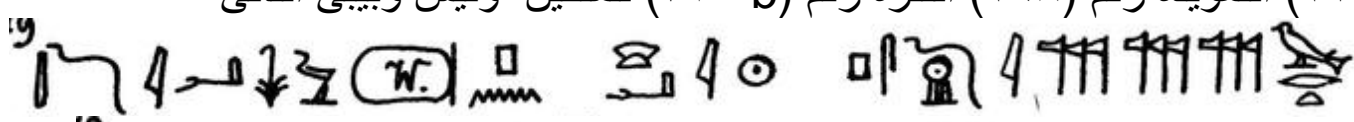
1.9

$\Delta$ 国 Jô

\footnotetext{
${ }^{40} \mathrm{~Wb}, \mathrm{v} . \mathrm{V}, \mathrm{p} .57$

${ }^{41} \mathrm{~Wb}$, v. IV, p. 20

${ }^{42}$ Wb, v. I, p. 134
} 
دراسات في آثار الوطن العربيه 1

Dd molw ja sw $N$ xa RapsD PsDt wr.t oA(w) Nbi tt atS $m \times m t$ itr.t

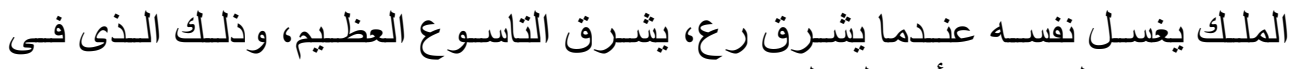
نوبت ست عالى عند رأس المجلس.

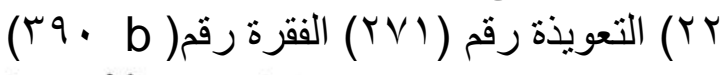

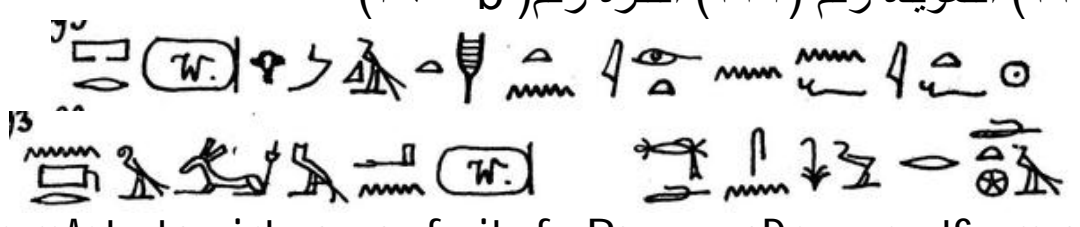
pr (W) $H$ mAqt th irt .n $n$.f it .f Ra, $n D$ i $r$ atS ma $\mathrm{n}(\mathrm{y}) \mathrm{w}$ Sol(w) .sn sw $r$ dwAt

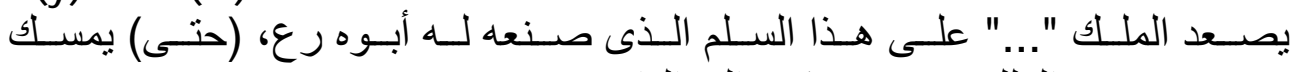

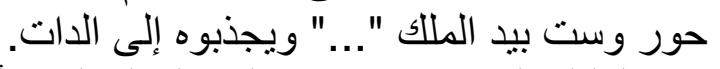

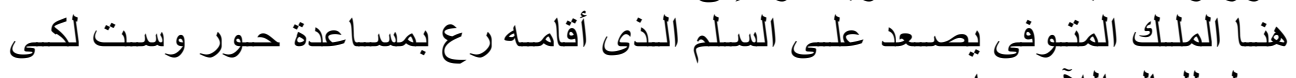

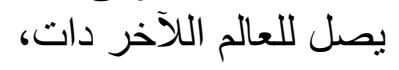

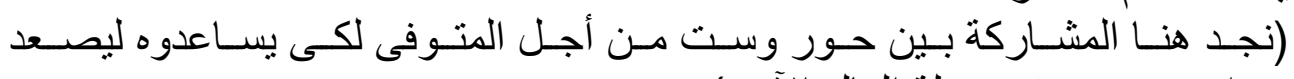
ويو اجه مصيره فى رحلة العالم الآخر ).

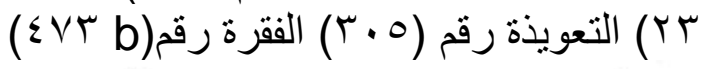
. "IH

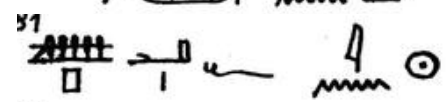

in Twt is nTr wabt pr $m$ wabt, ata $W$ in i $r$ Hms $W$ in \% 6 S Ssp aA .f in Ra

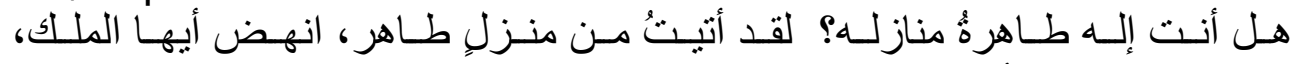

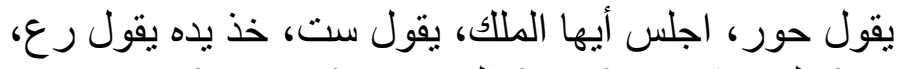

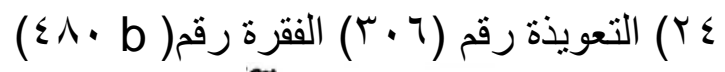

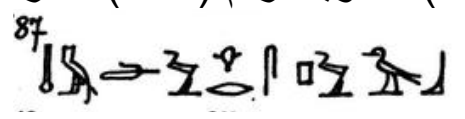

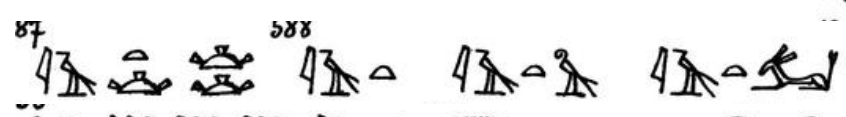

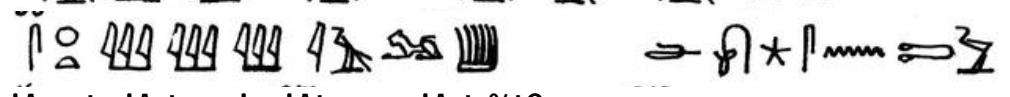

IAw.t iAt < i > iAt ; r iAt \%5

إنه جب الذى يتحدث عنها، إن التلال هى تلى وتل حور وتل ست. $-\leqslant 09$ 
دراسات في آثار الوطن العربيه 1 أو

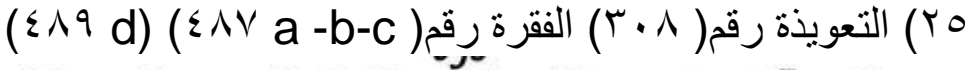

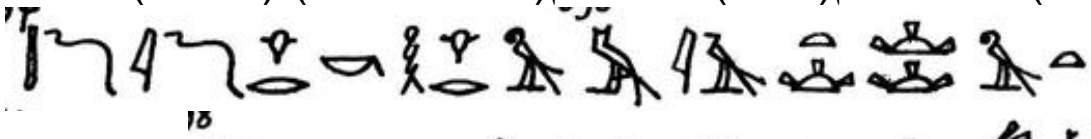

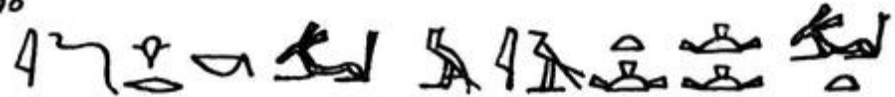

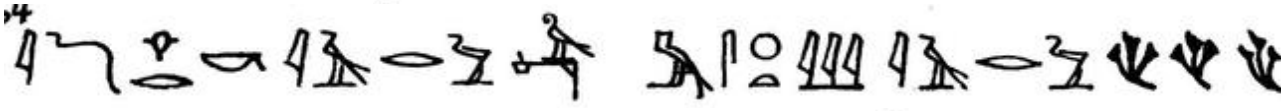
N

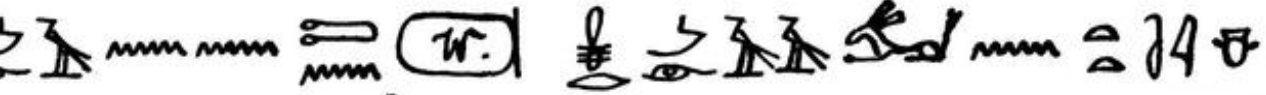

Dd mdw: i(n)D - H .k i $r$ m jAut i rjwt, inD-H.k \%S miAwt st(j.w)t, inD- H.k IArw, m sxwt IArw, mA.n n .Tn mi mA \% $\mathrm{n}$ t(w)ty.ib

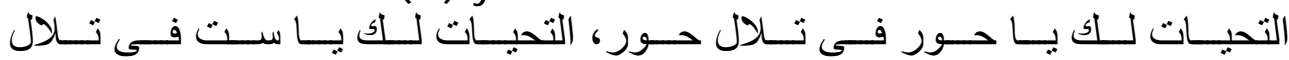

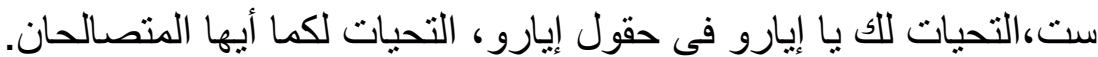

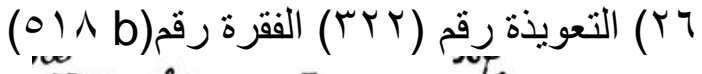

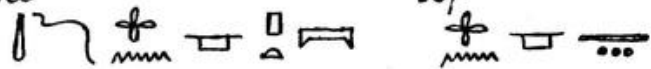

"ot

Dd molw wn aAwy sAt(y) n i r sn aAwy sAb.wt n \% 65

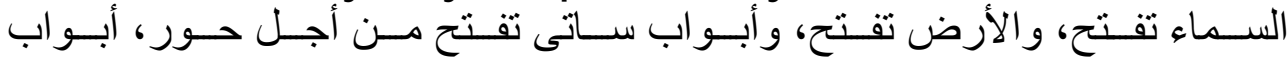

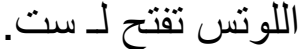

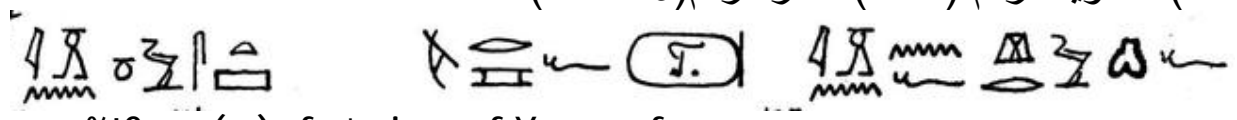

i innw \%5mr(w) .f I in n .f Xr.wy .f

رسول ست يحبنى وجلب لى خصيته

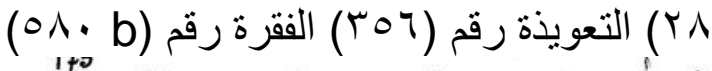

min

d.n Tw Nw.t mnTr n \% 65 mrn .k n(y) nTr

نوت جعلتك مثل إله لـ ست فى اسمك إله.

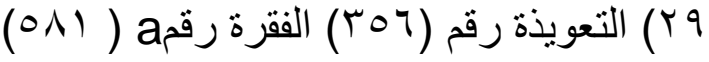

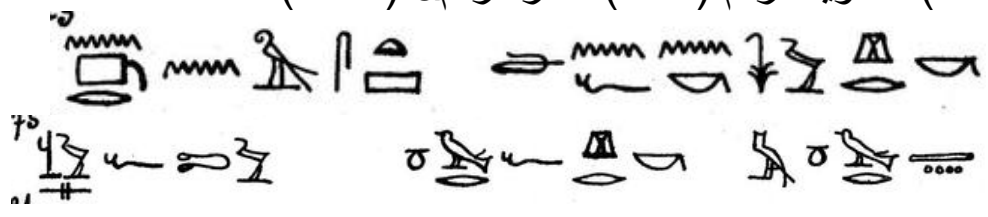


دراسات في آثار الوطن العربيه 1

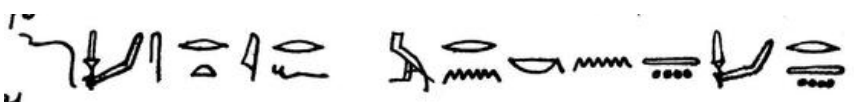

n̈D n @ ats d.n.f n .k sw Dr.k, wiा .f Tw nwr .f Xr.k m nwr tA Dsrtj jr .f m rn.k n tADsr tA

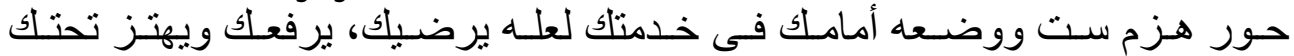

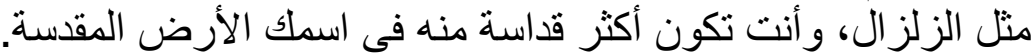

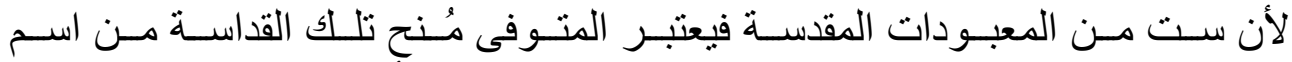
ست بالر غم من هزيمة حور لله، فإنه يجعل له القوة ويكون أكثر قداسة

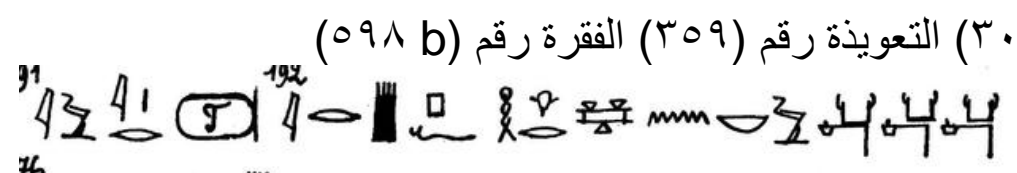

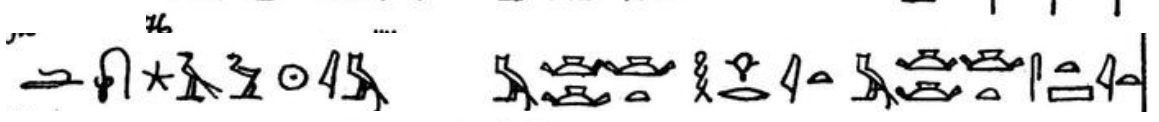

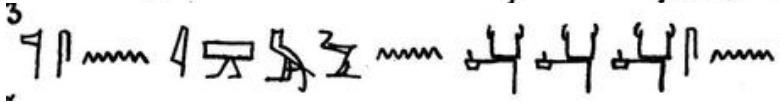

İwir I ir aH pf $\mathrm{Ht} n \mathrm{nb} \mathrm{kAw}$,

dwAw Ra im $m$ iAwt $H(y) .(w) t ~ m$ iAwt \% $\%(y)$.(w)t , is n i Smw n kAw.sn.

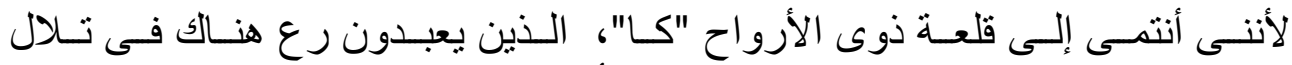

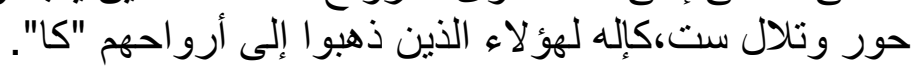

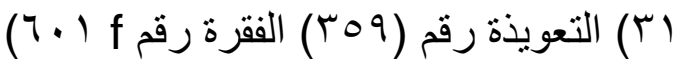

'

$<r>$ gs n(y) i iAbt(y) im(y) \%

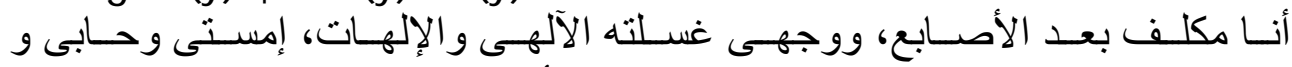

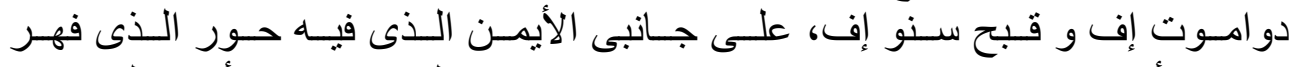

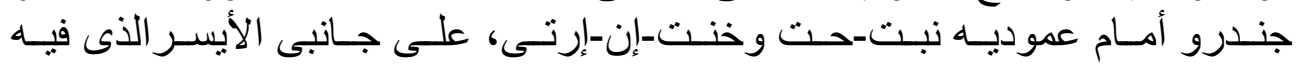

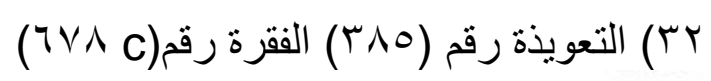

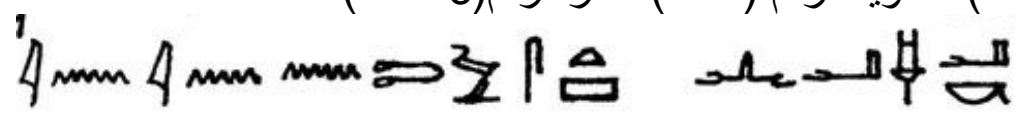

I nin .n Tw \% 65 nata(w) .k

هنا يقصد الثعبان سريو.

حور أسقطك ولن تحيا، وست قطعك ولن تنهض. 
دراسات في آثار الوطن العربيه

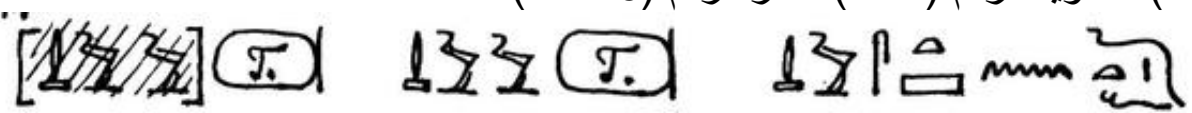

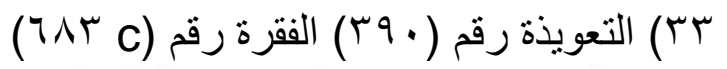

[wDAw] ; wDAw ; wDAw \%5n Dt .f

$$
\begin{aligned}
& \text { المللك معافى الملك معافى، وست معافى جسده. }
\end{aligned}
$$

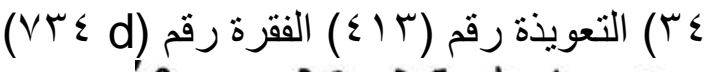

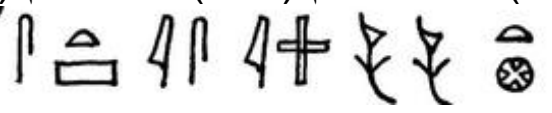

\%Sisim(y) ; nH.t

صعود الملك المتوفى إلى السماء:

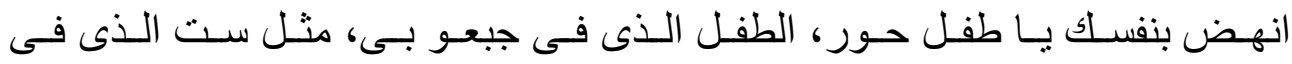

حis

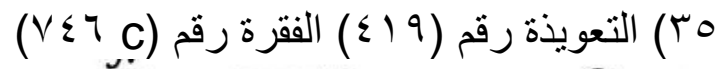

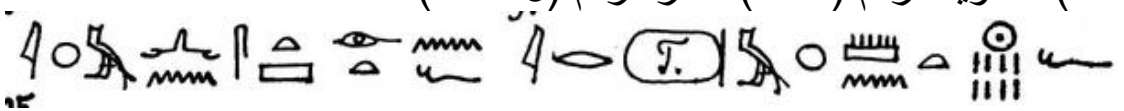

ixmn \% \%

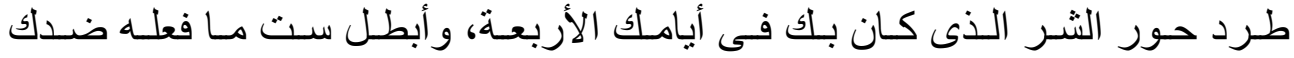
في أيامك الثمانية.

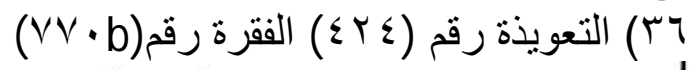

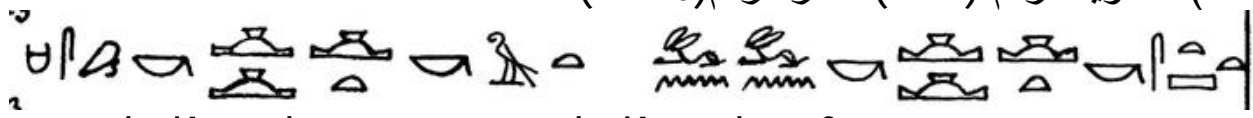
H'msy . k jAut.k @r, wnwn.k jAut .k atS

هذه من التعويذات القصيرة: بغرض حماية الملك المتوفى.

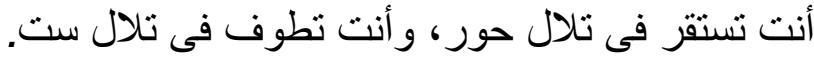

( Vqra) التعويذة رقم (

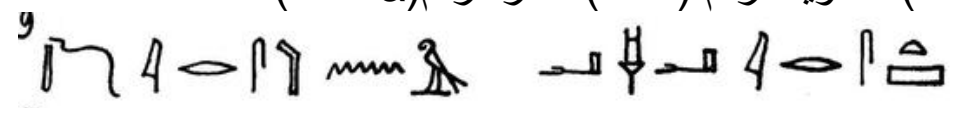

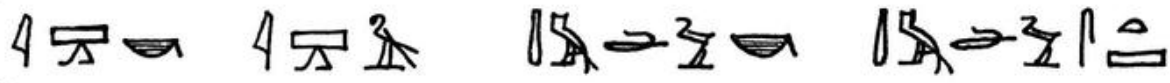

"थ

$\downarrow \downarrow t$ \&

Dd mdw i-rs $n$ i $r$ dta ir ats, j-Sm (w) .k j-Sm(w) @ , $m d(w)$.k md(w) ats, snsn(w) ib n(y) stS jr. k wr hs n(y) J wnw 
دراسات في آثار الوطن العربيه 1

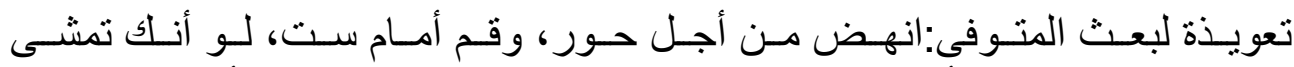

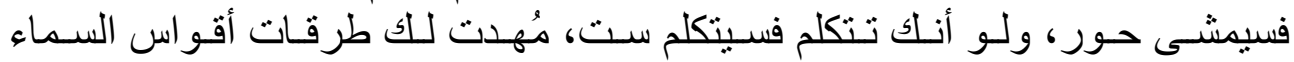
الصاعدة إلى حور، ويؤ اخيك ست مثل النّ العظيم فى آون. 人

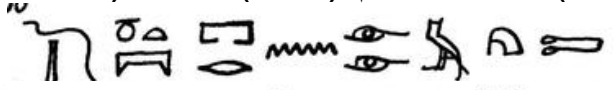

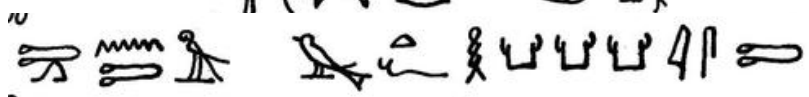

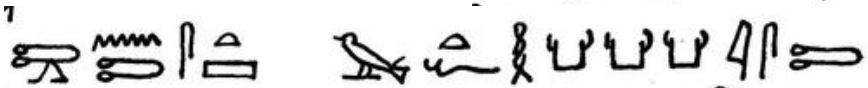

Dod mdw Nwt pr.n jr.ty m to .T, jT̄́n .T@r Wrt .f HkAw jsT, iTn .T\% 6 Swr.t.f HkAw isT

يـا نـوت بـدت العيون مـن رأسك، وقد حملت حور عظيم السـحر، وحملت سـت

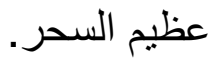

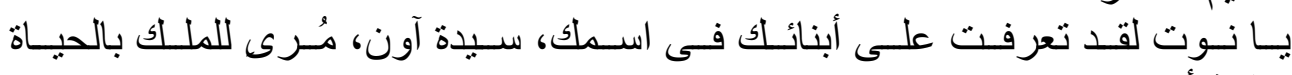

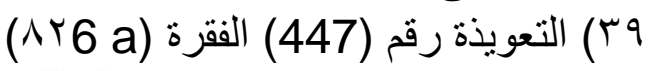

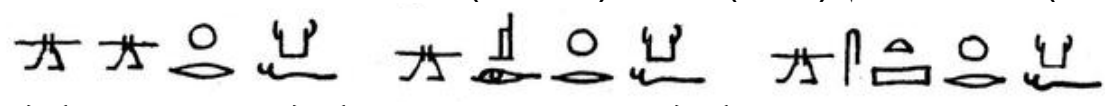
sb(.w) sb(w) xr kA.f sb(.w) Wsir xr kA.f sb(.w) \% $15 x$ x kA.f

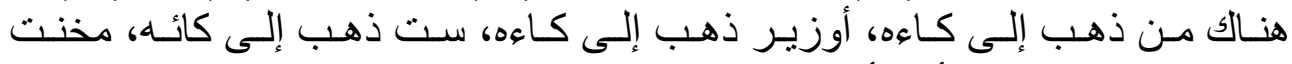

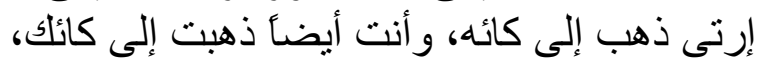

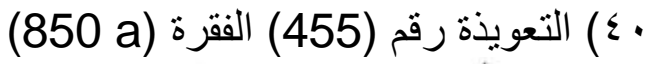
4 喝吗 iSspr(.w) mrAi r isd pr(.w) mrA\%

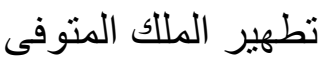

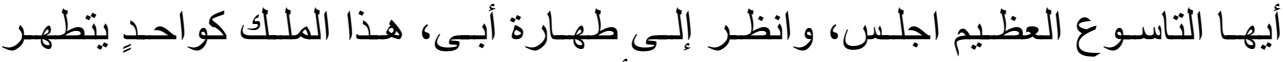

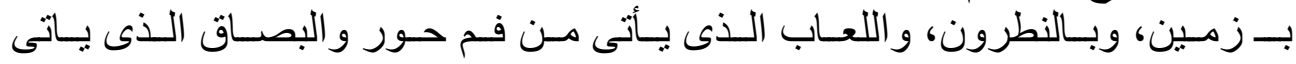

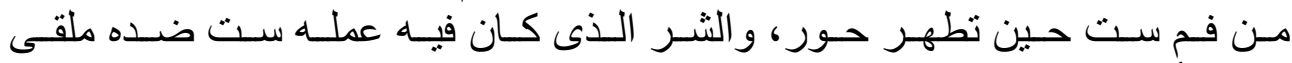

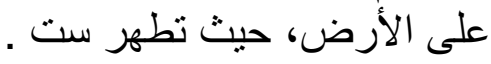

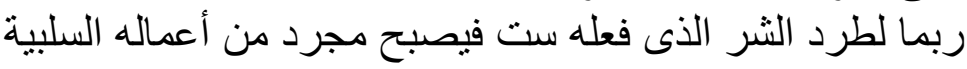

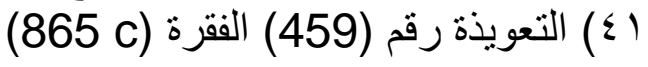

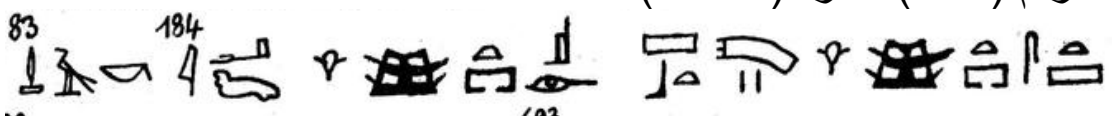

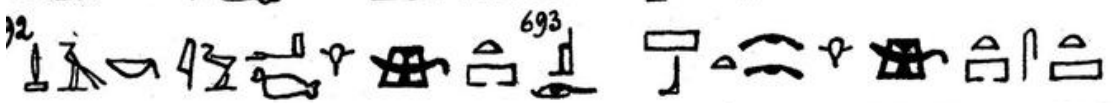


داسات في آثار الوطن العربيه

DA=kia H ... Wsir, Sot H... atS

تجديد الحياة للملك المتوفى:

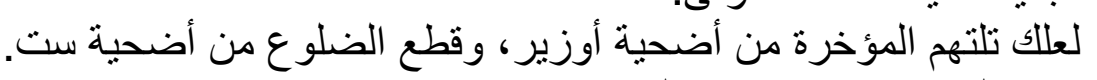

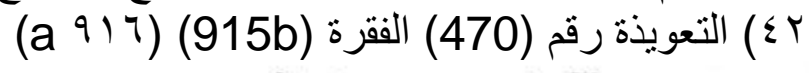

40 4 ir iAnt oAt,ir iAnt ats

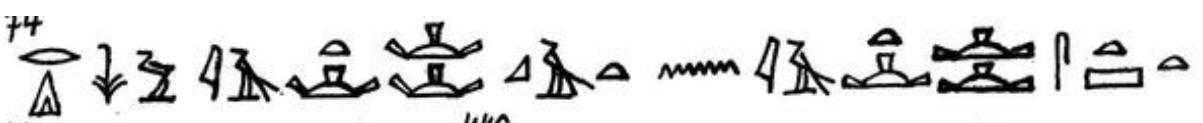
iw.K ir iAnt oAit ir iAnt atS rdi sw iAnt oAit $n$ atS $n$ nht.f oft (m) iAbt pt.

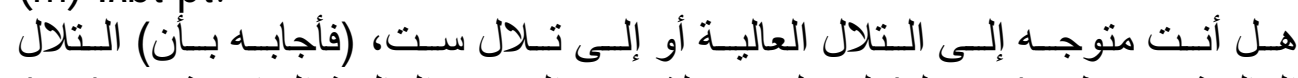

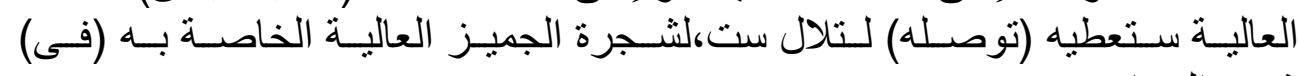

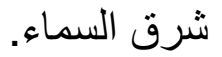

(

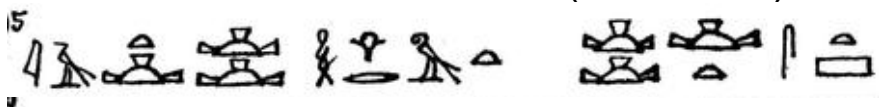

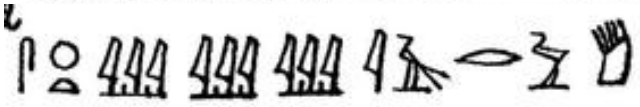

$\operatorname{mon}$ (9.)

Sxwt-iAww iAnt i $r$ iAwt atSn (P) pn tm

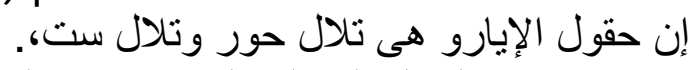

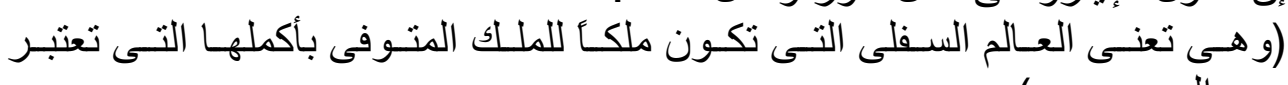

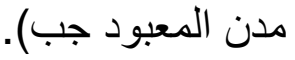

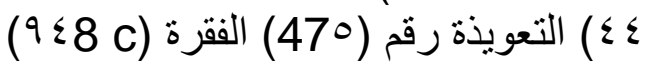

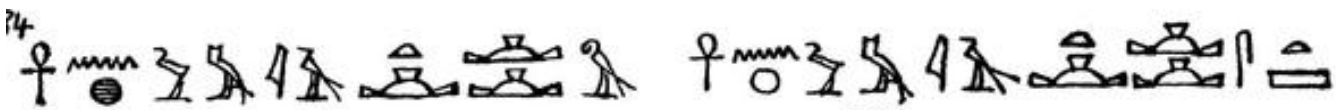
anxw miAnt ; $r$ anxw miAnt ats

الذين بعيشون فى تلال حور ، ويعيشون فى تلال ست.

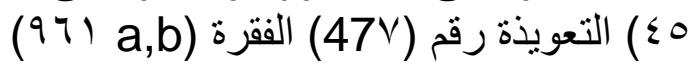

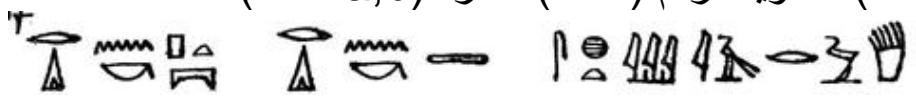

$-\varepsilon 7 \varepsilon-$ 
دراسات في آثار الوطن العربيه 1

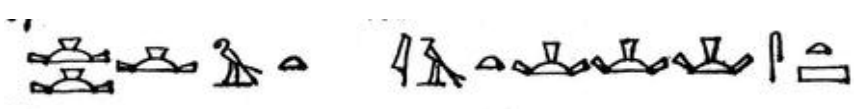

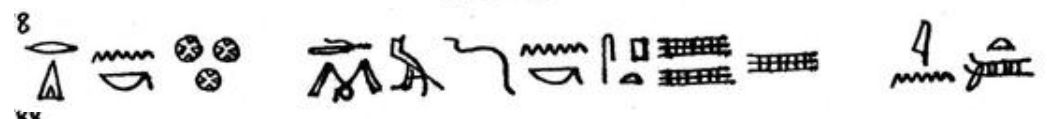

8r

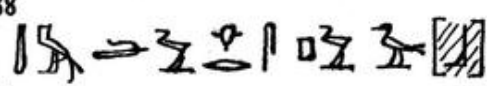

rdi n.k pt rdi n.k tA sxt iArw iAnt i rj(w)t iAnt atS rdi n.k njwt dmD n.k spAwt in itm mdw H.s pw Gb.

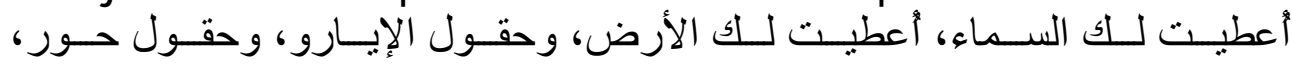

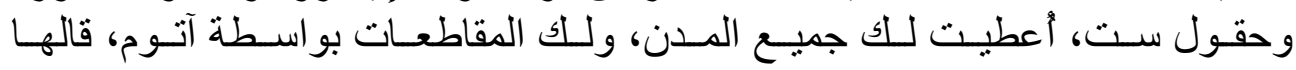

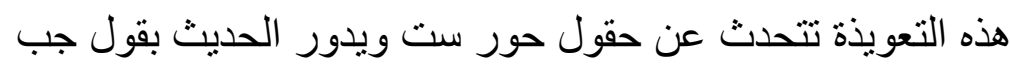

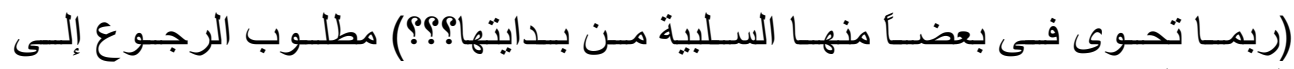

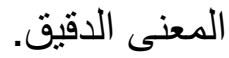

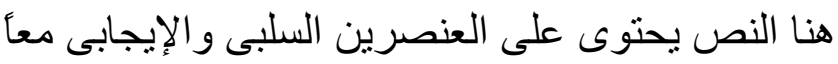

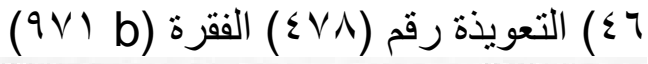

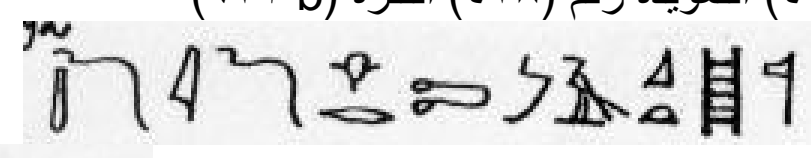

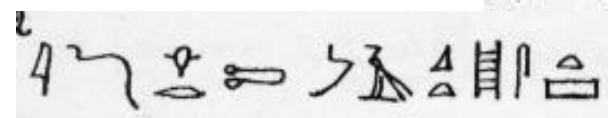

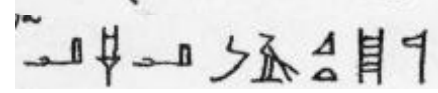

Dd mdw: i(n)D - H .T mAqt nTr, Dd mdw H .T mAt atS, atamAq t nTr,

$$
\text { التبجيل للك يا سلم الإله، التبجيل للك يا سلم ست، انتصب يا سلم الإله، }
$$

ath mAat ats, ath mat @r, irt $n$ Wsir pr .f H .s ir pt stp .f sAir Ra

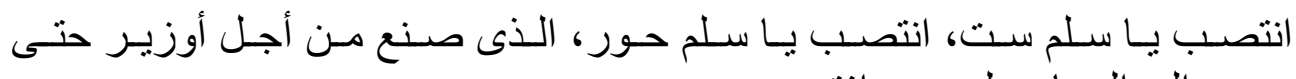

يصعد إلى السماء عليه، وير افق ر عان.

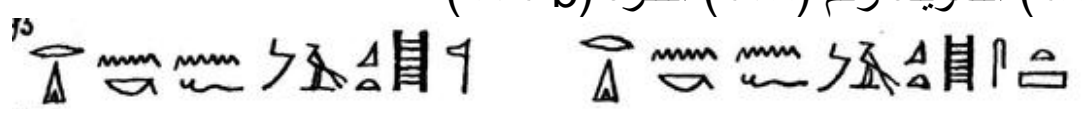


دراسات في آثار الوطن العربيه 1

rdi .n.k n.f mAqt nTr, rdi .n.k n.f mAat atS

منحته سلم الإله، منحته سلم ست، لعله يصعد عليه إلى السماء، وير افق رع.

9 §) التعويذة رقم (975 a (

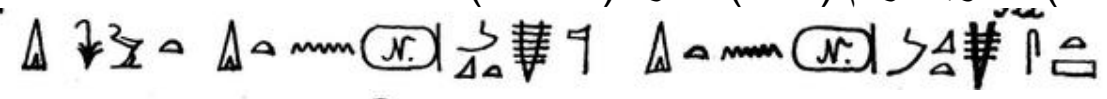

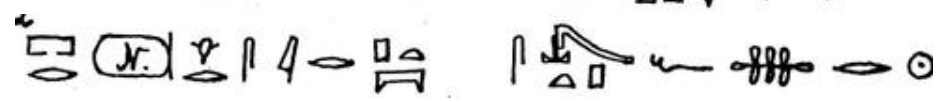

rdi sut rdit $n \mathrm{M}$ mAqt nTr, dit $\mathrm{n} N$ mAqt atS, pr $\mathrm{N}$ H.s ir pt, stp.f sAir Ra

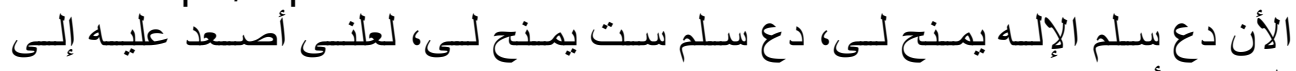

Xa $m$ iart imjt wpt atS

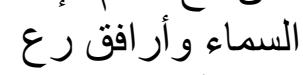

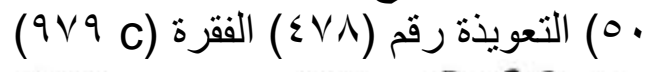

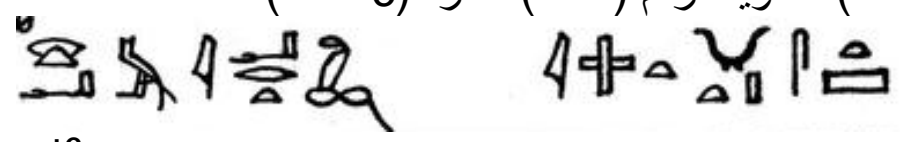

لأنى أتجلى الصل المقدس الذى على جبهة ست.

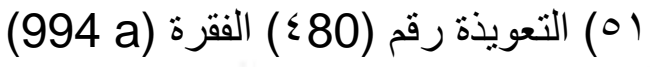

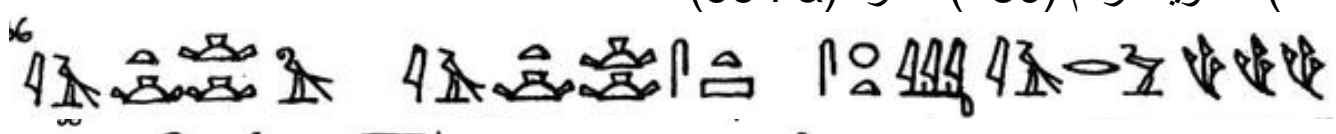

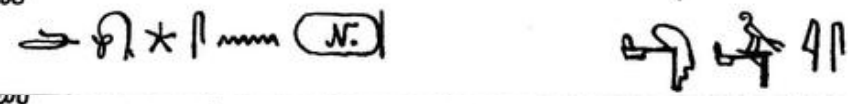

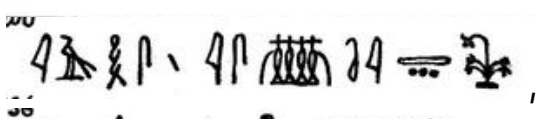

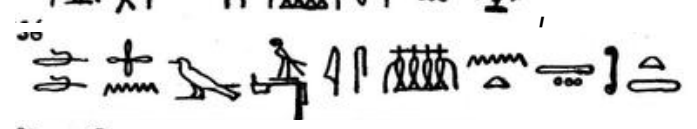

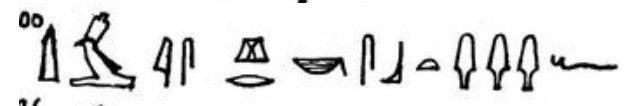

ïAw)t i r jAut atS sxt - iArw, dwA.sn $N$ dwAw is, jAHb tASma _dwn is xntj tAstw spd is Xr ksbt.f

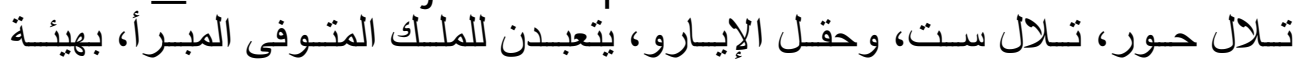

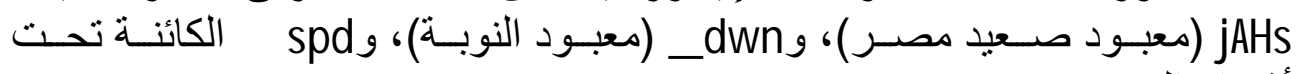

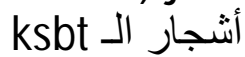

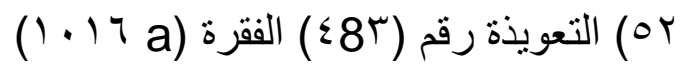


دراسات في آثار الوطن العربيه 1

I a .n=kn nTr, snsn' atSir $=k$

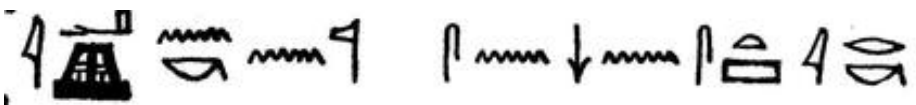

لعلك تصعد إلى الإله، ولعل ست يكون أخأ للك (يؤاخيك)

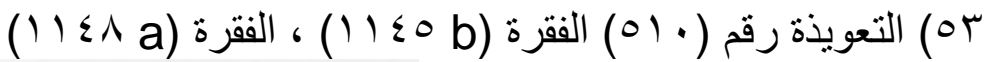

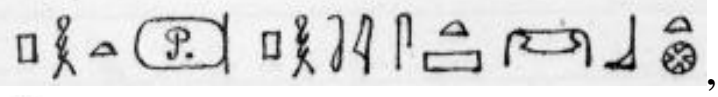

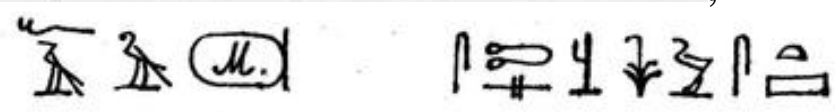

pHty (P) pHty atSNubt, fAy @ (M) wTs sw atS

قوتى هى قوة ست من نوبت. يرفعنى حور وينهض بـ ست

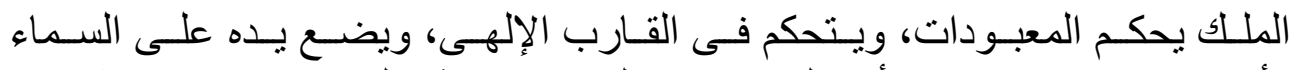

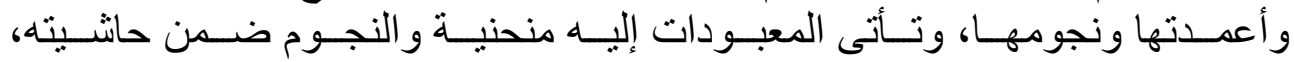

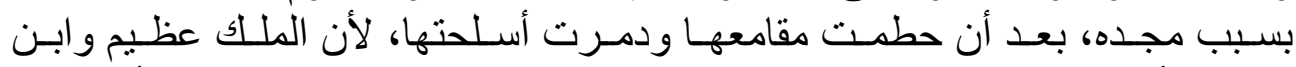

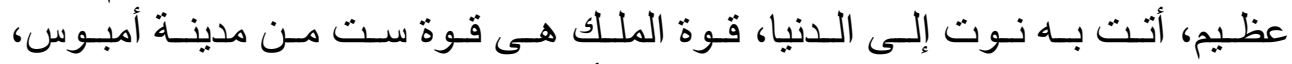

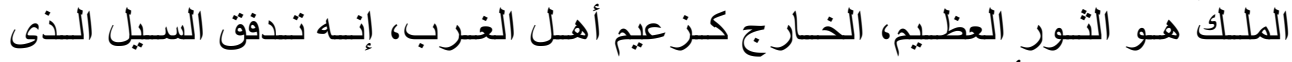

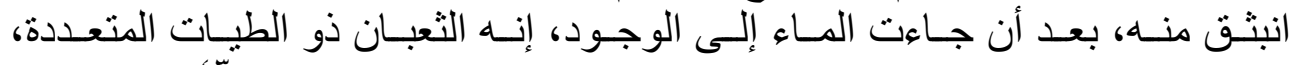

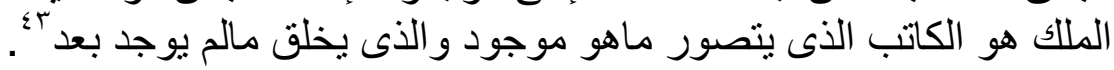

$$
\begin{aligned}
& \text { ـ 0) التعويذة رقم (1) }
\end{aligned}
$$

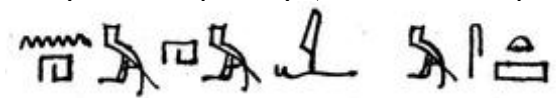

$\mathrm{n} \mathrm{hmhm}=\mathrm{i}=\mathrm{fm}$ ats

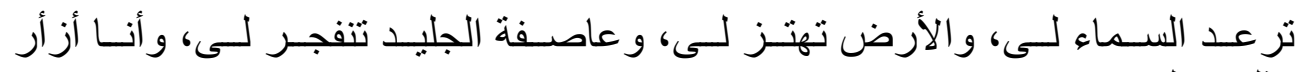

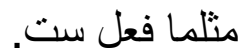

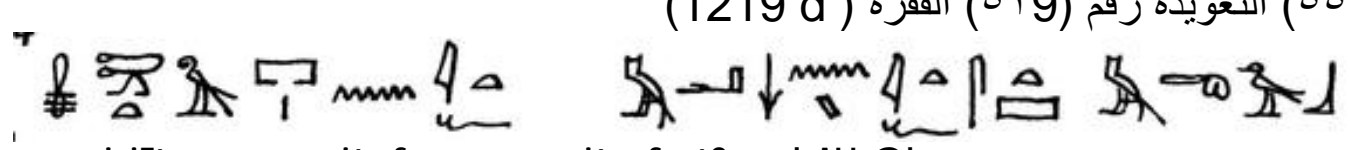
mi iti @ pr n it .f , masny it .f atSmbAHGb

بـ كلير لالويت، نصوص مقدسة ونصوص دنيوية من مصر القديمة، المجلد الأول، ثرجمة: ماهر

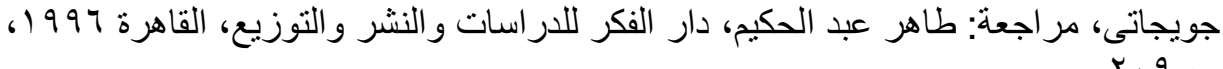
$-\Sigma T \vee-$ 
دراسات في آثار الوطن العربيه 1

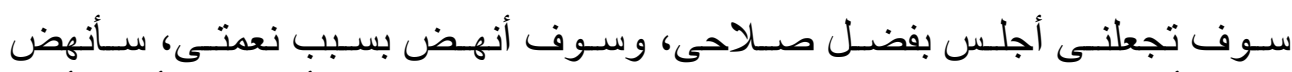

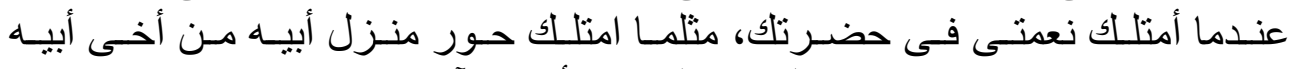

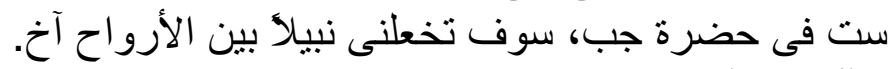

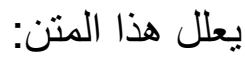

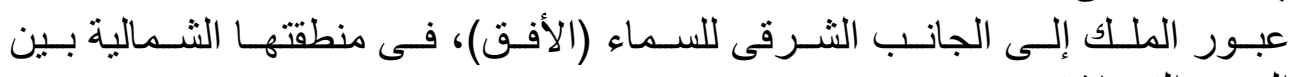

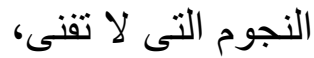
يمكن له أن يحمل العنصرين الإيجابى و السلبى.

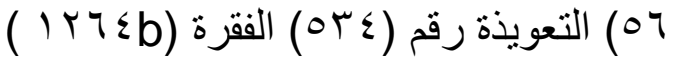

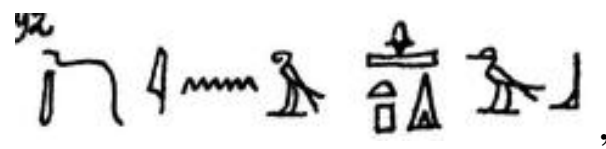

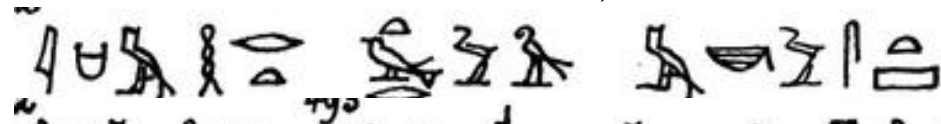

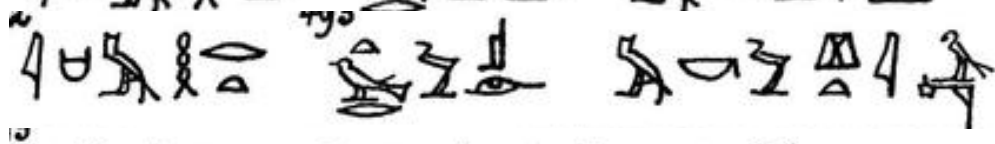

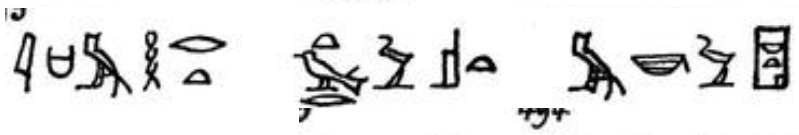

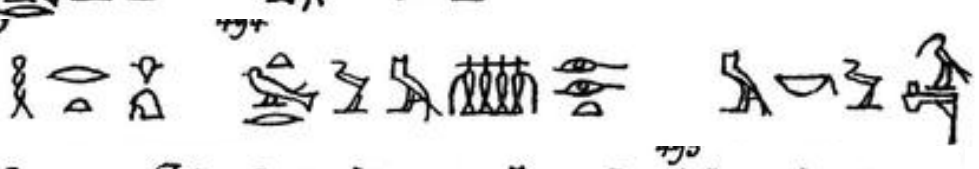

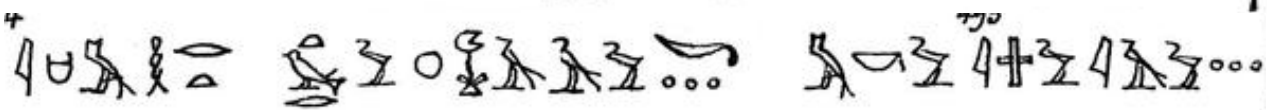
Dd mdw.w jn @rw Hp dj Gb , j.Hm H.t twr @rw mkw atS , jHm H.t twr Wsjr mkw \$rjtj j, jHm H.t twr Is.t mkw Nb.t@.t, H.t H-tp twr Mxntjj jr.tj mkw CHwtj, j.Hm H.t twr $\Varangle$ Atjj.w mkw I mjj.wjAw.w

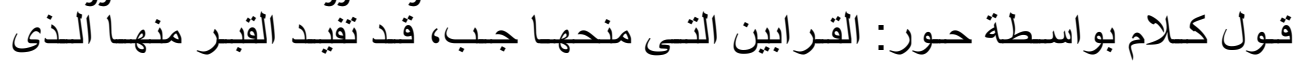

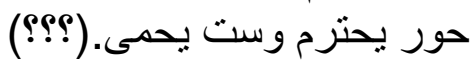

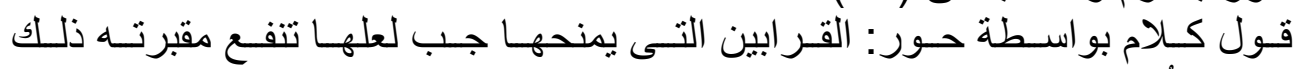

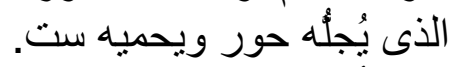

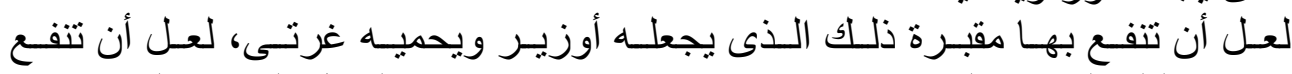

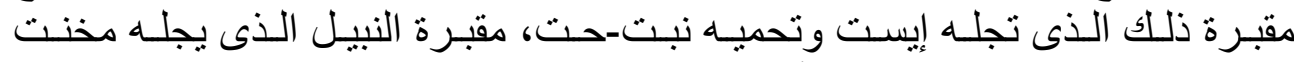

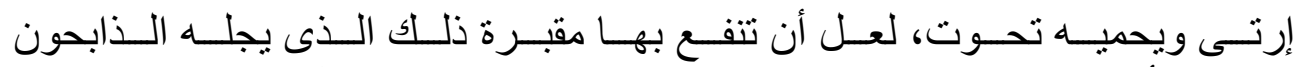

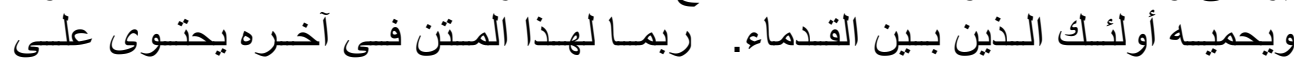
العنصرين الإيجابى و السلبى.

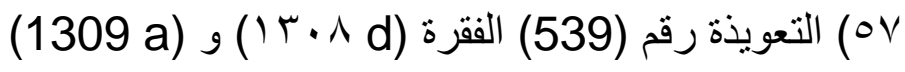


دراسات في آثار الوطن العربيه 1

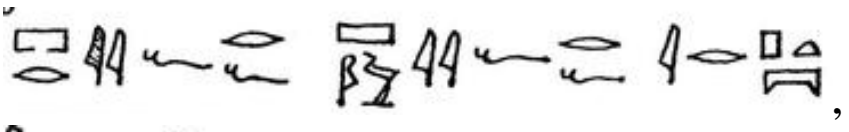

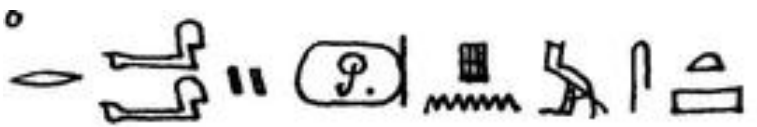

pry .f $r$.f Swjj .f $r$.f ir pt, rmmwy (P) pn m atS

سأصعد وأرتقى إلى السماء، وكتفاى بمثابة ست.

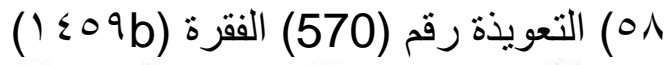

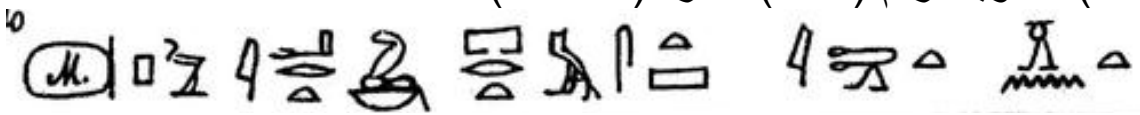

(M) pwiat prt mats, i

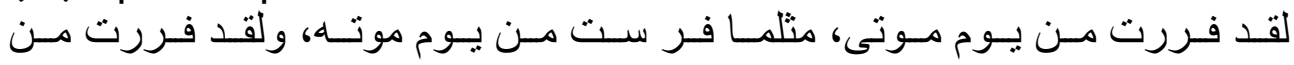

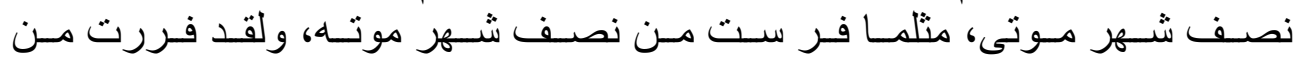

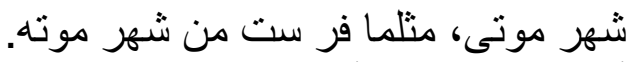

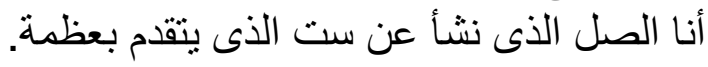
( ) التعويذة رقم (OVY

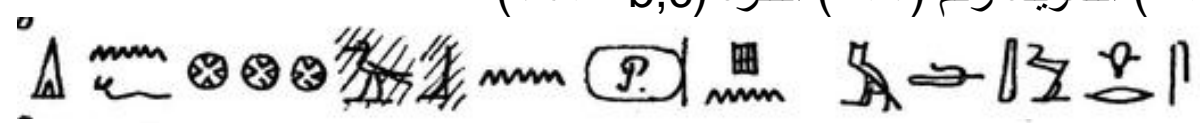

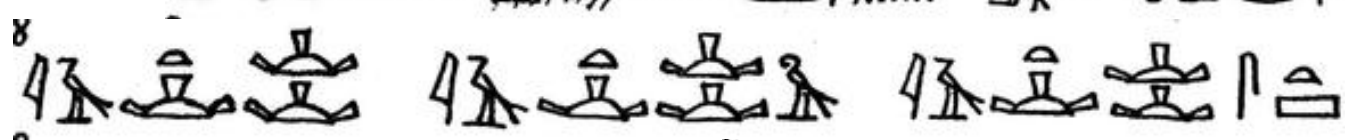

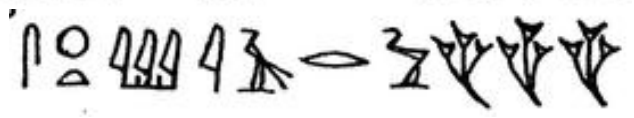

di.n.f njunt Gb $n(P)$ pn mdw H.S, iAut iAnt i $r$ iAnt atS , sxt-iAw.

لقد أعطى (آتوم) مـدن جب للملك (بيبـى) هذا، قـائلا عنهـا (إنها) التنلال، تـلال حور، وتلال ست، وحقل مقل الإيارو.

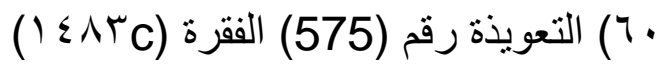

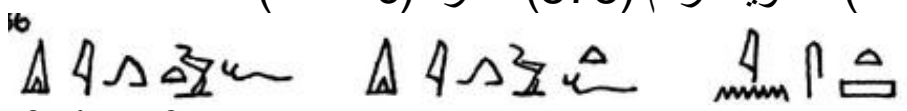
dj .j jw .f dj .j jw.f jnatS لقد جعلته يأتى، لقد جعلته يأتى، يقول ست.

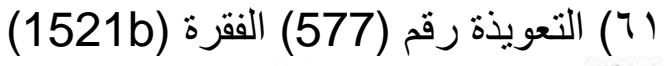

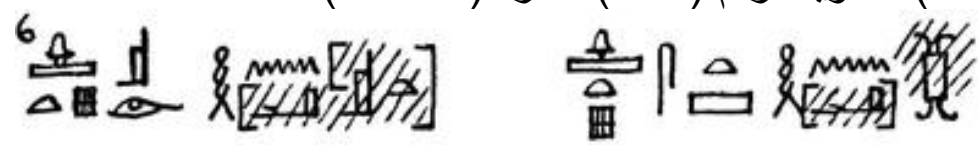
Htp Wsir Hal s.t Hp atSHa Nt

راضيان هما أوزير و إيست، راضيان هما ست ونيت $-\leqslant 79$ - 
دراسات في آثار الوطن العربيه 1

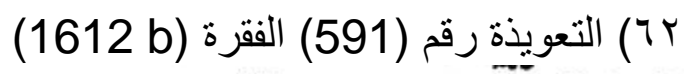

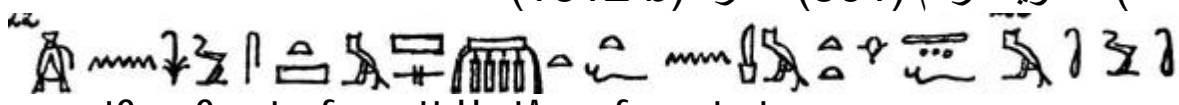
DbAn sw atSm Ssmt . f nmtt H tAw . f m twt

زين نفسه ست بمئزر شزمت، الذى سافر عبر أرضه بأكملها.

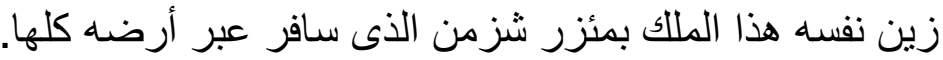

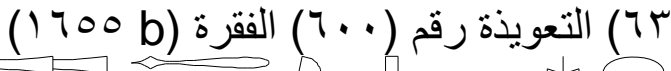

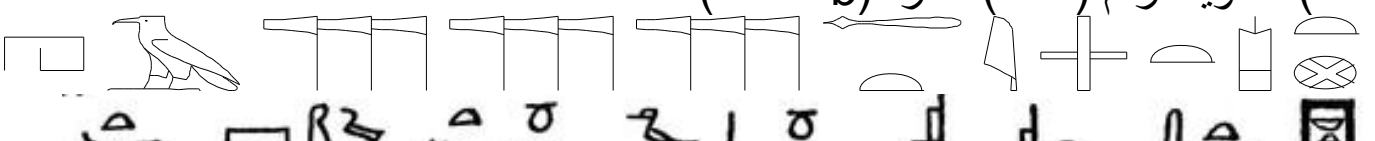

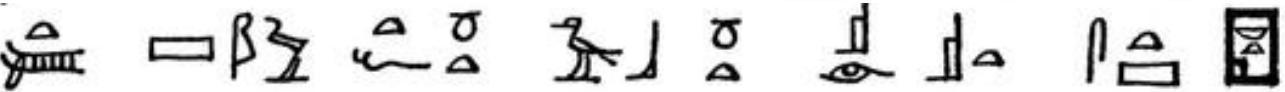
hA psDt at imyt I wnw Itm w I fnwt Gb Nwt Wsir Ast atS Nbt-@it

| $\mathrm{m} \mathcal{W}$ | fnt Gbb Nt Wsir Ist atSNbt - @

ظهور المعبود "ست" فى ماعية تاسوع "بسجت" عئ عين شمس "أون" المقدس:

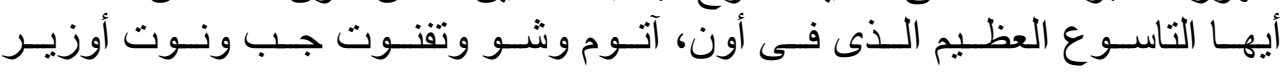

atSmNwbt

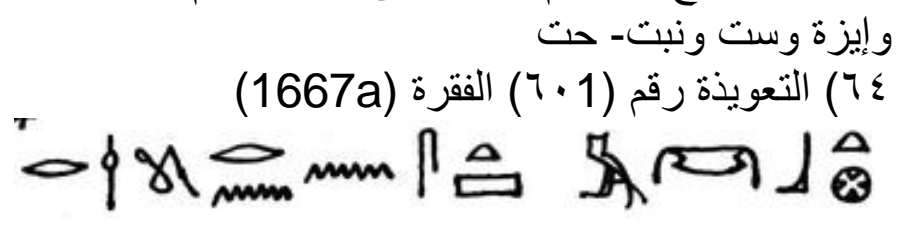

نفس التعويذة السابقة ولكنها تحدد مكان عبادة ست:

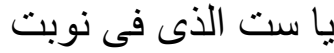

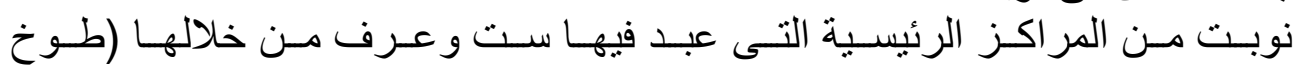
الإقليم الخامس من مصر العزب العليا) 07) التعويذة رقم (610) الفقرة (1710a)

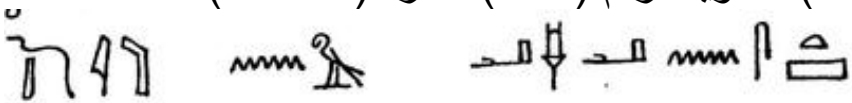

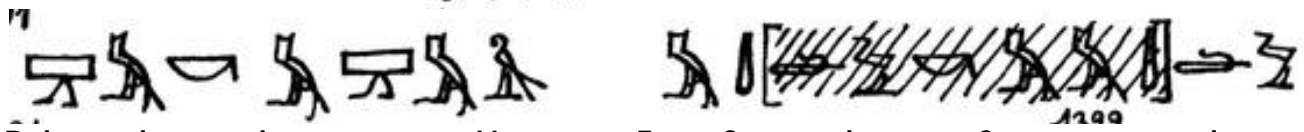

Dól mdw $r s j n$ @r th $n$ ats, $S m=k m$ Sm @ar mdww $=\mathrm{k} \mathrm{m}$ molww ats

$$
\begin{aligned}
& \text { انهض من أجل حور، و انهض من أجل ست } \\
& \text { لعلك تمشى مسيرة حور، لعلك التحد تلحدث بحديث ست. } \\
& \text { 47) التعويذة رقم (612) الفقرة (1735a,c) }
\end{aligned}
$$


لدراسات في آثار الوطن العربيه 1

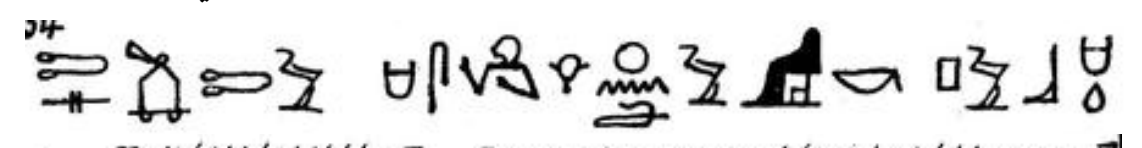

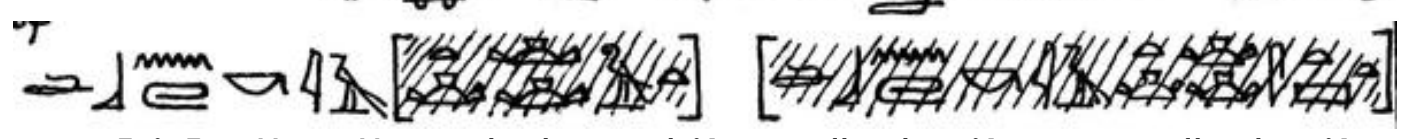
Tsi Tw Hms $H$ xndw.k pw biA ... dbn.k iAvt i $r$ dbn.k iAvt ats

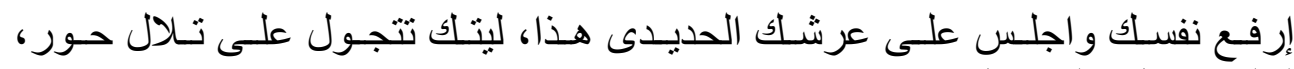

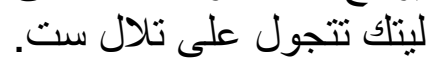

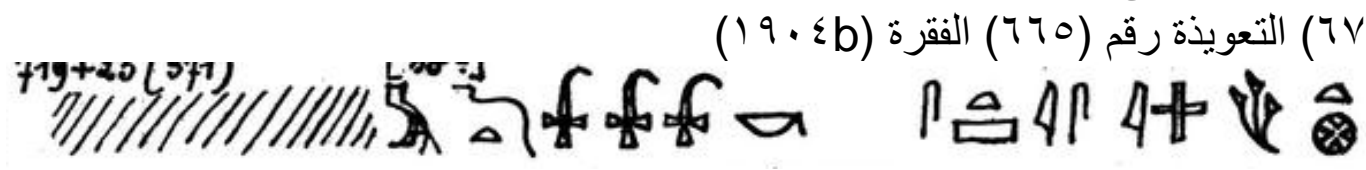
ats is imj @int.

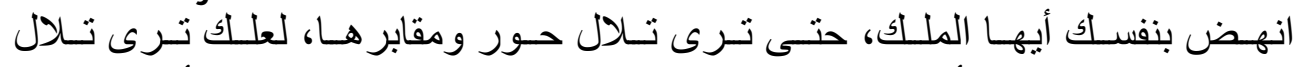

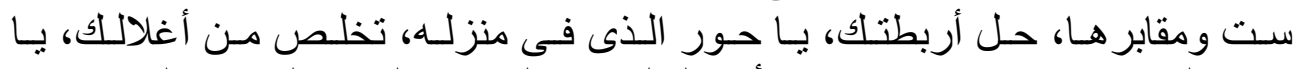

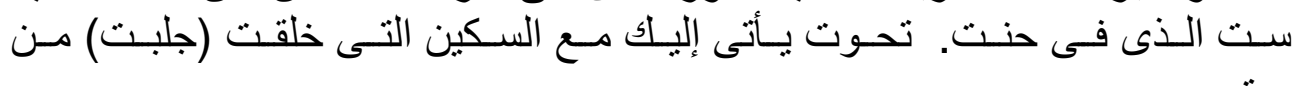

14) التعويذة رقم (673) الفقرة (d (1993)

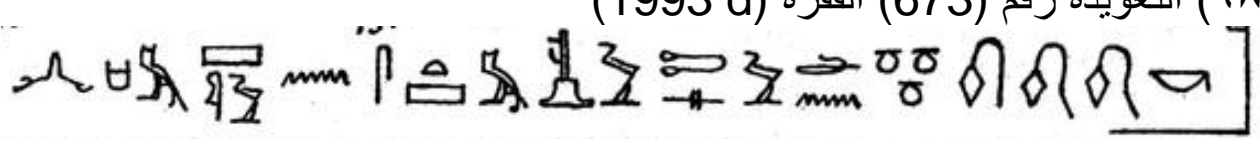
n nHmSw n atSm....

ست لن يكون في حل من حمل أثقالك.

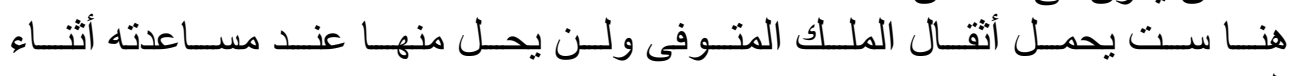

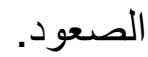
97) التعويذة رقم (683) الفقرة (2047d)

iat nn prt mats

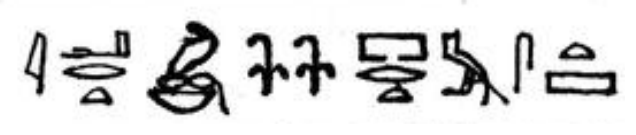

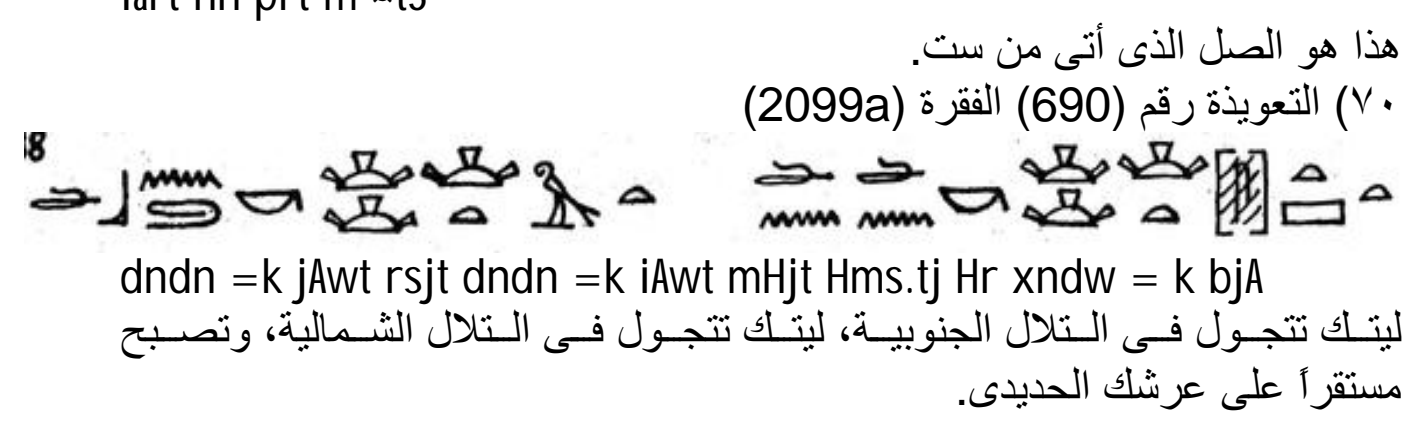


دراسات في آثار الوطن العربيه

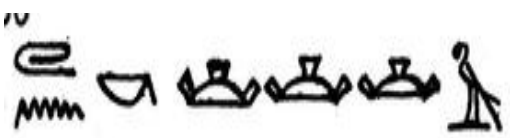

(2263) التعويذة رقم (734) الفقرة (2)

pXr n.kjAut i r pXr n.kjAut atS

تتجول تلال حور، تتجول نلال ست.

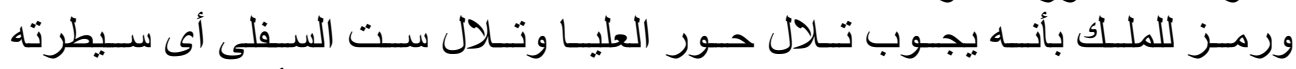

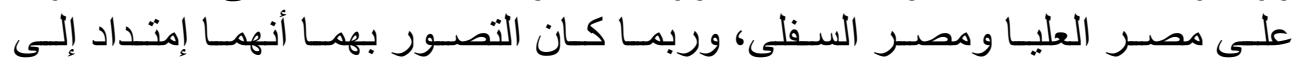

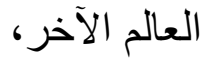

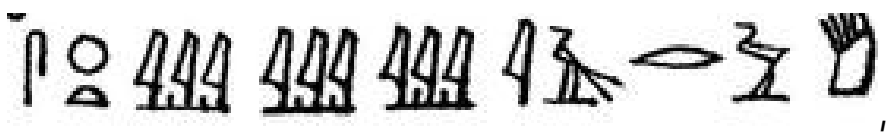

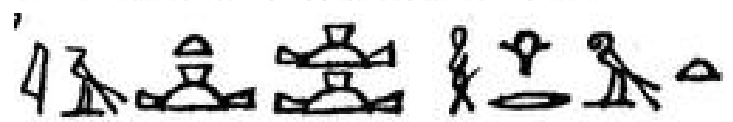

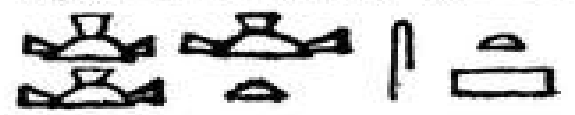

sxut-iAwwiAnt i r iAt ars

إن حقول الإيارو هى تلال حور وتلال ست

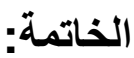

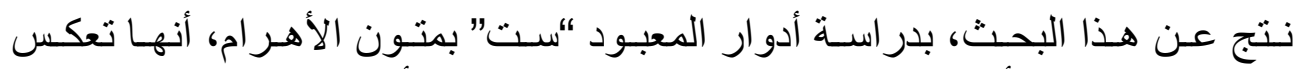

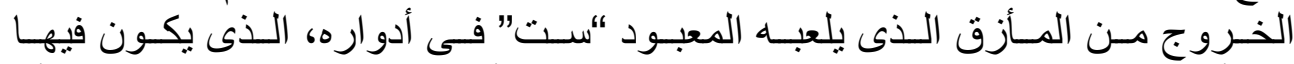

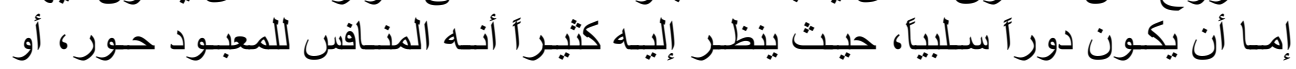

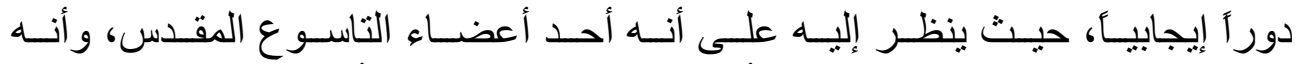

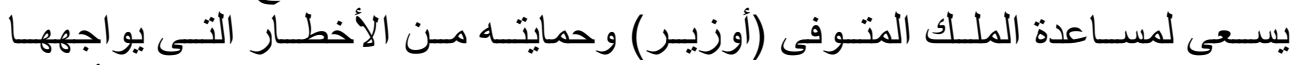

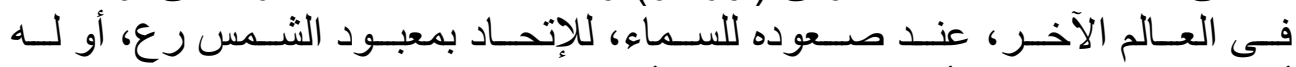

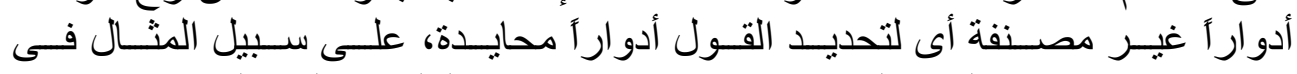

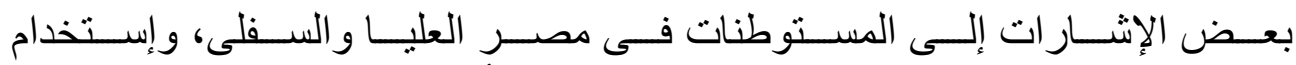

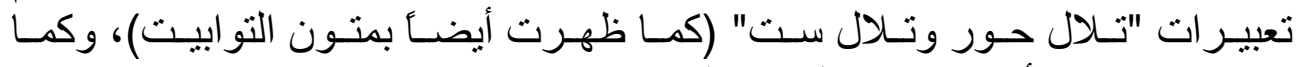
ظهر فى منون الأهر ام من خلال هذه الدراسة. 